\title{
A Highway Accident Involving Unirradiated Nuclear Fuel in Springfield, Massachusetts, on December 16, 1991
}

Manuscript Completed: May 1992

Date Published: June 1992

Prepared by

R. W. Carlson, L. E. Fischer

Lawrence Livermore National Laboratory

P.O. Box 808

Livermore, CA 94551

\section{Prepared for}

Division of Safeguards and Transportation

Office of Nuclear Material Safety and Safeguards

U.S. Nuclear Regulatory Commission

Washington, DC 20555

NRC FIN A0291 


\section{DISCLAIMER}

This report was prepared as an account of work sponsored by an agency of the United States Government. Neither the United States Government nor any agency Thereof, nor any of their employees, makes any warranty, express or implied, or assumes any legal liability or responsibility for the accuracy, completeness, or usefulness of any information, apparatus, product, or process disclosed, or represents that its use would not infringe privately owned rights. Reference herein to any specific commercial product, process, or service by trade name, trademark, manufacturer, or otherwise does not necessarily constitute or imply its endorsement, recommendation, or favoring by the United States Government or any agency thereof. The views and opinions of authors expressed herein do not necessarily state or reflect those of the United States Government or any agency thereof. 


\section{DISCLAIMER}

Portions of this document may be illegible in electronic image products. Images are produced from the best available original document. 


\begin{abstract}
In the early morning of Dec. 16,1991 , a severe accident occurred when a passenger vehicle traveling in the wrong direction collided with a tractor trailer carrying 24 unirradiated nuclear fuel assemblies in 12 containers on Interstate I-91 in Springfield, Massachusetts. The purpose of this report is to document the mechanical circumstances of the severe accident, confirm the nature and quantity of the radioactive materials involved, and assess the physical environment to which the containers were exposed and the response of the containers and their contents.

The report consists of five major sections. The first section describes the circumstances and conditions of the accident and the finding of facts. The second describes the containers, the unirradiated nuclear fuel assemblies, and the tie down arrangement used for the trailer. The third describes the damage sustained during the accident to the tractor, trailer, containers, and unirradiated nuclear fuel assemblies. The fourth evaluates the accident environment and its effects on the containers and their contents. The final section gives conclusions derived from the analysis and fact finding investigation. During this severe accident, only minor injuries occurred, and at no time was the public health and safety at risk.
\end{abstract}




\section{Table of Contents}

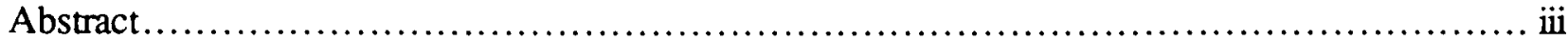

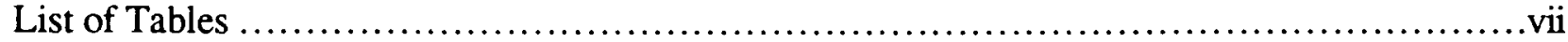

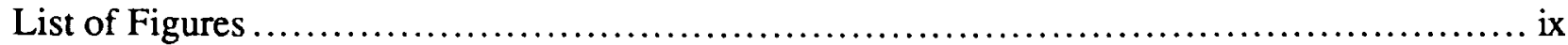

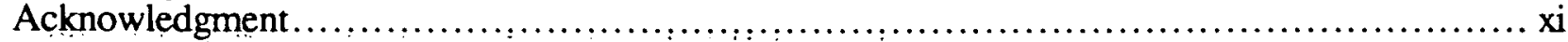

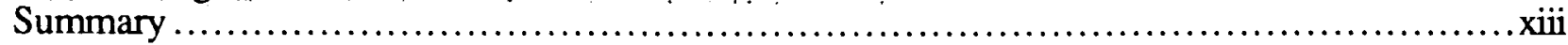

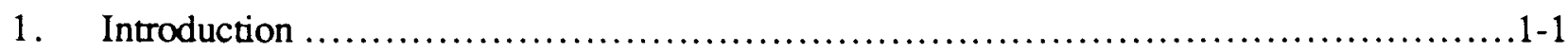

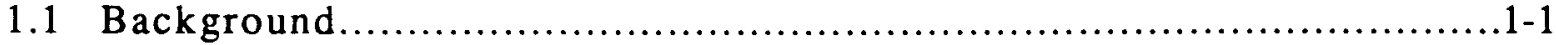

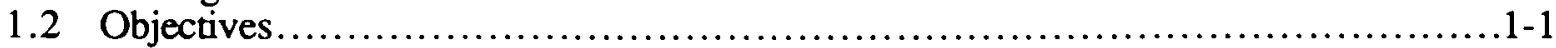

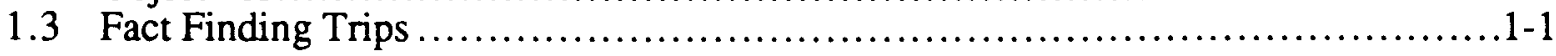

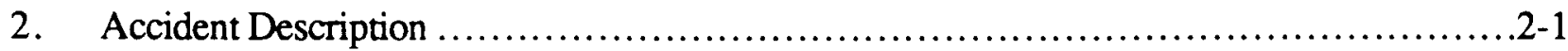

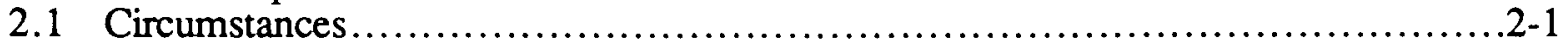

2.2 Accident Site....................................................................

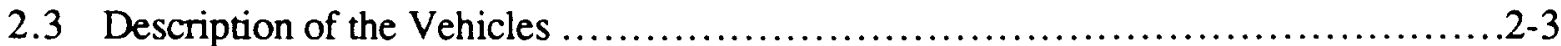

2.4 Description of the Accident ................................................ 2-10

2.5 Disposition of Fuel Assemblies ......................................... 2-12

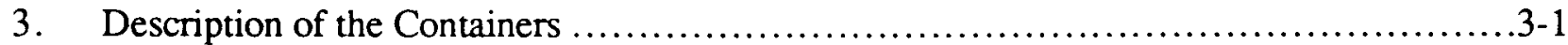

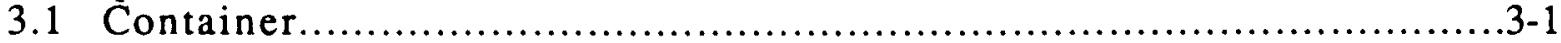

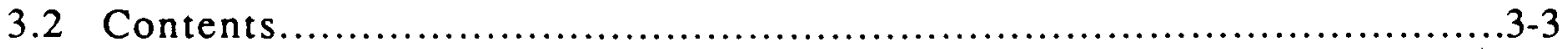

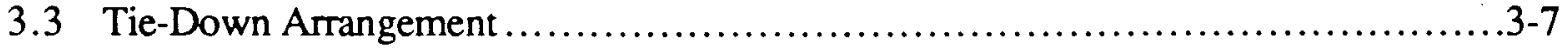

4. Damage Sustained by Containers ................................................

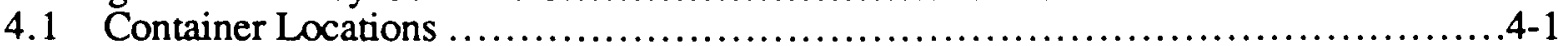

4.2 Impact Damage ............................................................4-4

4.2.1 Damage to Tractor and Trailer...........................................4.4

4.2.2 Damage to Container ................................................... $4-5$

4.2.3 Damage to Fuel Assemblies ............................................. $4-5$

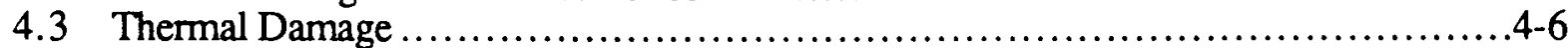

4.3.1 Damage to Tractor and Trailer............................................. $4-6$

4.3.2 Damage to Container ................................................. $4-6$

4.3.3 Damage to Fuel Assemblies ....................................... 4-14

5. Evaluation of Accident: Effect on Containers............................................5-1

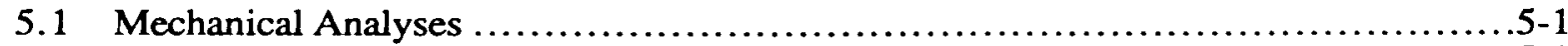

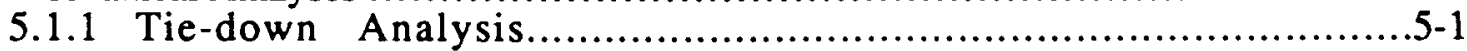

5.1 .1 .1 Pre-tension ....................................................

5.1.1.2 Frictionless Contact Between Strap and Tarpaulin ..................5-4

5.1 .2 Trailer Dynamics.................................................. 5-14

5.1.2.1 Analysis of Load Distribution of Tractor and Trailer............. 5-14

5.1.2.2 Kinetic Analysis of Trailer Motion During Accident .............. 5-16

5.1 .3 Container Impact Analysis......................................... 5-20

5.1 .4 Evaluation of Container Resting on Guardrail.............................. 5-24

5.1.5 Kinematic Analysis of the Containers as They Fall ........................ 5-30

5.1.5.1 Fall from Trailer to Roadway ...............................5-30

5.1.5.2 Fall of Inner Container within Outer Container ................ 5-32

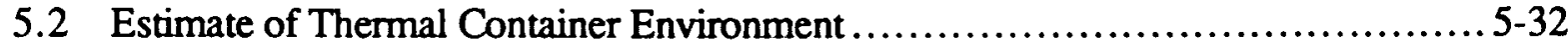

5.2.1 Estimate of Fire Temperatures........................................ 5-32

5.2.2 Evaluation of Transient Heat Conduction in Outer Container .............. 5-36

5.2.3 Evaluation of Transient Heat Conduction in Inner Container.................. 5-42 


\section{Table of Contents (cont.)}

5.3 Fuel Rod Temperatures ............................................... 5-42

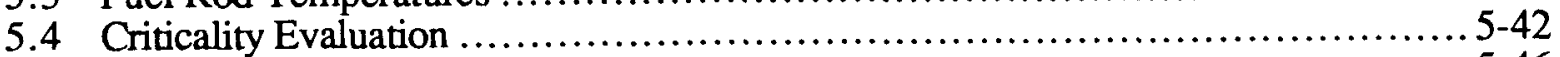

5.5 Shielding Evaluation.......................................................... $5-46$

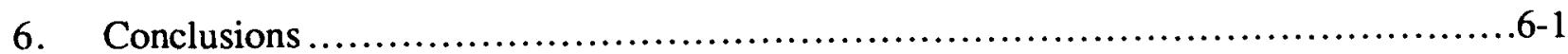

7. References................................................................. 


\section{List of Tables}

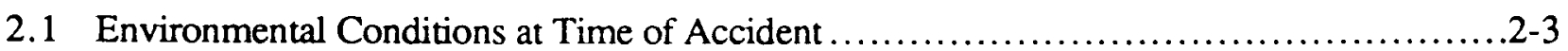

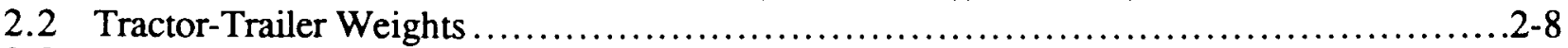

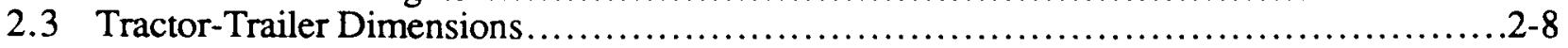

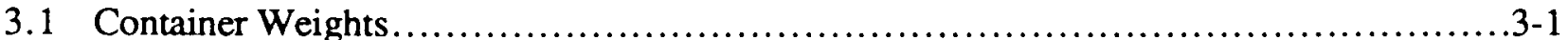

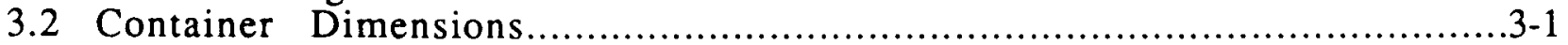

5.1. Ignition Temperatures and Flame Temperatures for Flammable Materials in

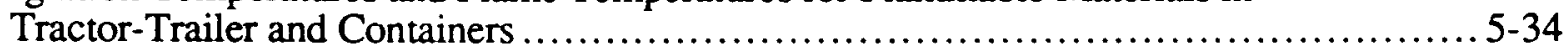

5.2. Time Required for Ignition of Plywood and Paper-Honeycomb ....................... 5-39 

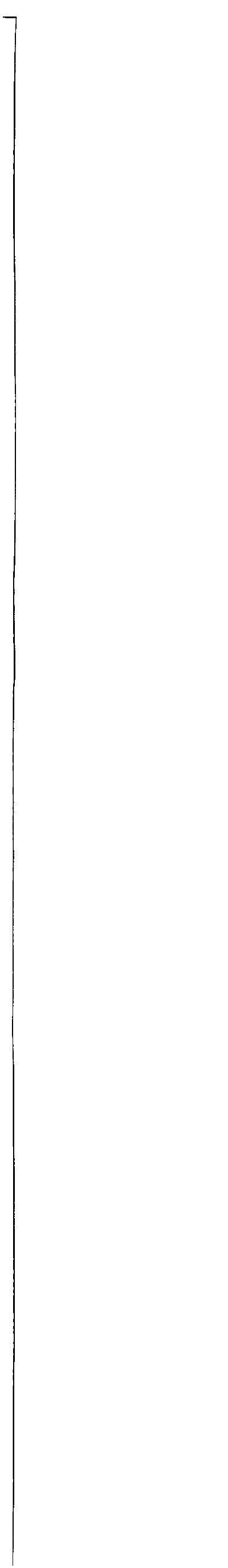


\section{List of Figures}

2.1 Site of Collision and Path of Vehicles Following Collision ..............................2

2.2 Concrete Barrier at Outside of Roadway at Site of Collision .............................

2.3 Guardrail and Area Where Tuck Burned After Removal of Debris.......................2

2.4 Multiple Views of Undamaged Tractor (similar to tractor involved in

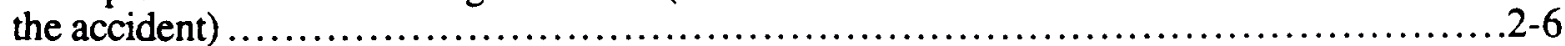

2.5 Multiple Views of Undamaged Trailer (similar to trailer involved in the

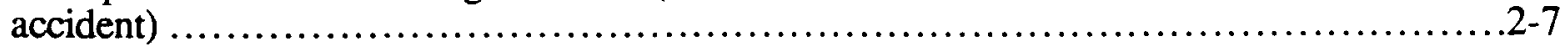

2.6 Undamaged Trailer with Placard.....................................................

2.7 Damaged Car Following Collision ................................................. $2-9$

2.8 Photograph of Accident Scene Near End of Fire .....................................

3.1 Exploded View of Wooden Outer RA-3 Container.................................... $3-2$

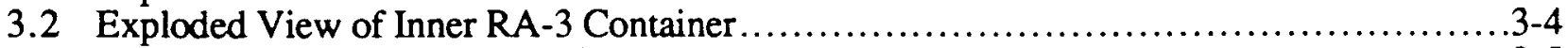

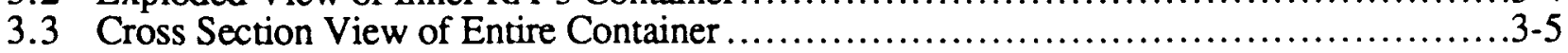

3.4 Photograph of Upper End of a BWR-6 fuel Assembly ..................................

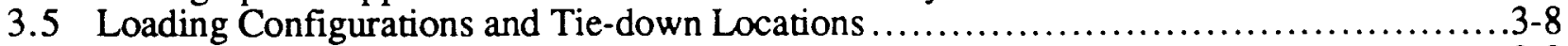

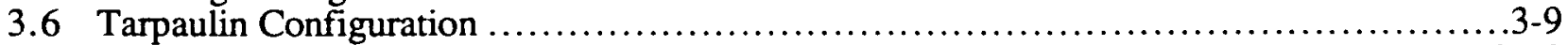

3.7 Undamaged Tie-down and Ratchet........................................... $3-10$

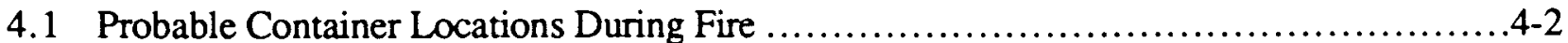

4.2 Photograph of Removal of Damaged Containers . . . . . . .

4.3 Photographs of Damaged Trailer ................................................... $4-7$

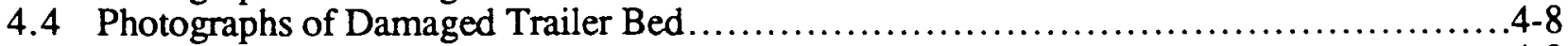

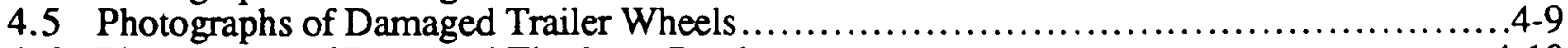

4.6 Photographs of Damaged Tie-down Ratchet ..................................... 4-10

4.7 Photographs of Turn Warning Signs on Trailer .................................... $4-11$

4.8 Photographs of Damaged Tractor Frame and Trailer Attachment....................... 4-12

4.9 Photographs of Damaged Tractor Wheels .......................................... 4-13

4.10 Photograph of Damaged Inner Container......................................... 4-15

4.11 Photograph of Damaged Inner Container.........................................

5.1 Load-Strain Curve for Nylon Straps ...............................................5-2

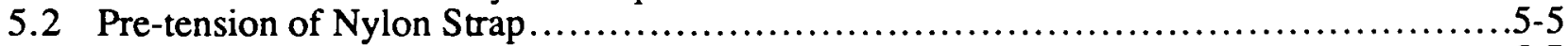

5.3 Strain in Tie-down Assuming No Friction Under Tie-down ..........................5-7

5.4 Tension in Tie-down Assuming No Friction Under Tie-down . . . . . . . . . . . . . . . . . . . . . $5-8$

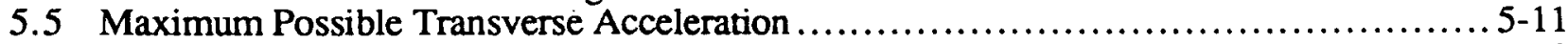

5.6 Maximum Possible Longitudinal Acceleration ...................................... 5-13

5.7 Trailer Dynamics During Impact Portion of the Accident .............................. 5-17

5.8 Shear Force and Moment Distribution in Beam Model of Container Supported

by Guardrail ............................................................. 5-27

5.9 Maximum Shear Force and Moment in Beam Model of Container Supported

by Guardrail ................................................................... 5-28

5.10 Temperature Dependence of Strength of Steel ....................................... 5-29

5.11 Motion of Container Falling off Trailer During Fire..................................... 5-31

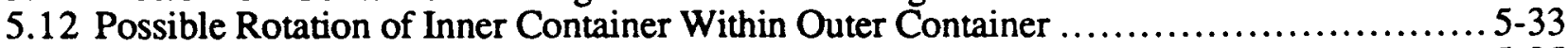

5.13 Flame Temperature Distribution During Fire.................................. 5-35

5.14 Plywood Temperature History When Exposed to Fire.................................... 5-38

5.15 Extended Plywood Temperature History When Exposed to Fire..................... 5-40

5.16 Plywood Temperature Distribution at Selected Times After Exposure to Fire ............. 5-41

5.17 Temperature Histories in Inner Container After Direct Exposure to Fire ................ 5-43

5.18 Stress in Clad at Elevated Temperatures .......................................... 5-45 


\section{Acknowledgment}

This work was funded by the Transportation Branch, Office of Nuclear Material Safety and Safeguards, under the U.S. Nuclear Regulatory Commission. Marissa Bailey was the technical monitor for this work. The authors express their appreciation to the persons listed in Section 1.3 whose help in providing information was invaluable in the preparation of this report.

The authors also acknowledge the assistance of many colleagues within the Nuclear Systems Safety Program at Lawrence Livermore National Laboratory who willingly viewed video tapes, asked questions, and made suggestions that contributed to the overall understanding of the mechanics of this accident.

Particular appreciation is due to Merry Carter for her assistance in preparing the final manuscript and for dealing with the "red tape" that accompanies the publication of this report. 


\section{Summary}

An inquiry, assessment, and analysis were performed of a severe accident involving a passenger vehicle colliding with a tractor-trailer carrying 12 containers each containing 2 unirradiated nuclear fuel assemblies. When the accident occurred at 3:15 a.m. on Dec. 16, 1991, the tractor-trailer was presumably traveling near the legal speed limit $(55 \mathrm{mph})$, under clear conditions, on U.S. Interstate I-91 in downtown Springfield, Massachusetts.

In the collision, the truck veered to the left to miss an oncoming car which was driving on the wrong side of the interstate The car struck the right side of the truck near the right fuel tank. The truck continued northbound, striking the center guardrail and outer concrete barrier before coming to a stop at the center guardrail. The front axle of the truck separated from the truck during impact with the concrete roadside barrier, but the cargo of unirradiated nuclear fuel assemblies apparently remained intact on the truck during the collision. Following the collision, a fire started in the engine compartment which engulfed the tractor and then the trailer. No attempt was made to extinguish the fire which burned approximately three hours. The emergency response measures undertaken during the accident are the subject of a separate report (see NUREG-1458, Emergency Response to a Highway Accident in Springfield, Massachusetts, on December 16, 1991).

The fire completely destroyed the tractor-trailer and caused significant damage to several of the containers and their contents. An evaluation of the collision process and a fact finding investigation confirm that the containers probably remained on the trailer throughout the collision. During the fire, eight containers fell off the trailer, from a height of about $7 \mathrm{ft}$, at various times and sustained minor damage during the impact. The fire consumed the wood outer containers and caused damage to the inner metal containers ranging from minimal to severe depending on the location of the container during the fire. Localized regions near the tires had flame temperatures around $1800^{\circ} \mathrm{F}$; however, only portions of a few containers were exposed to this temperature. The remainder of the containers endured flame temperatures of $1300^{\circ} \mathrm{F}$ or less. The fuel assemblies inside the container were distorted to conform to the configuration of the metal container. The plastic fuel rod separators and foam protection for the fuel assemblies burned during the fire. In addition, some of the clad tubes had swollen due to the increase in pressure within the fuel rod as a result of the elevated temperatures during the accident. Analyses indicate that temperatures in excess of $1500^{\circ} \mathrm{F}$ are required to cause this type of damage.

The containers provided protection for the unirradiated nuclear fuel assemblies throughout the accident such that there was no release of radioactive material from the container and the radiation levels in the vicinity of the containers did not exceed background levels. There were only minor injuries during this accident. 


\section{A Highway Accident Involving \\ Unirradiated Nuclear Fuel in Springfield, Massachusetts, on December 16, 1991}

\section{Introduction}

\subsection{Background}

On Dec. 16, 1991, a passenger vehicle traveling in the wrong direction collided with a tractortrailer carrying unirradiated fuel from the General Electric Company (GE) fabrication plant in Wilmington, North Carolina, to the Vermont Yankee Nuclear Plant.

During the accident, a fire began that burned for almost three hours resulting in substantial damage to the truck. During the fire, the wooden outer containers were completely consumed and the shipping containers sustained damage varying from little to severe. There were only minor injuries during this accident.

\subsection{Objectives}

The objective of this report is to determine and document the environment that the containers were forced to endure during this accident. This includes:

- Document the arrangement of the containers on the vehicle and the method of tie down.

- Determine and describe the mechanical circumstances of the accident.

- Describe the accident scene, estimate the type and magnitude of accident environment produced (e.g., impact g-loads, temperature and duration of the fire).

- Describe and quantify the response of the containers and fuel assemblies to the forces involved in the accident (i.e. correlate any gross container deformation with the accident environment).

- Characterize and quantify the damage sustained by the shipping containers.

- Determine if the contents were damaged, the extent of the damage, the number of fuel assemblies damaged, and the quantity of radioactive material released (if any).

\subsection{Fact Finding Trips}

During the fact finding portion of the review of this accident, three trips were made as follows:

Location

Springfield, Massachusetts

Wilmington, North Carolina

Joplin, Missouri

Wilmington, North Carolina
Arrived

December 17, 1991

December 18, 1991

January 5, 1991

January 13, 1991
Departed

December 18, 1991

December 19, 1991

January 6, 1991

January 18,1991 
While in Springfield, Massachusetts, the authors talked to the Springfield Fire Department, the Massachusetts State Police, the Springfield Police Department, and Harold's Towing to determine the conditions surrounding the accident. The extension of this trip to Wilmington, North Carolina, permitted observation of the containers as they were returned to the GE fabrication plant. The trip to Joplin, Missouri, resulted in close observation of the remains of the truck and an opportunity to discuss the damage with the person responsible for insurance claims associated with the truck. The trip to Wilmington permitted first-hand observation of the opening of the damaged containers and dismantling of the fuel assemblies. In addition, this trip provided an opportunity to talk to the truck drivers and an opportunity to talk to the person that loaded the containers on the truck.

Numerous other contacts were made by telephone to gather information relevant to the study of this accident. The persons contacted and their corporate affiliation is presented in the following list:

Gary G. Cassanelli .........Chief, Springfield Fire Department

Jim Controvich............. Office of Emergency Preparedness, Springfield

Melanie G. Creech.........Specialist-Site Traffic, General Electric Co.

Ron Downing .............General Electric Co.

Joe Dunn..................Truck Driver, McGil Specialized Carriers

Janet Dunn................Truck Driver, McGil Specialized Carriers

Joe Furia ...................NRC Regional Office

Joe Gura .....................Trooper, Massachusetts State Police

Harry Hasegawa ...........Group Leader, Fire Science Group, Lawrence Livermore National

Laboratory

John Heard ................Core Components Engineer, Yankee Atomic Electric Co.

Dan J. Kennedy ............Sergeant, Massachusetts State Police

Robert Leach .............. Health Physicist, Vermont Yankee Atomic Electric Co.

Mike Livingston.............Truck Driver, McGil Specialized Carriers

Chuck Mally...............Commonwealth Ambulance Service

Scott Murray..................Manager-Nuclear Safety Engineering, General Electric Co.

Bill Meyers ................ White GMC Trucks of Oakland, Inc.

Van Palmer .................Tri-State Motor Transit Co.

James Sinclair ...............Foreman of Maintenance Crew, Vermont Yankee Atomic Electric Co.

James M. Sheehan.........Captain, Massachusetts State Police

Tom Schimelpfenig.........Director of Procurement, Yankee Atomic Electric Co.

Dan Spellacy................Deputy Chief of Police, Springfield Mass.

Fred Walker ...............Manager-Transportation, General Electric Co.

Dave Weiss ................Project Manager, General Electric Co.

Randy Yopp ..............Transportation Specialist, General Electric Co. 


\section{Accident Description}

\subsection{Circumstances}

At approximately 3:15 a.m. on Dec. 16,1991, a passenger vehicle traveling in the wrong direction collided with a flat-bed, tractor-trailer carrying 24 unirradiated nuclear fuel assemblies in 12 Model No. RA-2 and RA-3 containers from the GE fabrication plant in Wilmington, North Carolina, to the Vermont Yankee Nuclear Plant. The collision occurred on I-91 where it passes through downtown Springfield, Massachusetts. A sketch of the roadway and buildings surrounding the accident site is presented in Figure 2.1.

The trip from Wilmington, North Carolina, to Vernon, Vermont, normally requires about 24 hours, allowing time for refueling stops. Travel is continuous, requiring two drivers that alternate driving and sleeping. Less than one hour of travel remained for the truck to reach its destination.

The truck was reported to have stopped for refueling shortly before the accident. The truck carries two saddle tanks on either side of the cab of the tractor. Each tank is rated at $125 \mathrm{gal}$; however, the positioning of the fill necks on the tanks prevents each tank from carrying the rated capacity. Consequently, the inventory of diesel fuel on board the truck has been estimated at about 210 gal. As with any vehicle, the cab of the tractor has numerous combustible materials (seats, blankets, floor mats, maps, etc.). The engine also contains several flammable liquids (power steering fluid, engine oil, etc.).

The containers were secured to the trailer with nylon tie down straps on top of tarpaulins that provided weather protection for the payload. The nylon straps were preloaded when the load was prepared for shipment. The tarpaulins were secured to the bed of the trailer by wooden boards that were nailed to the trailer bed with the nails passing through the tarpaulin.

At the time of the accident, weather conditions were ideal for driving. Weather conditions were recorded by two stations in the general vicinity of the accident. The reported conditions from before the accident to after the accident are reported in Table 2.1. The description of the conditions provided by the Emergency Medical Technicians who reached the accident site about 5 min after the accident, essentially duplicate the conditions reported by the weather stations. The only exception is the Emergency Medical Technicians described the winds as gusty.

Westover Air Force Base is located about six miles northeast of the site of the accident, while the Hartford Airport is about 15 miles southwest of the accident site. The weather conditions reported by both stations were essentially the same. At the time of the accident, both stations reported high scattered clouds with excellent visibility at ground level. The weather was not a factor in the accident. The only impact of the weather was the movement of the flames due to the wind. Based on photographs and videos of the fire, the wind direction at the scene of the accident was approximately parallel to, and in the direction of, the northbound lanes of the highway. This is consistent with the wind directions presented in Table 2.1 for Westover Air Force Base.

The barometric pressure was dropping at the time of the accident. This resulted in a snowstorm in the Springfield area; however, the snow began later in the day and had no impact upon the accident and cleanup.

\subsection{Accident Site}

The accident occurred on an interstate highway in downtown Springfield, Massachusetts. In this area the highway is elevated, has limited access, and is divided. The right hand side (outer edge) 


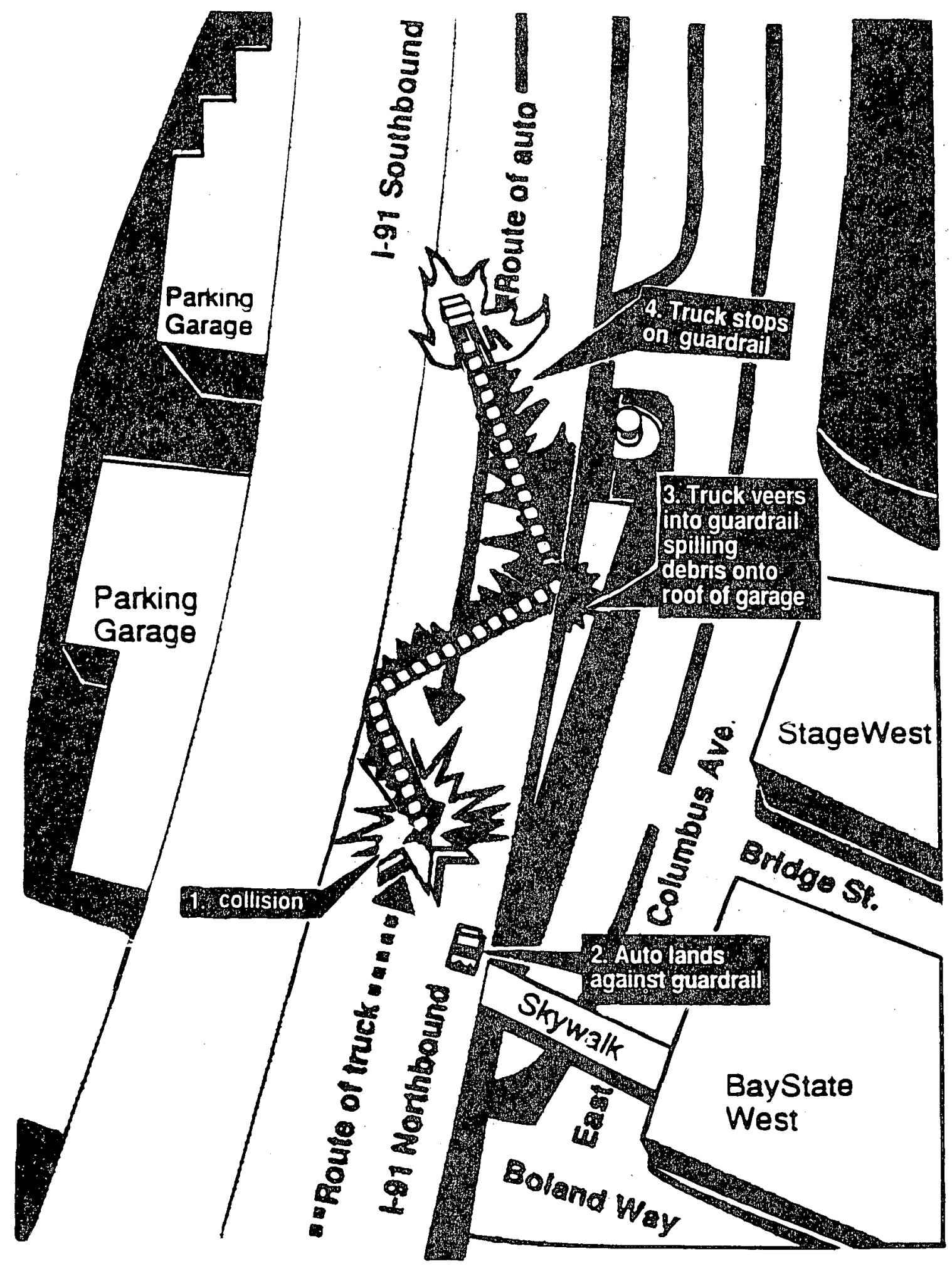

Figure 2.1 Site of Collision and Path of Vehicles Following Collision 
Table 2.1 Environmental Conditions at Time of Accident

Sunrise:.......................... 7:13 a.m. EST

Moon:...................... First Quarter (No moon at time of accident)

Westover AFB

Time, a.m. ........................2:55

Temperature $\left({ }^{\circ} \mathrm{F}\right) \ldots \ldots \ldots \ldots \ldots \ldots \ldots . .20$

Dew Point $\left({ }^{\circ} \mathrm{F}\right) \ldots \ldots \ldots \ldots \ldots \ldots \ldots \ldots 14$

Winds (knots) .......................... 1

Wind Direction $\left(^{\circ}\right) \ldots \ldots \ldots \ldots \ldots \ldots 150$

Visibility (miles) ...................20

Barometric Pressure (mbar)..... 1014.3

$\begin{array}{rrrr}3: 55 & 4: 55 & 5: 55 & 6: 55 \\ 18 & 18 & 23 & 24 \\ 14 & 14 & 15 & 15 \\ 1 & 2 & 1 & 0 \\ 140 & 160 & 200 & \mathrm{NA} \\ 20 & 20 & 20 & 20 \\ 1013.8 & 1013.6 & 1013.6 & 1013.6\end{array}$

\section{Hartford Airport}

Time, a.m. ......................2:50

Temperature $\left({ }^{\circ} \mathrm{F}\right) \ldots \ldots \ldots \ldots \ldots \ldots \ldots .25$

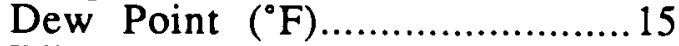

Winds (knots) ......................... 4

Wind Direction $\left(^{\circ}\right) \ldots \ldots \ldots \ldots \ldots \ldots . \ldots 230$

Visibility (miles) ....................25

Barometric Pressure (mbar)..... 1014.4

$\begin{array}{rrrr}3: 50 & 4: 50 & 5: 50 & 6: 51 \\ 26 & 26 & 25 & 26 \\ 16 & 16 & 16 & 16 \\ 7 & 7 & 6 & 9 \\ 190 & 210 & 200 & 230 \\ 25 & 25 & 25 & 25 \\ 1014.4 & 1013.8 & 1013.6 & 1013.8\end{array}$

of the northbound lanes is bordered by a concrete (with steel-reinforcing bars) barrier that is approximately 3 -ft tall. This barrier is designed to return any vehicles that impact it to the roadway. The barrier is shown in Figure 2.2 at the point of impact. Note the small railing at the top of the barrier that was torn away during the impact. This railing appears to be the highest object that was involved in any of the impacts on the tractor or trailer. The barrier incorporates a curb that is about 6-in. higher than the roadway. The left-hand side (adjoining the southbound lanes) of the northbound lanes is bordered by a steel-beam type barrier that is designed to prevent cross-over type accidents. The shoulder at this side of the roadway is elevated by about 6 in. The guardrail and shoulder are shown in Figure 2.3. The highway is three lanes wide (each lane is $12 \mathrm{ft}$ wide) with a shoulder on the right side of the road that is equivalent to a narrow lane, and at the center of the roadway, the shoulder is about $2-\mathrm{ft}$ wide. The road is crowned with the high point in the center of the center lane and slopes to both sides of the northbound lanes. Drains exist at both sides of the roadway to channel water off the roadway into the Connecticut River. The interstate highway at the accident site passes over parking garages and is adjacent to the Springfield Marriott and Springfield Sheraton Hotels.

\subsection{Description of Vehicles}

The tractor was manufactured by White-Volvo, and had an aluminum cab with fiberglass hood and fenders. Sleeping accommodations allowed nearly continuous travel using two drivers. This satisfied the DOT requirement for driver rest periods. Photographs of the right and left sides of a White-Volvo tractor similar to the one involved in this accident are presented in Figure 2.4. Photographs of trailers similar to the one involved in this accident are presented in Figure 2.5. The trailer involved in the accident did not have the spare tire rack that is apparent on the trailers shown in Figure 2.5. Weights and significant dimensions of the tractor and trailer at the time of the accident are presented in Tables 2.2 and 2.3 . 


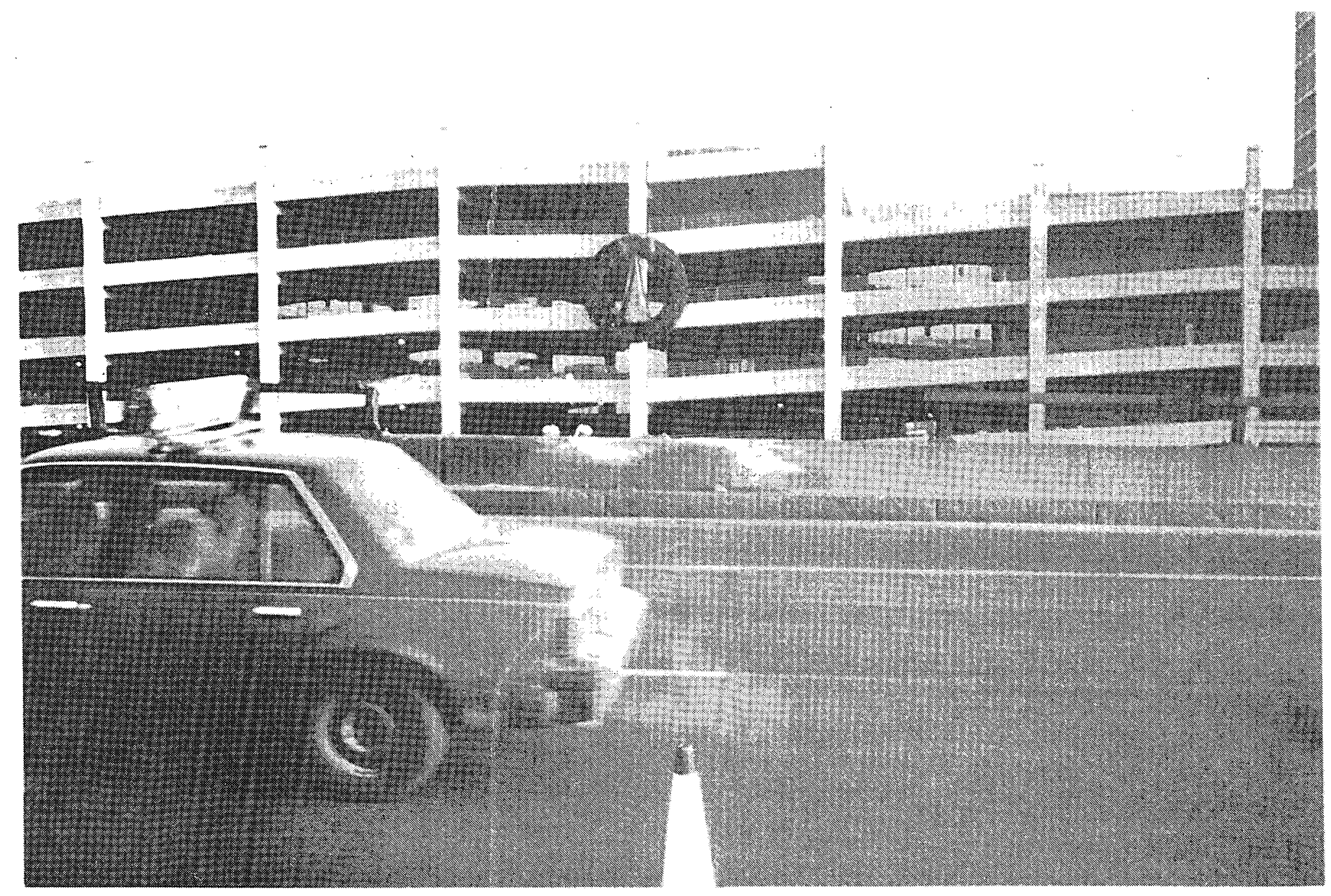

Figure 2.2 Concrete Barrier at Outside of Roadway at Site of Collision 


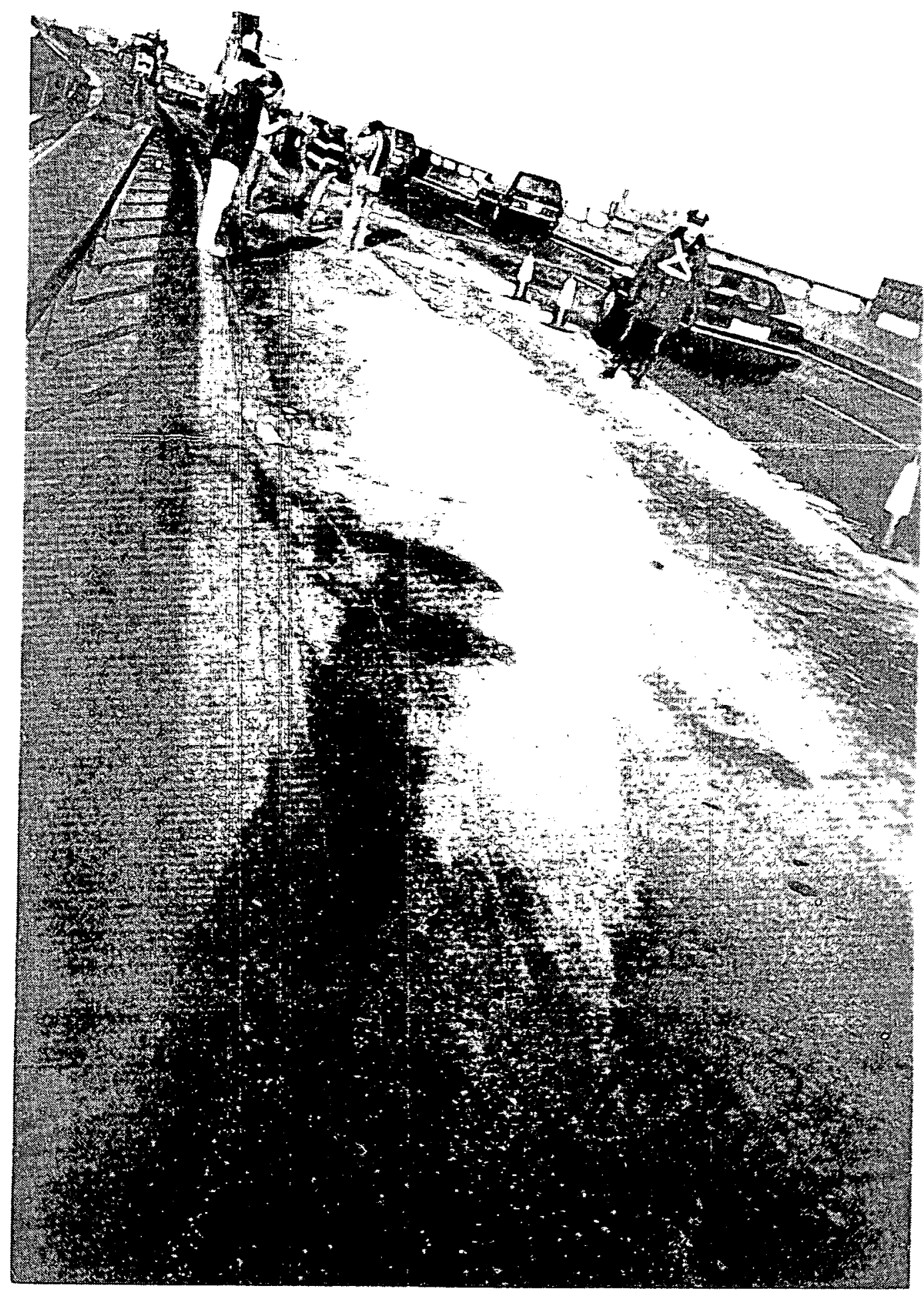

Figure 2.3 Guardrail and Area Where Truck Burned After Removal of Debris 

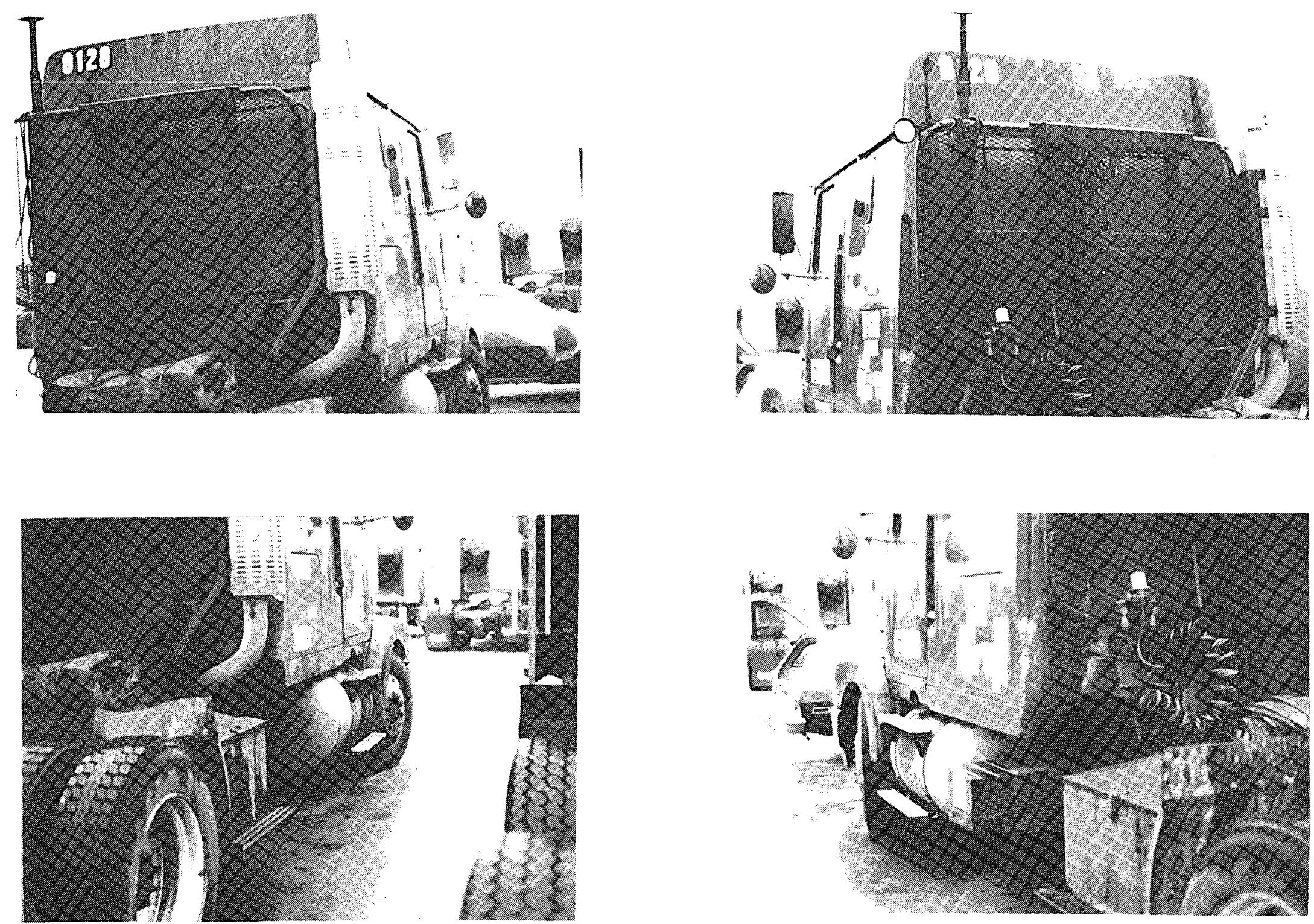

Figure 2.4 Multiple Views of an Undamaged Tractor (similar to tractor involved in the accident) 

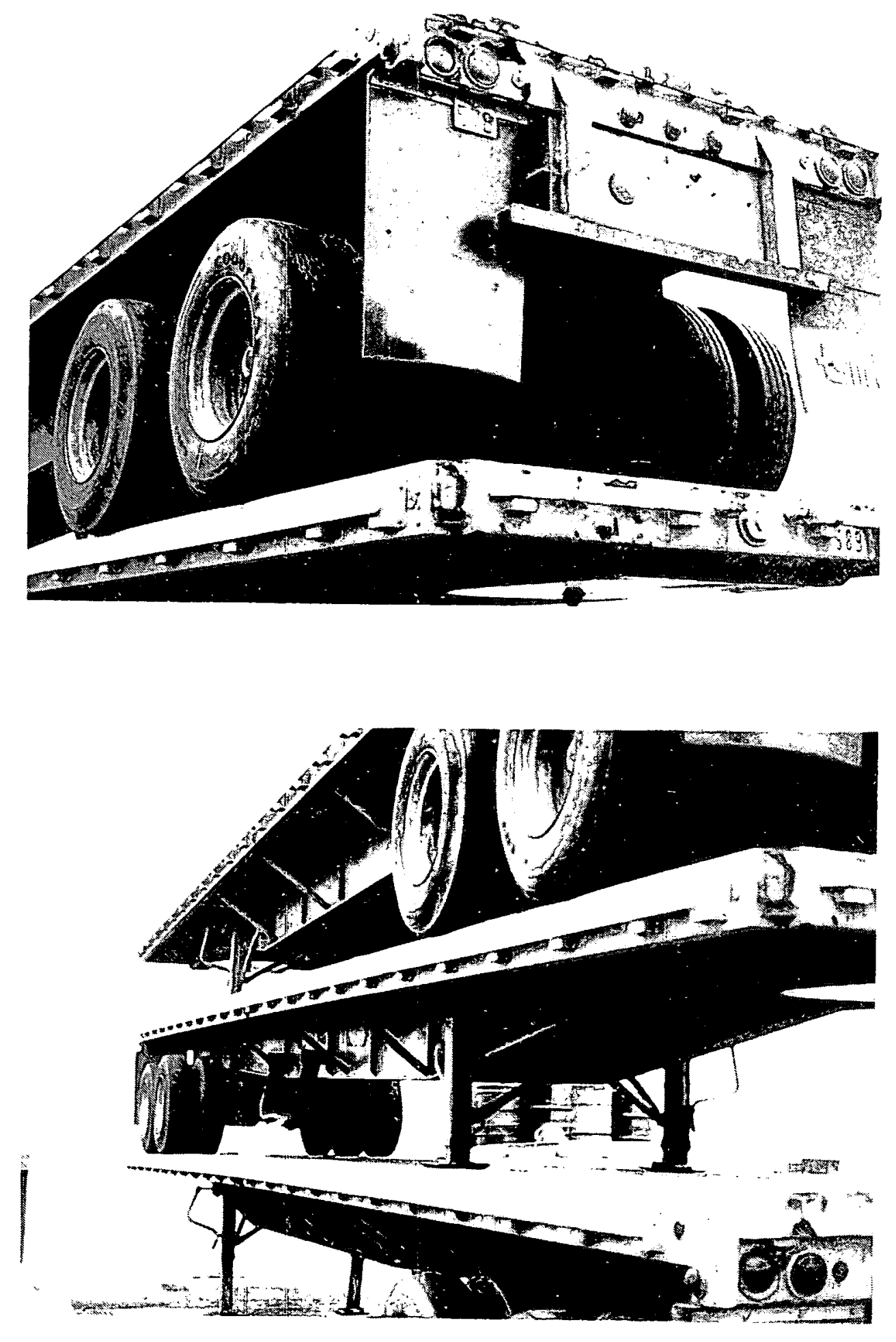

Figure 2.5 Multiple views of an Undamaged Trailer (similar to trailer involved in the accident) 
Table 2.2 Tractor-Trailer Weights

\begin{tabular}{lr}
\hline Component & Weight, lb \\
\hline Tractor & 16,800 \\
Trailer & 14,000 \\
Driver, passenger, and personal effects & 800 \\
Tarpaulins, tie-downs, and miscellaneous & 1,000 \\
Diesel Fuel (210 gal @ 6.8 lb/gal) & 1,400 \\
Payload (12 containers @ 2800 lb (or less)/container) & 31,500 \\
Total Tractor-Trailer and Payload Weight & 65,500 \\
\hline
\end{tabular}

Table 2.3 Tractor-Trailer Dimensions

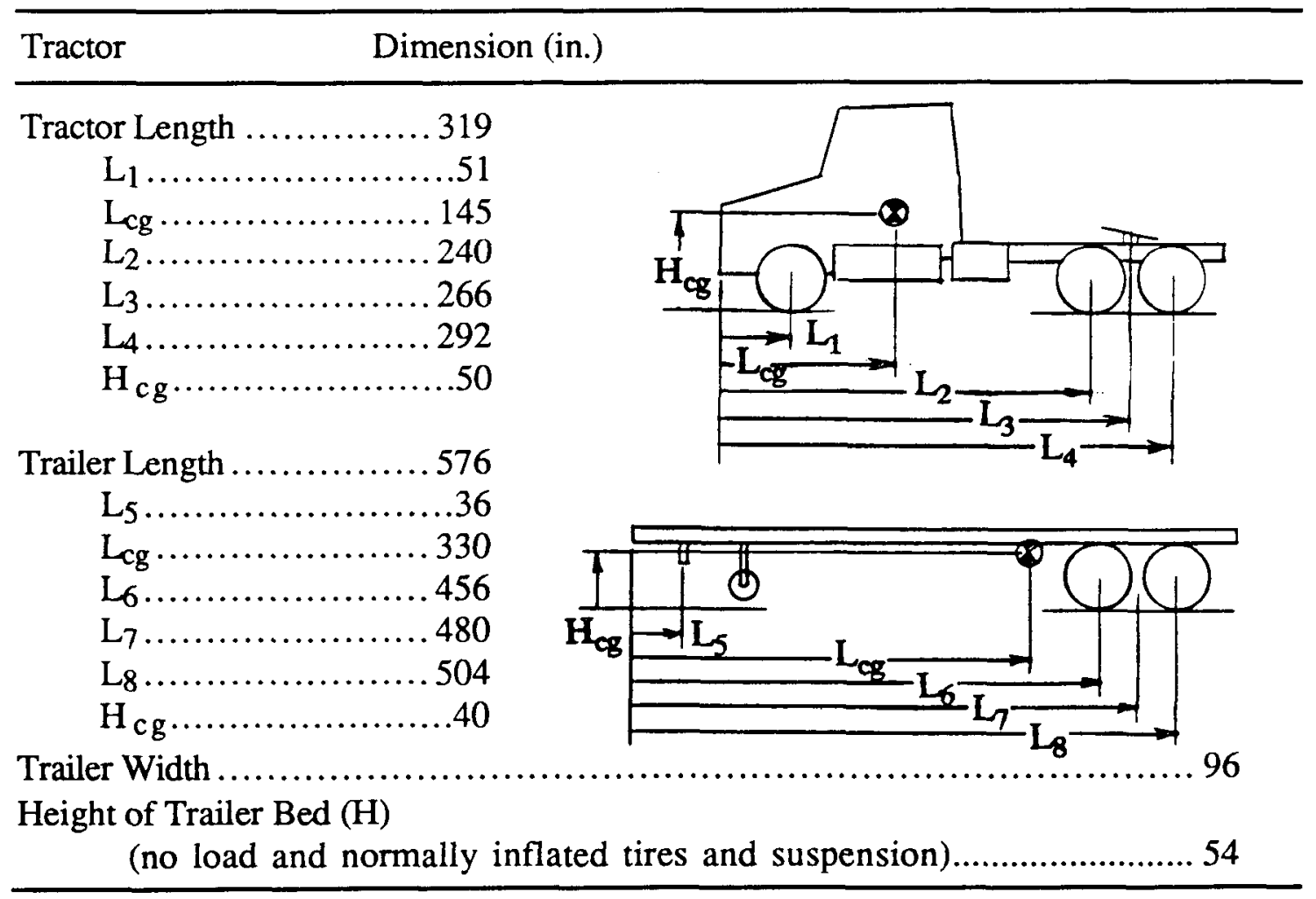

Placards were not required on the trailer and a careful examination of the wreckage indicates that they were never installed on this trailer. A photograph of a trailer with a placard mounted, per normal practice for Tri-State Motor Trucking and McGill Carriers, is presented in Figure 2.6. One of the ambulance drivers is reported to have observed placards. It is possible that this individual observed the radioactive labels that are affixed to each outer container at the time of shipping. However, the containers were completely covered with a tarpaulin so the labels were not visible until the tarpaulin burned off. At this time, the wooden outer containers were beginning to burn, therefore observation of a label would be very difficult. It is possible that fluctuations in the wind could have diverted the flames and allowed the labels to be observed for brief periods of time. However, the confusion of a label for a placard can only be considered as an erroneous observation. 


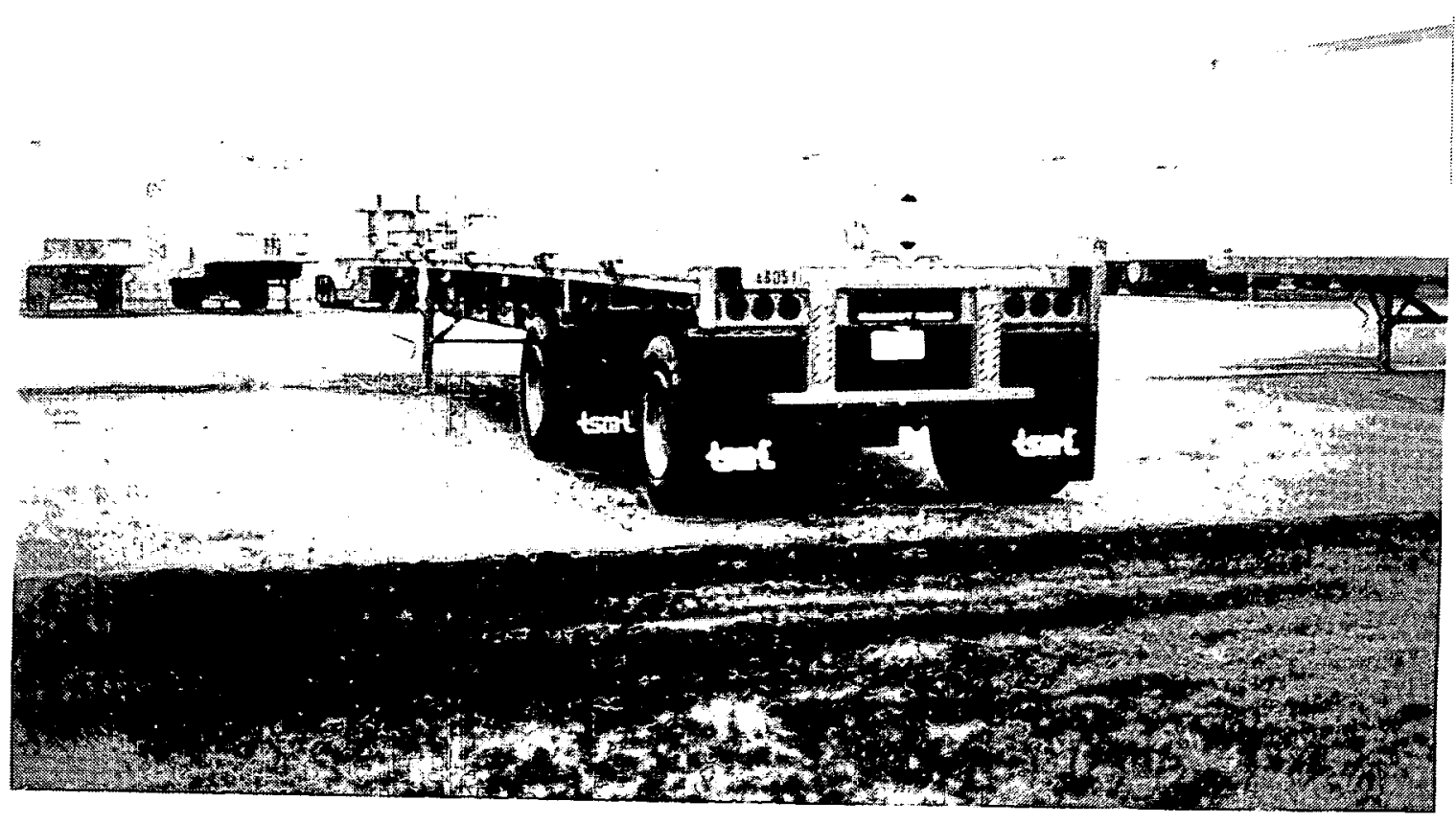

Figure 2.6 Undamaged Trailer with Placard

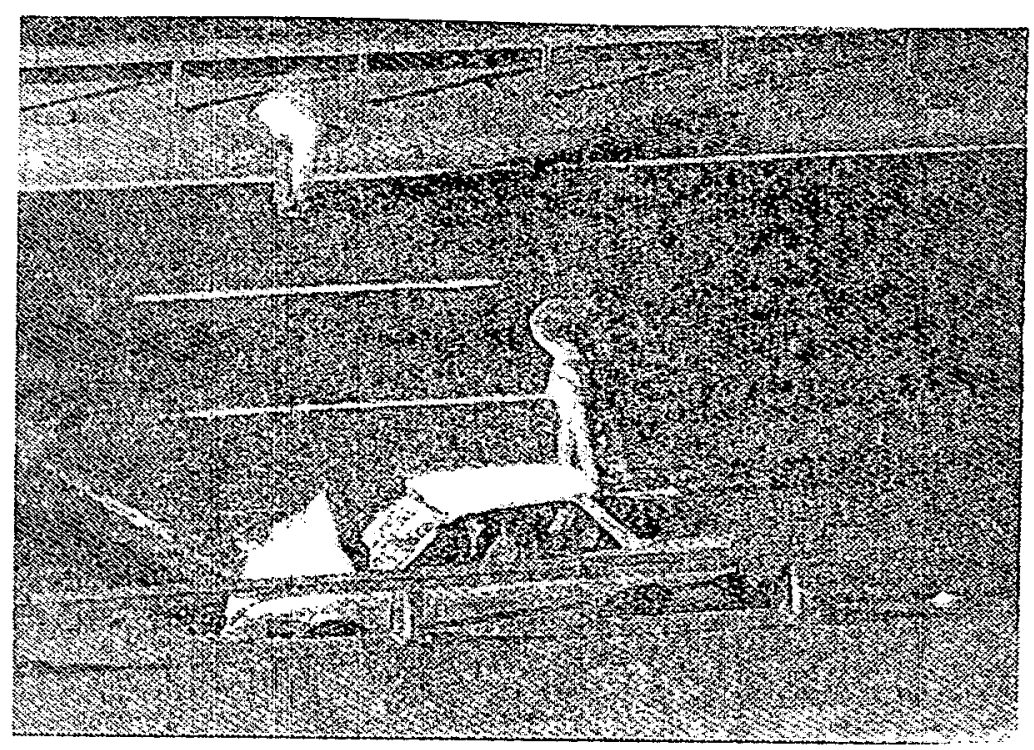

Figure 2.7 Damaged Car Following Collision 
The car suffered extensive damage to its front, right corner. Following the accident, one front wheel with the strut attached and several smaller components of the car can clearly be seen lying in the roadway as shown in Figure 2.7. The car does not appear to have been involved in any fire.

\subsection{Description of the Accident}

In the following description of the accident, the terms north and south refer to the approximate travel directions of I-91 and are not compass directions. At the location of the accident, the northbound lanes of I-91 are directed approximately northwest. Similarly, the terms left and right refer to the driver's side and the passenger side of the truck, respectively.

Shortly before 3:10 a.m. on Monday, Dec. 16,1991, an allegedly intoxicated motorist entered the northbound lanes of I-91 traveling in a southbound direction. After driving several miles without encountering any other traffic, this car collided at about 3:15 a.m. with the tractor-trailer that was transporting unirradiated nuclear fuel assemblies to the Vermont Yankee Nuclear Plant. Police notification of the accident occurred at 3:18 a.m. probably by radio transmission from a southbound truck driver.

A sketch of the accident scene is presented in Figure 2.1. Both the car and the truck were reported to be traveling in the center lane. The driver of the truck veered left in an attempt to avoid the collision. The car appeared to continue in a straight path and struck the tractor of the truck at an angle causing damage to the passenger side of the car and the passenger side of the truck. The initial impact appeared to involve the fuel tank and/or storage compartment on the right side of the tractor. (See Figure 2.4 for a view of an undamaged tractor in the vicinity of the impact.)

Following the initial impact, the truck continued northbound veering toward the center of the Interstate and impacting the small curb and guardrail that separates the northbound from the southbound lanes. The impact was a glancing blow that apparently dislodged the left front wheel of the tractor and probably damaged some of the air tanks and/or tubing that provide compressed air to operate the brakes, suspension, and several accessories. The co-driver (also an experienced driver) was sleeping in the sleeper portion of the tractor and reported hearing an explosion during this impact. The source of this explosion is speculative, but one possibility could be the failure of any one of several compressed air components. This could also explain the loss of air pressure in the braking system.

The truck rebounded from the second impact and continued northbound but headed across the roadway toward the curb and barrier at the outside of the roadway (see Figure 2.2) where the tractor impacted on the barrier with a glancing blow. This impact was relatively severe. The following major components separated from the tractor:

- The hood and fenders of the tractor separated from the tractor and fell off the roadway onto the roof of a parking garage that was beneath the roadway.

- The front axle, with both wheels attached, was separated from the tractor (see Figure 2.8).

- Some fluids from the engine leaked onto the side of the roadway and onto the garage below the roadway (the fluid on the side of the roadway stained the outside of the concrete barrier, while the fluid on the garage below the roadway burned). 


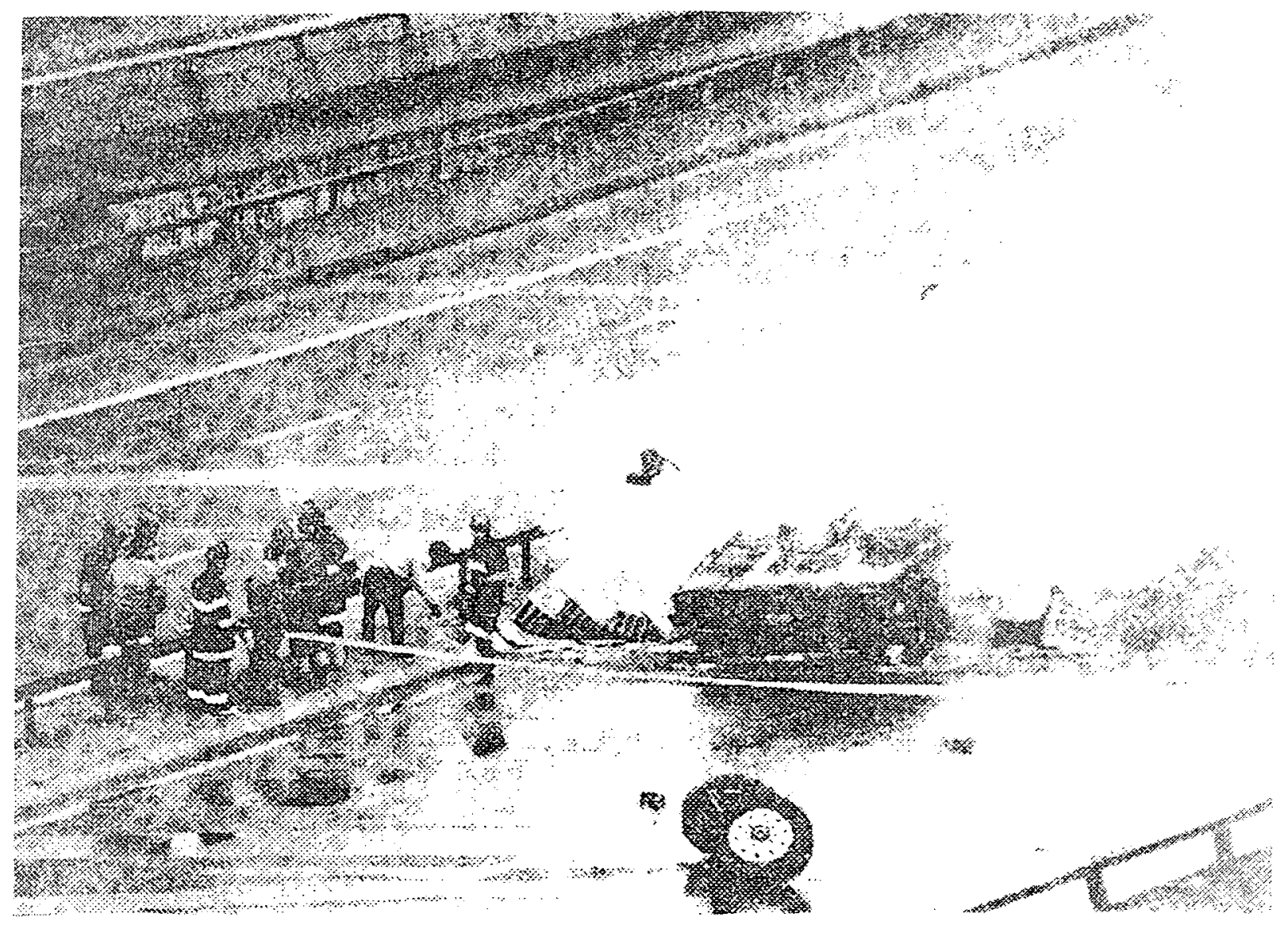

Figure 2.8 Photograph of Accident Scene Near End of Fire

During the impact with the concrete barrier, it is apparent that at least one of the truck's fuel tanks ruptured. The fluid on the roof of the parking garage was burning so it must be concluded that some of the combustible fluids in the engine compartment were also burning.

After rebounding from the collision with the outer barrier, the truck skidded further along the northbound lanes, crossed the highway and came to rest against the guard rail, as shown in Figure 2.1. During this travel across the highway, the tractor was without the front axle and wheels.

The tractor-trailer came to rest against the center guardrail with the tractor and trailer almost perfectly in line (see Figure 2.8). After the truck came to rest against the guardrail, the driver was able to get out of the tractor on the passenger side (the driver's side door was jammed). Fire was observed in the engine compartment and around the tires at the rear of the tractor. The co-driver reported stepping into a large puddle of diesel fuel on exiting from the tractor. At this time the fire was restricted to the engine and tires of the tractor. The fire gradually expanded to engulf the entire tractor and the tractor was reported to have burned vigorously for at least three-quarters of an hour.

The driver and co-driver were the closest observers at the conclusion of the impact portion of the accident and at the start of the fire portion of the accident. Both reported that the entire payload remained intact on the trailer based on the tarpaulin and tie downs being intact and in place. One early witness reported that he could not identify the form of the contents of the truck which tends to corroborate the fact that the tarpaulin was intact. 
The fire in the tractor was allowed to burn. About one hour after the impact, ignition of the tarpaulin lead to ignition of the wooden outer containers, the bed of the trailer, and ultimately the tires on the trailer. This fire was also allowed to burn until all of the combustible materials were consumed. Various accounts place the length of the fire between two and three hours with the principal differences arising from differing definitions of the end of the fire. For the purpose of this analysis, the fire no longer had an effect on the containers about three hours after the initial impact. The containers fell off the trailer at various times during the fire and were exposed to varying amounts of flames after falling from the trailer; therefore, some containers could have been exposed to fire for as little as one hour while others appear to have been exposed for over two hours.

The principal sources of combustion that impacted the containers were the following:

- Diesel fuel from the fuel tanks of the truck.

- Rubber from the tires on the truck.

- Asphalt from the roadway.

- Wood from the deck of the trailer.

- Wood from the outer containers of the containers.

Not all of the diesel fuel from the truck burned during the fire. The cleanup included distributing sand on the roadway to absorb the diesel fuel that remained on the roadway after the fire.

\subsection{Disposition of Fuel Assemblies}

During and after the fire, several surveys of the accident scene were made to determine the amount of radioactive contamination. No measurable amounts of radioactivity were identified and it was determined that it was safe to remove the fuel assemblies from the accident site. The fuel assemblies were loaded onto trucks and transported to a temporary holding site. The personnel, cranes, and flat-bed trucks for transporting the containers were provided by Vermont Yankee.

The inner containers were not opened to prevent any possibility of dispersal of radioactive materials. New shipping containers (inner containers and wood outer containers) were provided by GE and the original inner containers were placed in new wood outer containers and prepared for shipment to the GE plant in Wilmington, North Carolina. At about 10:00 a.m. on Wednesday, Dec. 18, 1991, the damaged containers were transported in an auto/truck convoy. The convoy arrived at the GE plant at about 10:30 a.m. on Thursday, Dec. 19, 1991. The twelve containers were transported on two flat-bed trucks similar to the one involved in the accident. A third truck transported non-radioactive materials that were made available to support the repackaging effort. Three or more cars provided escort to the trucks and transported personnel from GE and security forces. In some states, a police escort was also provided. The lead truck was equipped with a QUALCOMM satellite tracking system that allowed continuous monitoring of its location.

Several surveys (both contamination smears and area surveys) of the area surrounding the fire were performed during the fire. Additionally, surveys of the containers were made at the following times:

- After the fire, prior to loading the damaged containers for removal from the accident scene.

- During repackaging. 
- Prior to transport of the damaged containers to the GE plant in Wilmington, North Carolina.

- Upon receipt of the damaged containers at the GE plant in Wilmington, North Carolina.

- During opening of the damaged containers and removal of the fuel rods from the fuel assemblies.

None of these surveys indicated any escape of radioactive materials from the containers or from the fuel assemblies. Consequently, the cleanup following the accident did not involve any removal of contaminated materials. 


\section{Description of the Containers}

The containers involved in this accident are identified as Model Nos. RA-2 or RA-3 inner and outer containers. The containers are authorized for shipment by Certificate of Compliance No. 4986. These containers are Fissile Class I, Type A containers. The Fissile Class I designation applies when the container contains fissile material, and it has been shown that any number of undamaged containers and 250 damaged containers would be subcritical in any arrangement and with optimum interspersed moderation. Type A applies when the contents may be released under accident conditions. The significant weights and dimensions of the inner and outer containers and contents are presented in Tables 3.1 and 3.2

Table 3.1 Container Weights

\begin{tabular}{lc}
\hline Component & Weight, lb \\
\hline RA-3 Inner Container & 610 \\
RA-3 Outer Container & 885 \\
Fuel Assembly & 610 \\
Complete Container & 2,715 \\
\hline
\end{tabular}

Table 3.2 Container Dimensions

\begin{tabular}{|c|c|}
\hline Component & Dimensions, in. \\
\hline 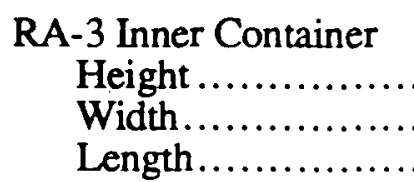 & $\begin{array}{l}\ldots \ldots \ldots 11.5 \\
\ldots \ldots \ldots 18.125 \\
\ldots \ldots \ldots 179.5\end{array}$ \\
\hline $\begin{array}{r}\text { RA-3 Outer Container } \\
\text { Height ................ } \\
\text { Width................ } \\
\text { Length................ }\end{array}$ & $\begin{array}{l}\ldots \ldots \ldots .31 \\
\ldots \ldots \ldots . .29 .875 \\
\ldots \ldots \ldots \ldots 207 \\
\ldots \ldots \ldots . .207\end{array}$ \\
\hline
\end{tabular}

\subsection{Container}

The RA-series container consists of a right rectangular metal inner container cushioned in a wooden outer container. An exploded representation of the wooden outer RA-3 container is shown in Figure 3.1. The exterior sides, ends and top of the wooden outer containers are constructed of one half in. thick CDX plywood with 2 in. $x 4$ in. cleats framing each panel. The bottom is constructed of 2 in. $x 8$ in. and 2 in. $x 10$ in. planks fastened to 4 in. $\times 4$ in. skids that are crosswise to the planks. In addition, four 4 in. $\times 4$ in. skids are fastened to the sides of the bottom in a lengthwise orientation to provide stability for the container. The container is painted a royal blue color with white stenciled lettering which identifies the container and provides pertinent dimensions, weights, and instructions. Radioactive material labels are attached to the ends of the containers prior to placing the containers on a truck for shipment. 


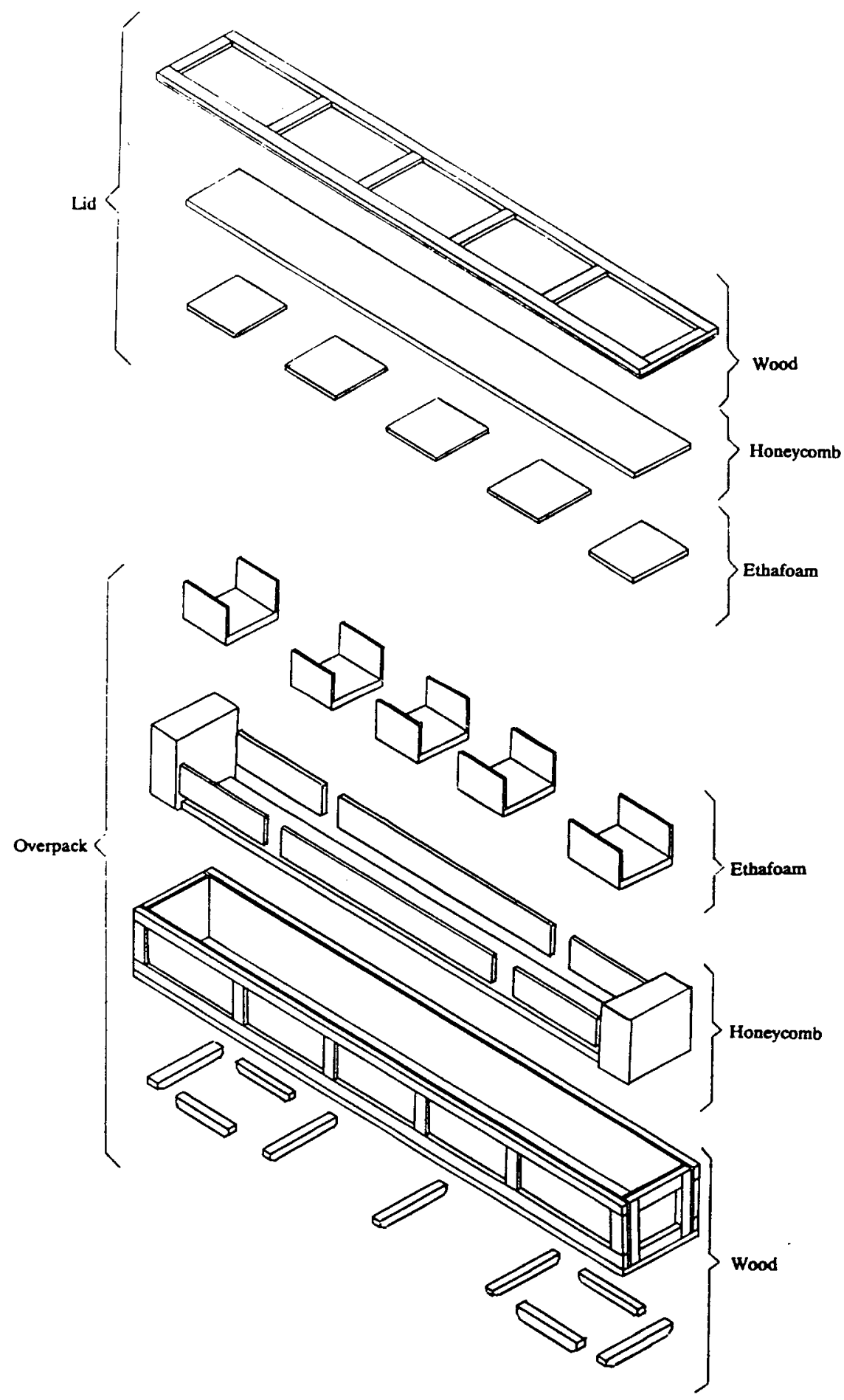

Figure 3.1 Exploded View of Wooden Outer RA-3 Container 
A 3-in.-thick layer of plastic-coated, paper honeycomb cushioning material surrounds the inner metal container on the sides, on the top, and on the bottom. The ends contain additional honeycomb material bringing the total thickness to 9 in. The honeycomb material has a crush strength of 110 to $300 \mathrm{psi}$. In addition, the sides, the top, and the bottom are protected by pads of Ethafoam. The Ethafoam pads on the top and bottom are 3-in.-thick while the Ethafoam pads on the sides are 0.5 -in.-thick.

Lifting of the combined inner and outer RA containers is normally accomplished with a fork lift where the forks slide between the 4 in. $x 4$ in. cleats on the bottom of the container. However, optional chain lifting is permitted with the chains lifting the container from outside the 4 in. $x 4$ in. cleats. The location of the chain lifting points is clearly marked on the outside of the container.

The inner metal container has two internal perforated channel sections which may contain one fuel assembly each, or groups of up to fifty unassembled fuel rods each as shown in Figure 3.2. The inner channels are surrounded by an outer channel which is the principal structural component and also provides the surface to support the gasket that seals the gap between the cover and body of the container. The cover of the container is a hollow rectangle formed from carbon steel comparable to the outer surface of the body of the container with the bottom of the cover fabricated from perforated steel.

The ends of the body are protected by pieces of angle that are welded to the ends of the body. The entire body employs welded construction with the exception of the inner channels which may be welded or riveted to the body. The exterior of the body and cover are painted a bright yellow which is refurbished, as necessary, after each use of the container.

The inner channels and bottom of the cover are covered with Ethafoam that is 0.75 in. thick and perforated to match the perforations in the steel channels. Additional pads of Ethafoam are placed in the channels to support the fuel assemblies at the spacers. Also, plastic strips are placed between the fuel rods of the fuel assemblies to reduce the consequences of fuel rod vibration during transport.

A sketch of the cross-section of the inner and outer containers and the fuel assemblies is presented in Figure 3.3 to indicate the trapped air within the inner container and the positioning of the inner container relative to the crushable material in the wooden outer containers.

\subsection{Contents}

Each container provides protection during transport for two GE BWR fuel assemblies containing uranium dioxide $\left(\mathrm{UO}_{2}\right)$. The upper end of a typical GE BWR fuel assembly is shown in Figure 3.4. The fuel assemblies are shipped without channels. Fuel assembly identification numbers are stamped on the top of the handle for positive identification of each individual fuel assembly. These identification numbers are also indicated on the exterior of the wooden outer containers.

The radioactive material is low enriched uranium (less than $5 \%$ of the isotope uranium-235 in the isotope uranium-238). The fuel is in the form of uranium oxide sintered into cylindrical fuel pellets. Some of the fuel pellets may have small concentrations of gadolinium oxide $\left(\mathrm{Gd}_{2} \mathrm{O}_{3}\right)$ mixed with the uranium oxide.

The fuel assemblies in the shipment that was involved in the accident were $8 \times 8 \mathrm{BWR}$ fuel assemblies. The uranium oxide fuel had an average enrichment of $3.11 \% 235 \mathrm{U}$ in $238 \mathrm{U}$. Several of the fuel rods had gadolinia mixed with the uranium dioxide. ${ }^{155} \mathrm{Gd}$ and ${ }^{157} \mathrm{Gd}$ have very large cross section for absorption of thermal neutrons which aids in maintaining subcriticality of the fuel assemblies during transport. 


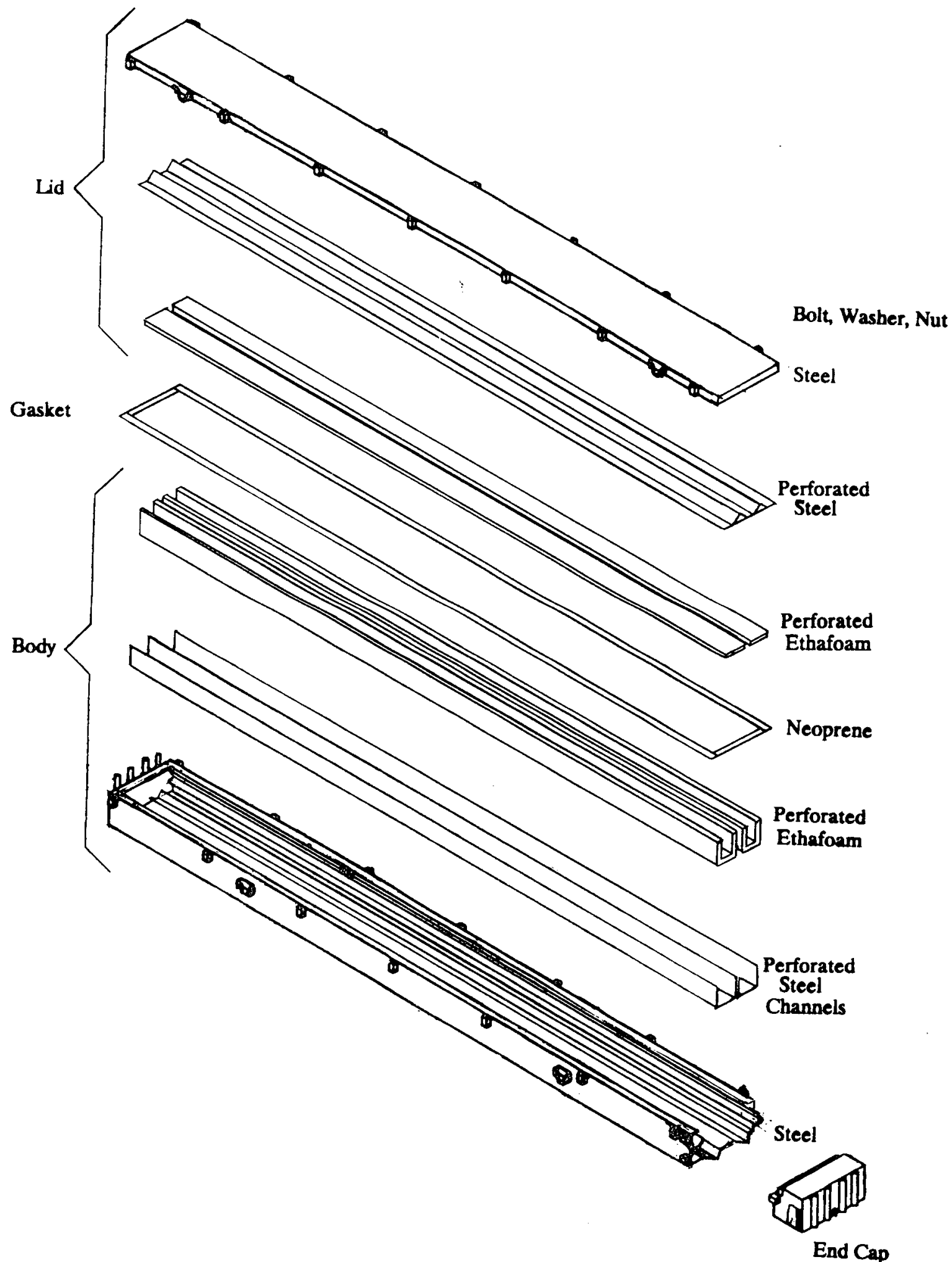

Figure 3.2 Exploded View of Inner RA-3 Container 


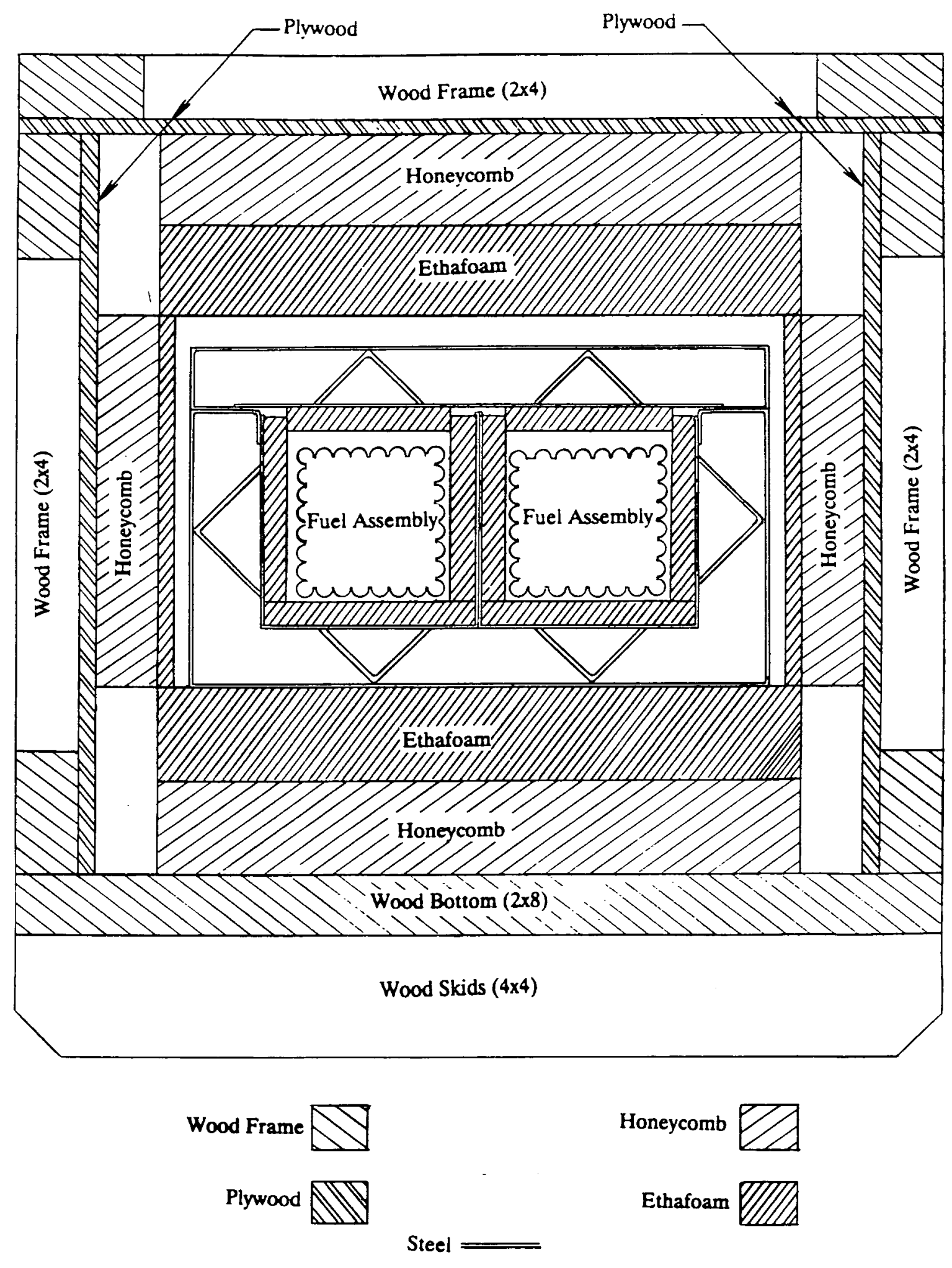

Figure 3.3 Cross Section View of Entire Container 


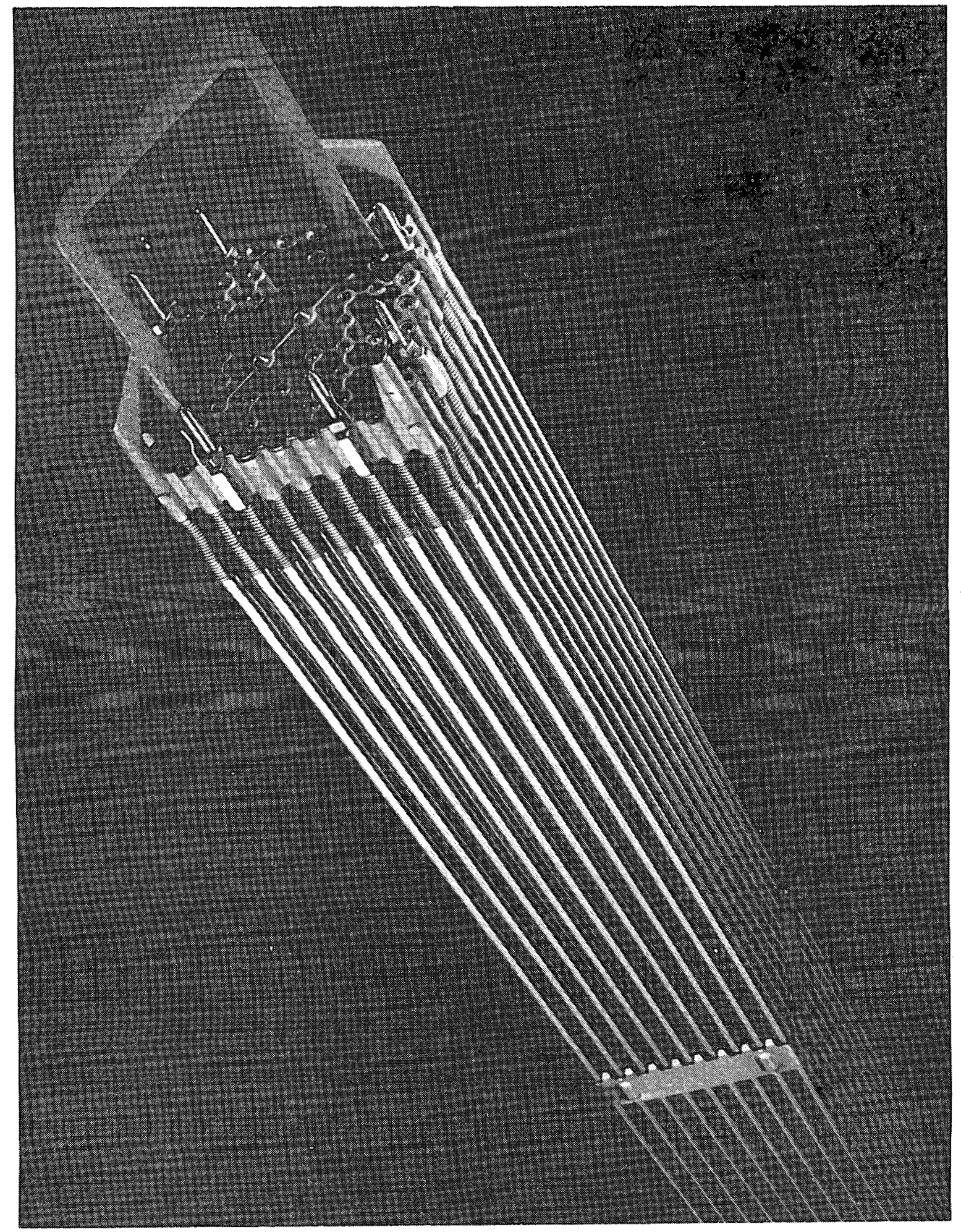

Figure 3.4 Photograph of Upper End of a BWR-6 Fuel Assembly 


\subsection{Tie-Down Arrangement}

Loading these containers onto trailers follows standard commercial practices and is accomplished with either a fork lift or hoist with a sling. The lifting points are clearly indicated on the wooden outer containers. The containers involved in this accident were initially loaded such that the twelve containers were centered longitudinally on the trailer in stacks two containers tall (as shown in Figure 3.5). No gaps were between the containers in this loading configuration.

After loading, GE procedures require that the containers be covered with a tarpaulin for weather protection. If more than one tarpaulin is used, the rear one is put in place first so that the front tarpaulin overlaps to provide coverage of the joint. Typically, the tarpaulin is held in place by bungee cords; however, if the truck driver considers it necessary, boards can be nailed through the tarpaulin and into the bottom of the lower containers to prevent displacement of the tarpaulins during transit. The tarpaulins are $20 \mathrm{ft} \times 30 \mathrm{ft}$ and constructed of rubber coated heavy duty canvas.

The tarpaulin is wrapped around the containers much like gift wrapping. Figure 3.6 shows the tarpaulin applied to one end of the containers for the load involved in this accident. Two tarpaulins were required to cover the load. For this load, wooden 2 in. $x 4$ in. were nailed to the bed of the truck to prevent wind from displacing the tarpaulin. The 2 in. $x 4$ in. were applied at the front, the sides, and the rear of the load. Additionally, a seventh tie-down strap was attached to this load at the rear of the front tarpaulin (over the rear set of containers) to prevent it from flapping in the wind.

Tie-down is accomplished by at least six nylon straps typically of 4 in. to 6 in. width, with a recorded minimum breaking strength of 13,000 lb. The straps are placed (as shown in Figure 3.5) about 36 in. from the end of each stack of containers and at the center of each stack of containers. Tension is applied by lever-actuated ratchets at the side of the trailer as shown in Figure 3.7 (Figure 3.7 shows an undamaged ratchet and nylon strap). The truck driver is responsible for tensioning the nylon straps to his satisfaction and assuring that tension is retained throughout the trip. Positioning of the nylon straps is somewhat imprecise because the containers are concealed by the tarpaulins. Tensioning of the nylon straps helps to hold the ratchets in place and the top brackets of the ratchets are frequently bent during normal usage. 


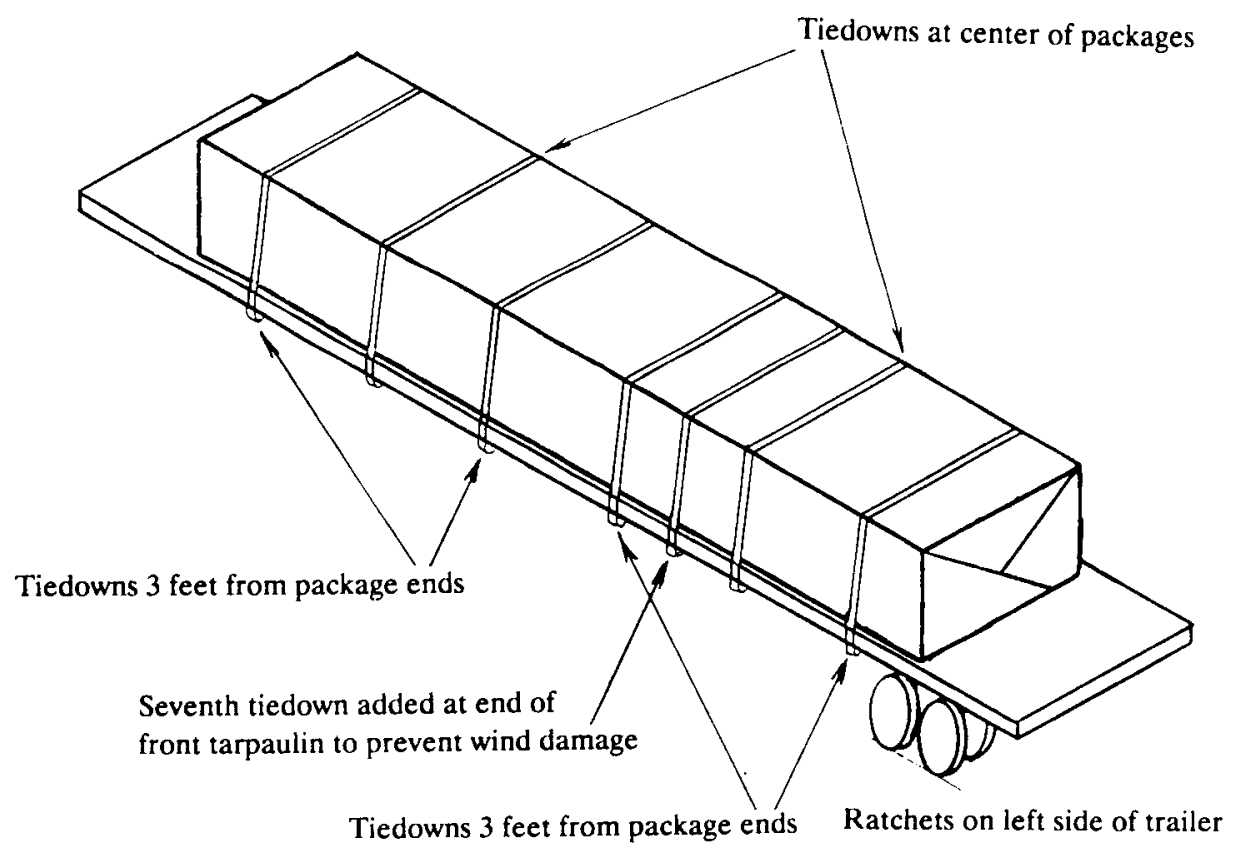

Figure 3.5 Tie-down Locations for Transport of RA-3 Containers 


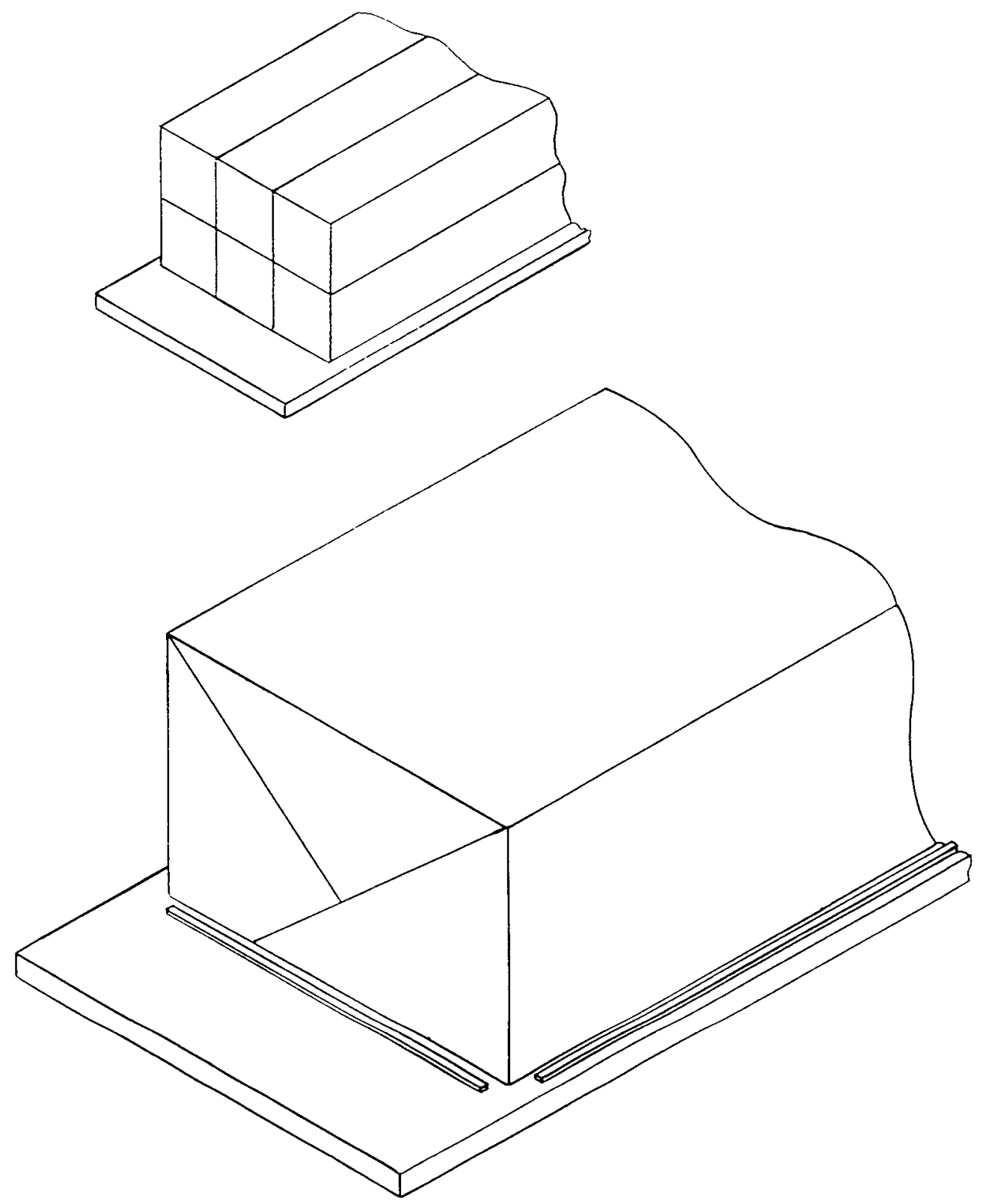

Figure 3.6 Tarpaulin Configuration 


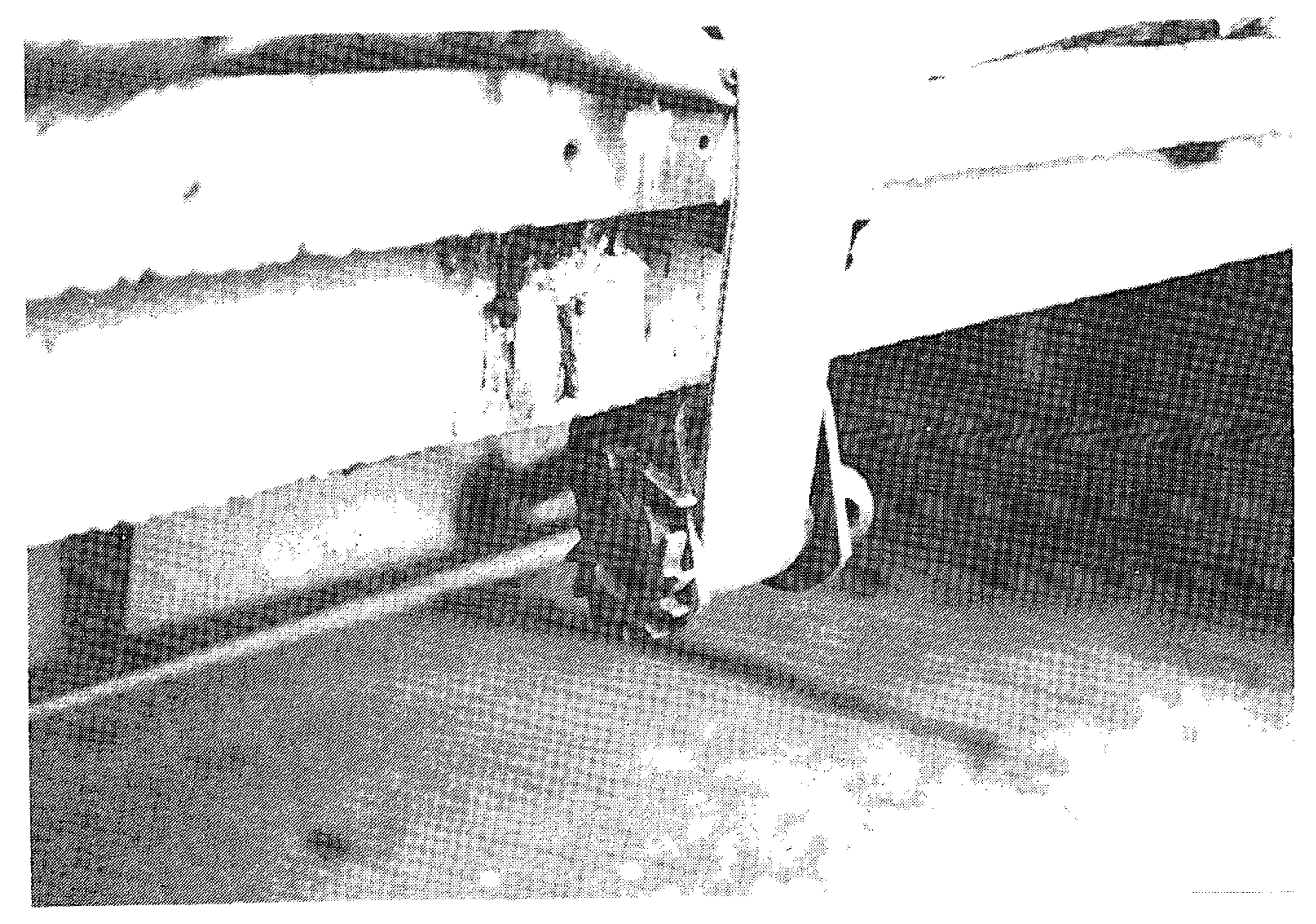

Figure 3.7 Undamaged Tie-Down and Ratchet 


\section{Damage Sustained by Containers}

\subsection{Container Locations}

The only witnesses to the impact portion of the accident were the drivers of the truck. Other witnesses are incapable of identifying the location of the containers because they were not in a position to observe all of the containers. The driver of the truck is positive that all of the containers were on the trailer and that the tarpaulin and tie-downs were intact and in place when he left the truck. In addition, photographs and videos taken by cameramen representing WGGB-TV and the Springfield Union-News show that all of the containers that were on the rear of the trailer were still there even when the fire became well developed. Several of the photographs and the videos show containers from the upper tier about to fall and containers that are in the process of falling. Consequently, it must be concluded that all of the containers remained on the trailer during the impact portion of the accident and that the containers fell off the trailer only during the fire portion of the accident. Further, the photographs and videos clearly show that the wooden outer containers were at least partially intact when the containers fell off the trailer and that the wood continued to burn after the containers were on the roadway.

The most likely description of the container motions during the accident is as follows:

(1) During the initial impact with the automobile and all subsequent impacts on the guardrail and outer concrete barrier, all containers remained on the trailer.

(2) All of the nylon straps and the tarpaulins melted or were disabled early in the fire so that the containers were unrestrained during the majority of the fire.

(3) The fire progressed from the front of the trailer to the rear causing damage to the front of each wooden outer containers before there was substantial damage to the rear of the container. This resulted in containers falling and rotating at one end while the other end was raised upward. Eventually the containers fell and rotated to the point where their center-of-gravity was outside the supporting container or the truck bed and the individual containers fell to the roadway.

(4) As the tires, the air bag suspension, and several bearings and other load-bearing components in the wheel assemblies and suspension burned or melted, the trailer tilted from side-to-side and front-to-back several times. This may have aided the movement of the containers as they were falling from the trailer or may have occurred after the containers had fallen from the trailer.

The containers on the trailer have been given identification numbers for reference purposes that correspond to the container locations at the time of shipment. These identification numbers are indicated in Figure 4.1. The most reasonable interpretation of the information that is available in the videos of the fire and post fire cleanup permits the second portion of Figure 4.1 where the final locations of the containers are shown schematically and the identification numbers are also indicated to characterize the movement of the containers as they fell off the trailer. Figure 4.2 is part of the record of removal of the damaged containers following the fire. This figure also gives an indication of the location of the containers at the conclusion of the fire; however, the perspective in this photo hampers precise identification of the container locations. 


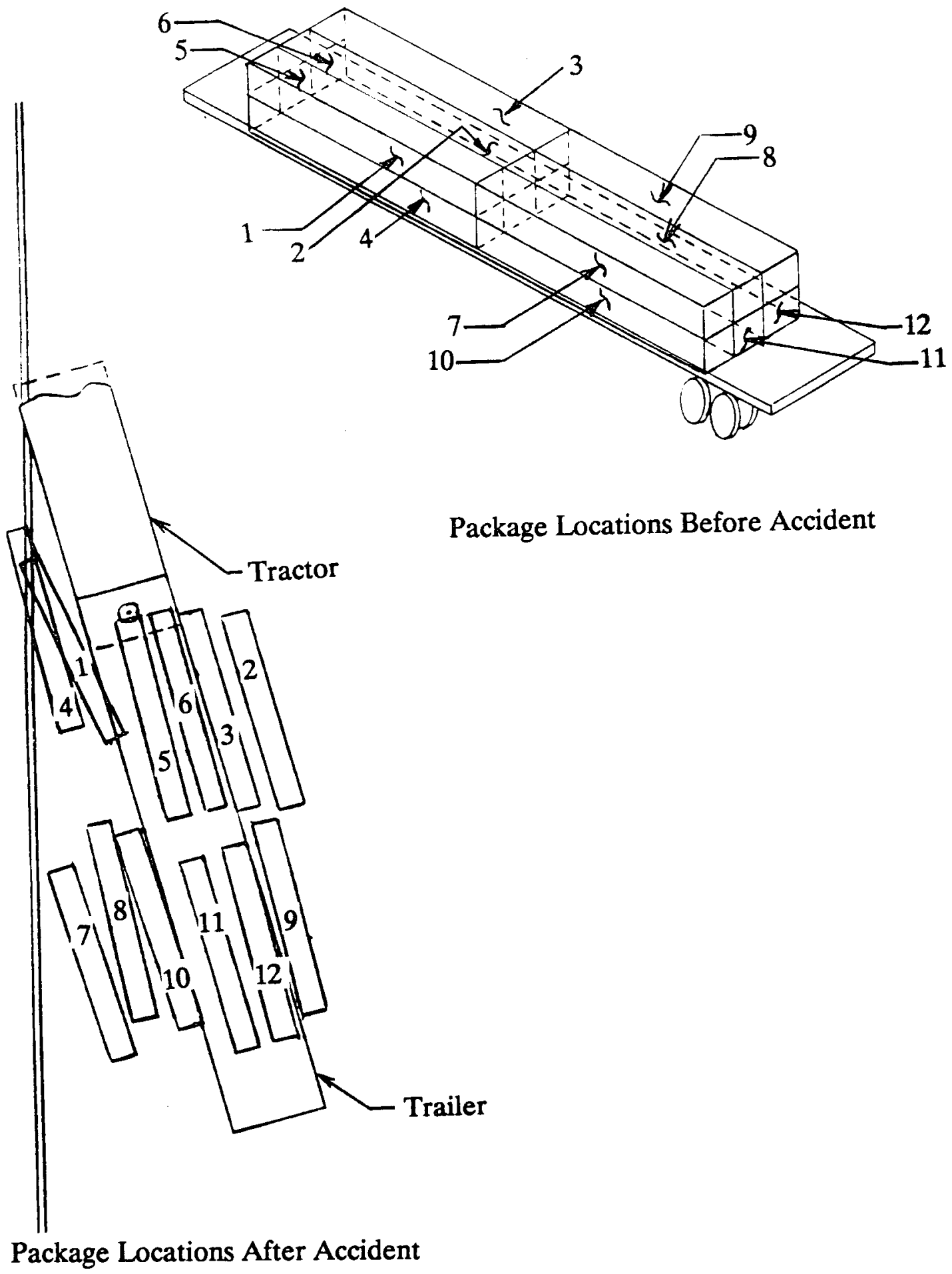

Figure 4.1 Probable Container Locations During Fire 


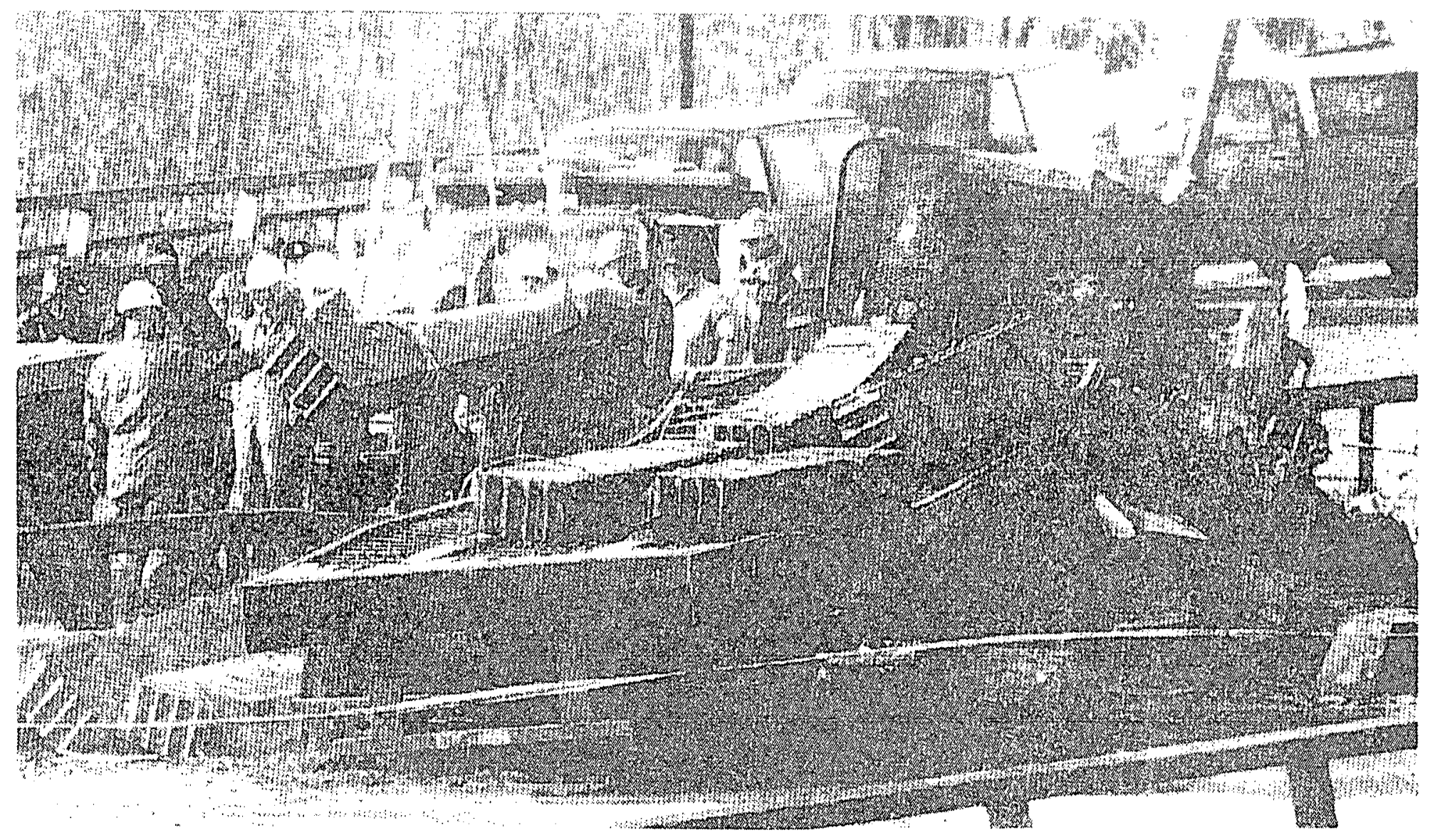

Figure 4.2 Photograph of Removal of Damaged Containers 
A summary of the final container locations is as follows:

- Four containers remained on trailer (but not in their original locations).

- Five containers were on the roadway between the trailer and the guardrail.

- Three containers were on the roadway beside the trailer on the side away from the guardrail.

Two summary statements are possible as a result of viewing the videos of the accident scene during and after the fire portion of the accident.

- All containers, except one, that fell from the trailer appear to have impacted on their lid.

- The final position of all containers appears to be closer to the front of the trailer than the initial position of the container when prepared for shipment.

Figure 4.1 characterizes the movement of the containers during the fire. The upper portion of this figure provides an identification number for each container in its original location on the trailer prior to the accident. The lower portion of this figure presents the location of each container at the conclusion of the fire. The coupling of the final locations to the initial locations represents the most reasonable interpretation of the information that is available in the videos taken during the fire and the videos taken during the removal of the containers after the conclusion of the fire. The location of several of the containers is certain because the falling of the containers from the trailer has been recorded on the videos. The remainder have been identified by a process of elimination and deductive reasoning and, as such, are subject to argument.

All of the containers suffered fire damage in the form of complete combustion of the wood outer containers and complete loss of the gaskets between the lid and body of the container.

\subsection{Impact Damage}

Following the impact with the automobile, the truck impacted on the center guardrail and the outer concrete barrier before coming to rest against the center guardrail. Each of these impacts changed the direction of motion of the tractor and trailer. The following sections assess the damage to the tractor, trailer, containers and fuel assemblies during the impacts of the truck. Additionally, the containers were subjected to impact loads that resulted when the containers fell from the trailer during the fire.

\subsubsection{Damage to Tractor and Trailer}

The tractor received extensive impact damage during the impact portion of this accident. The damage to the tractor can be summarized as follows:

Impact with automobile:

- Right side fuel tank probably ruptured.

- Right side auxiliary storage box was probably damaged. 
First impact with center barrier:

- Left front wheel was damaged.

- Attachments for front axle on left side was probably damaged.

- Compressed air tanks or lines were probably ruptured.

- Steering was partially disabled.

Impact on outside concrete barrier:

- Hood over the engine came off and fell to the garage below the roadway.

- Right front fender came off and fell to the garage below the roadway.

- Front axle including both wheels was separated from the tractor.

- Steering was totally disabled.

- One or more fluids (engine oil, power steering fluid, etc.) from the engine were leaking.

Second impact on center barrier:

- Driver's door was jammed.

By the end of the impact portion of the accident the tractor had received extensive damage but was essentially intact.

During the impact portion of this accident, the trailer appeared to suffer no damage and the containers (including tarpaulin and tie-downs) were in place on the trailer.

\subsubsection{Damage to Container}

Eight containers appeared to suffer impact damage in varying degrees. The impact damage resulted from the containers falling off the trailer while the trailer was on fire. Most of the impact damage appeared to have occurred after the containers had experienced high temperatures during the fire. The most severely damaged container appeared to be squeezed and twisted at a point about one quarter of its length. Beyond this point, the lid appeared to be buckled and a gap was opened between the lid and the lower portion of the container. The opening was about 2-in. wide and extended over a length of $6 \mathrm{ft}$. The fuel rods of one fuel assembly were plainly visible through the opening.

All of the eight containers that were on the roadway at the conclusion of the fire experienced a fall from the trailer to the roadway. The containers either (a) experienced a classical side impact where the longitudinal axis of the container was parallel to the trailer bed and parallel to the roadway or (b) the container came partially off the trailer before falling and impacted on an end followed by a slap-down type of impact.

\subsubsection{Damage to Fuel Assemblies}

There appeared to be very little impact damage to the fuel assemblies. No indication of buckling of the fuel rods or crushing of the spacers was apparent. All of the mechanical damage appears to have resulted from the fuel assemblies deforming to accommodate the shape of the inner containers. 


\subsection{Thermal Damage}

When the tractor impacted on the outer concrete barrier some fluids spilled onto the parking garage below the roadway. These fluids were on fire so there was fire in the engine compartment at the time of this impact. The fire spread to engulf the entire tractor and then spread to engulf the trailer. Some of the diesel fuel that was spilled onto the roadway also ignited and burned. The fire lasted until almost three hours after the initial impact and caused substantial damage to the tractor, trailer, containers and fuel assemblies.

\subsubsection{Damage to Tractor and Trailer}

The fire started in the engine compartment of tractor, spread to engulf the entire tractor, and then spread to the trailer. The significant damage to the tractor and trailer can be summarized as follows:

- The air bags in the tractor and trailer suspension were completely consumed.

- The frame of the trailer was heated to the point where it could no longer support its weight and the weight of the containers remaining on the trailer (see Figure 4.3).

- The tarpaulin was completely consumed.

- The nylon tie-down straps were completely consumed (see Figure 4.6 for ratchet that remained on trailer).

- The wooden bed of the trailer was consumed with the exception of about $2 \mathrm{ft}$ at the rear of the trailer (see Figure 4.4).

- The aluminum alloy hubs at the center of the wheels were melted and possibly partially combusted (see Figure 4.5 and 4.9 ).

- All tires were completely consumed with only the steel wires that are embedded in the rubber remaining (see Figure 4.5 and 4.9).

- The springs on the tractor were distorted upward near their center.

- The frame of the tractor was distorted over the rear wheels and beneath the trailer attachment (see Figure 4.8).

As a result of the fire, all of the non-metal components of the tractor and trailer were consumed and the tractor was reduced to a pile of rubble with only major drive train elements identifiable (see Figure 4.8). The trailer retained its shape and was easily recognizable as a trailer but all wood and rubber components were consumed by the fire. At the center of the trailer, the warning signs indicating wide right turns and the plastic reflectors were intact and the lettering was almost intact (see Figure 4.7).

\subsubsection{Damage to Container}

The thermal damage to the containers can be summarized as follows:

- The wooden outer containers on all containers was completely consumed during the fire. (Only the metal straps remained.) 

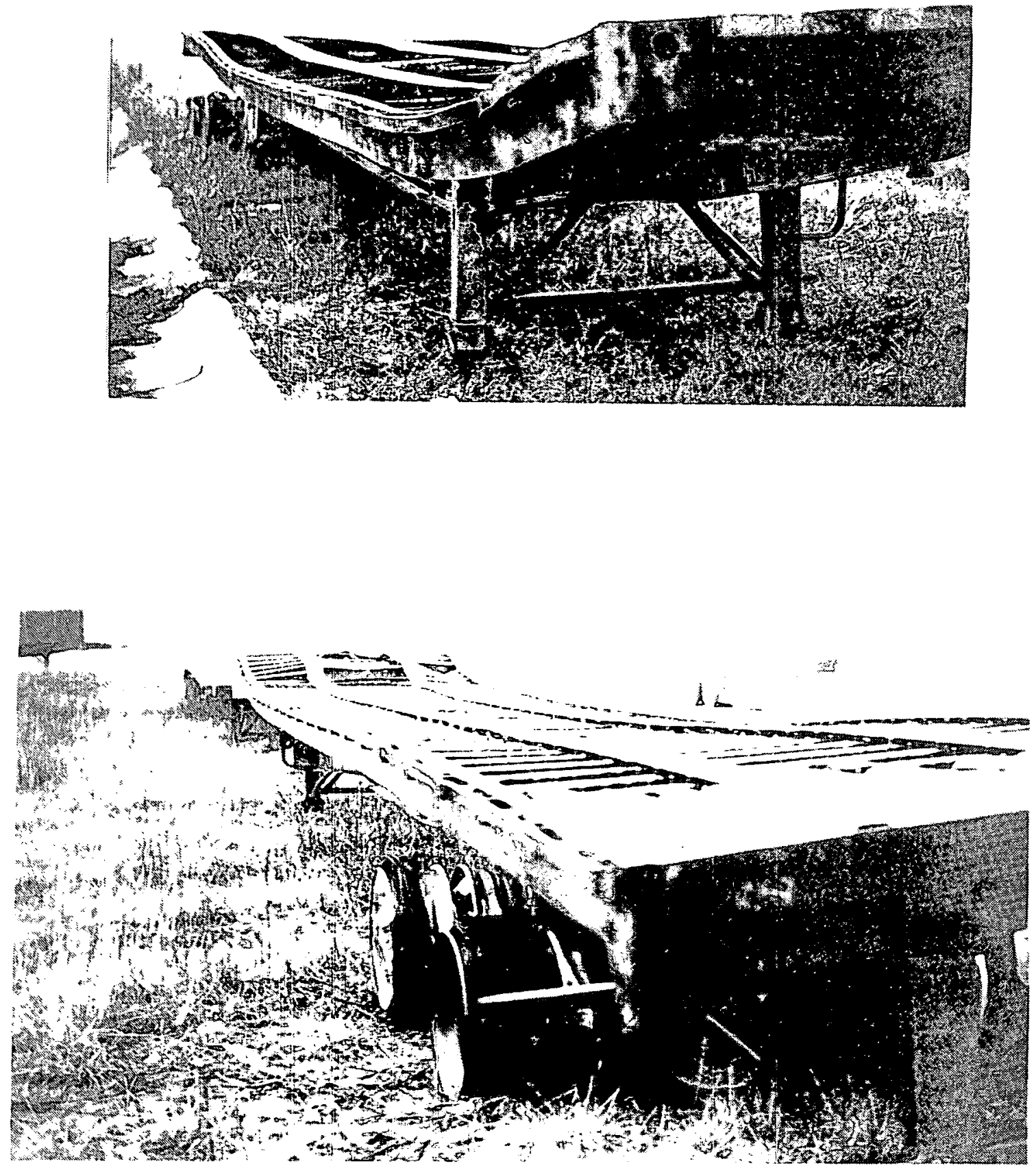

Figure 4.3 Photographs of Damaged Trailer 

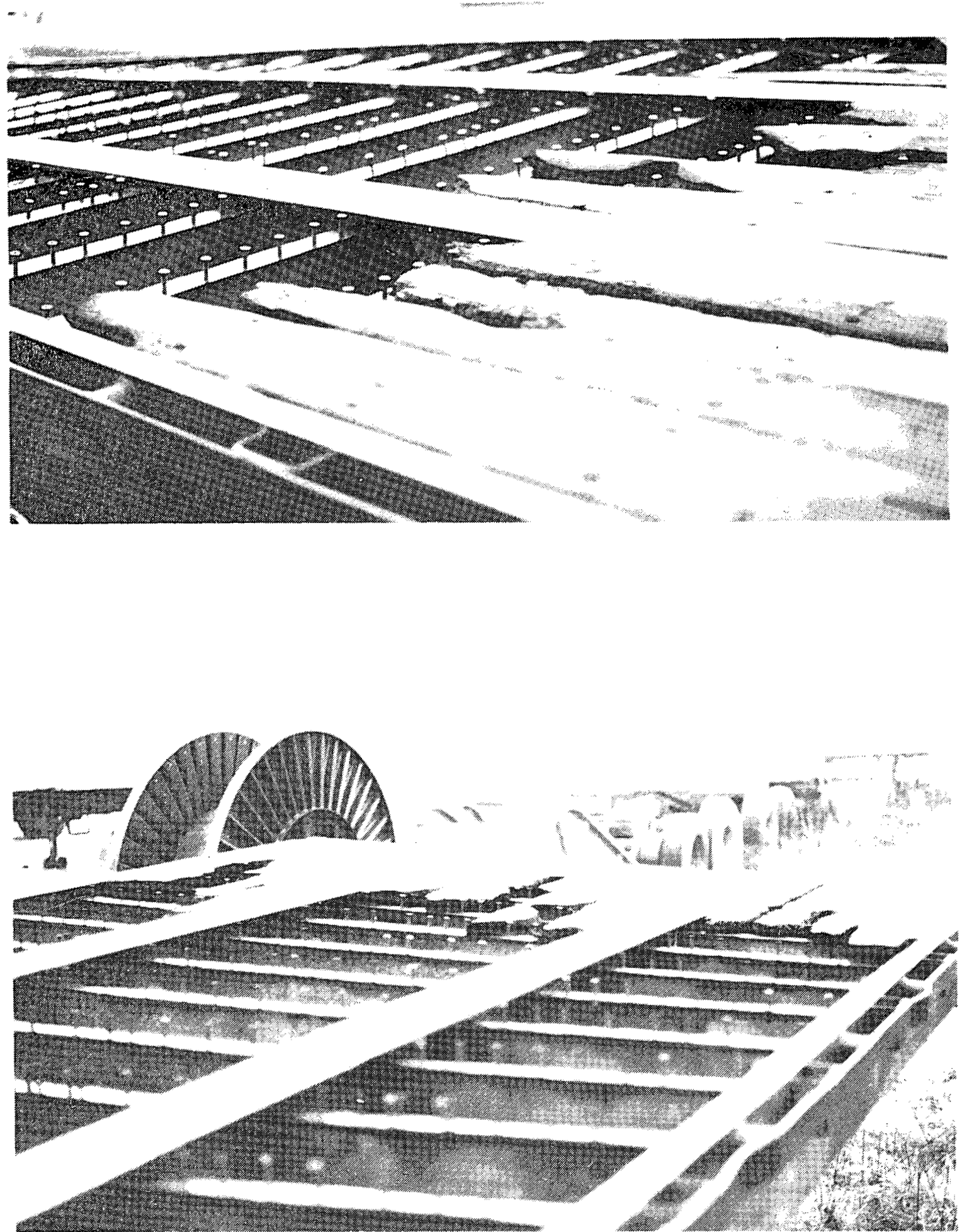

Figure 4.4 Photographs of Damaged Trailer Bed 


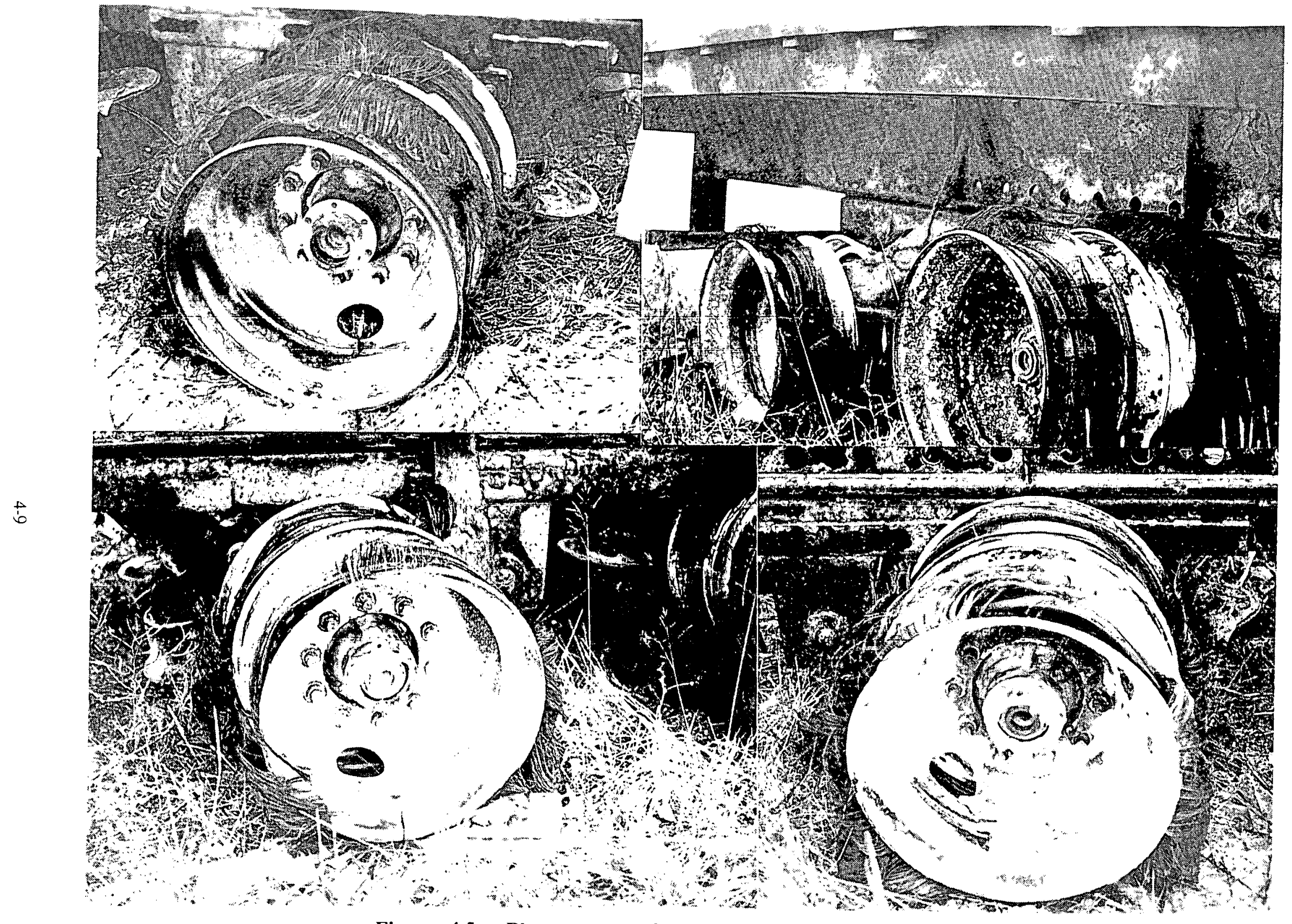

Figure 4.5 Photographs of Damaged Trailer Wheels 

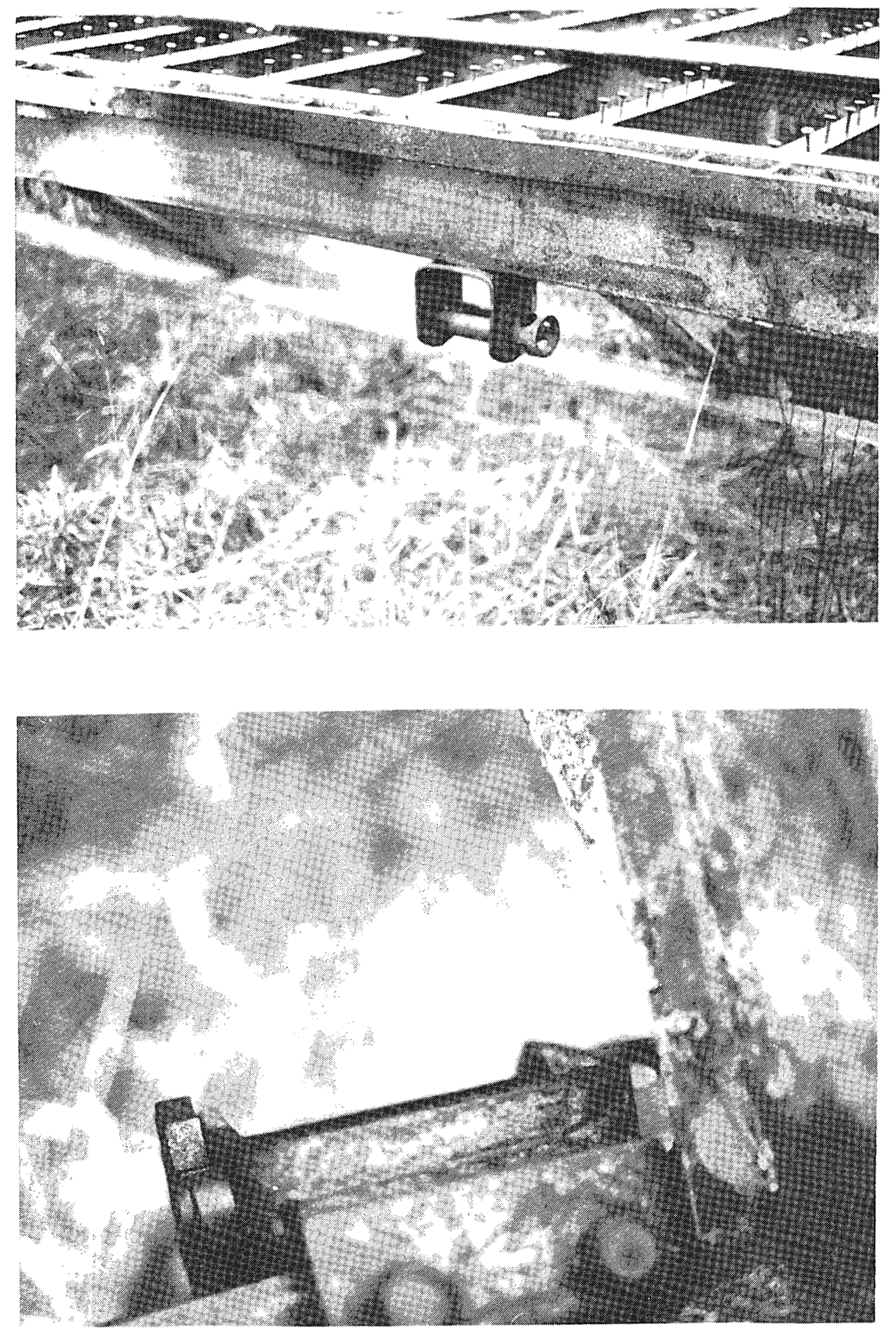

Figure 4.6 Photographs of Damaged Tie-down Ratchet 


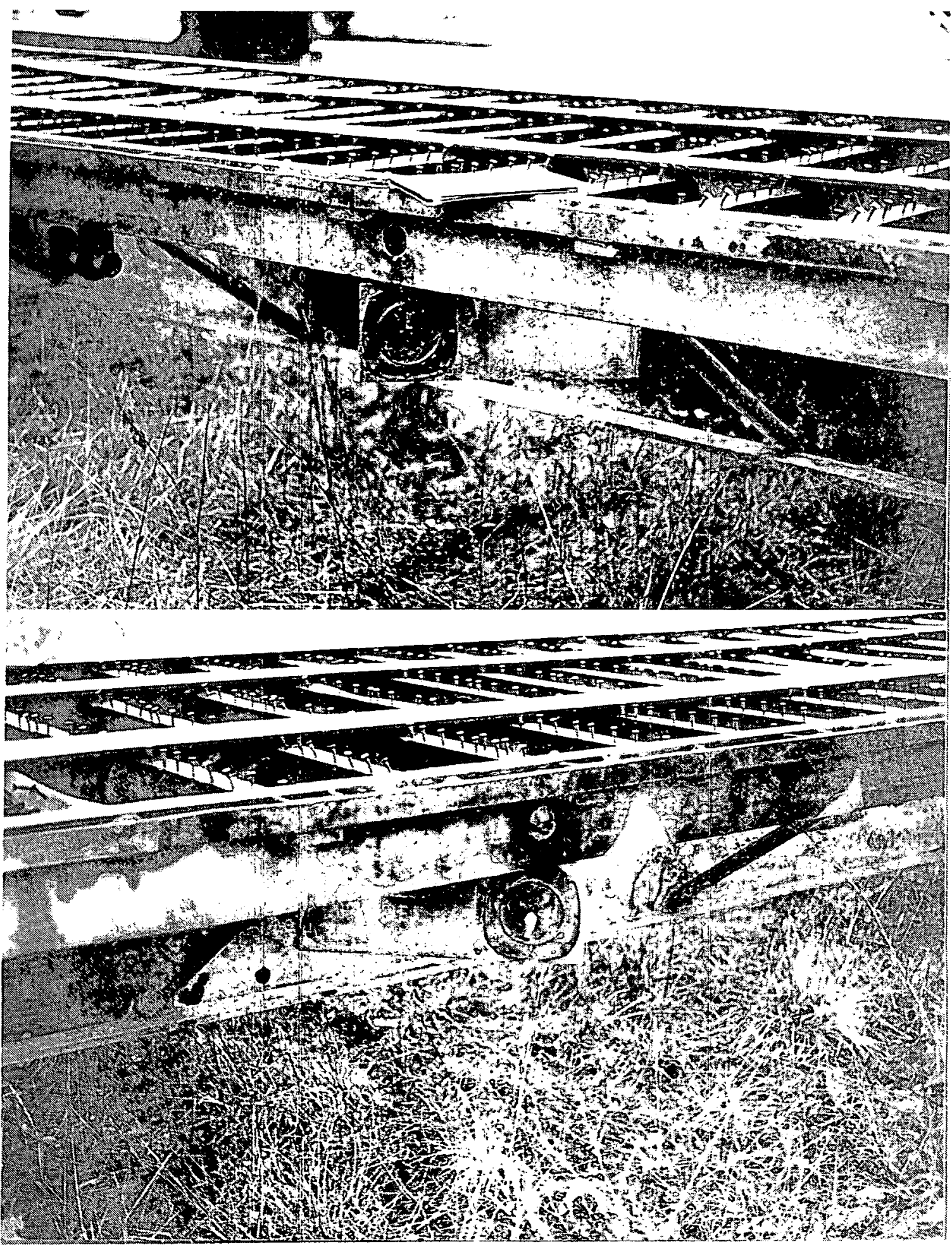

Figure 4.7 Photographs of Turn Warning Signs on Trailer 

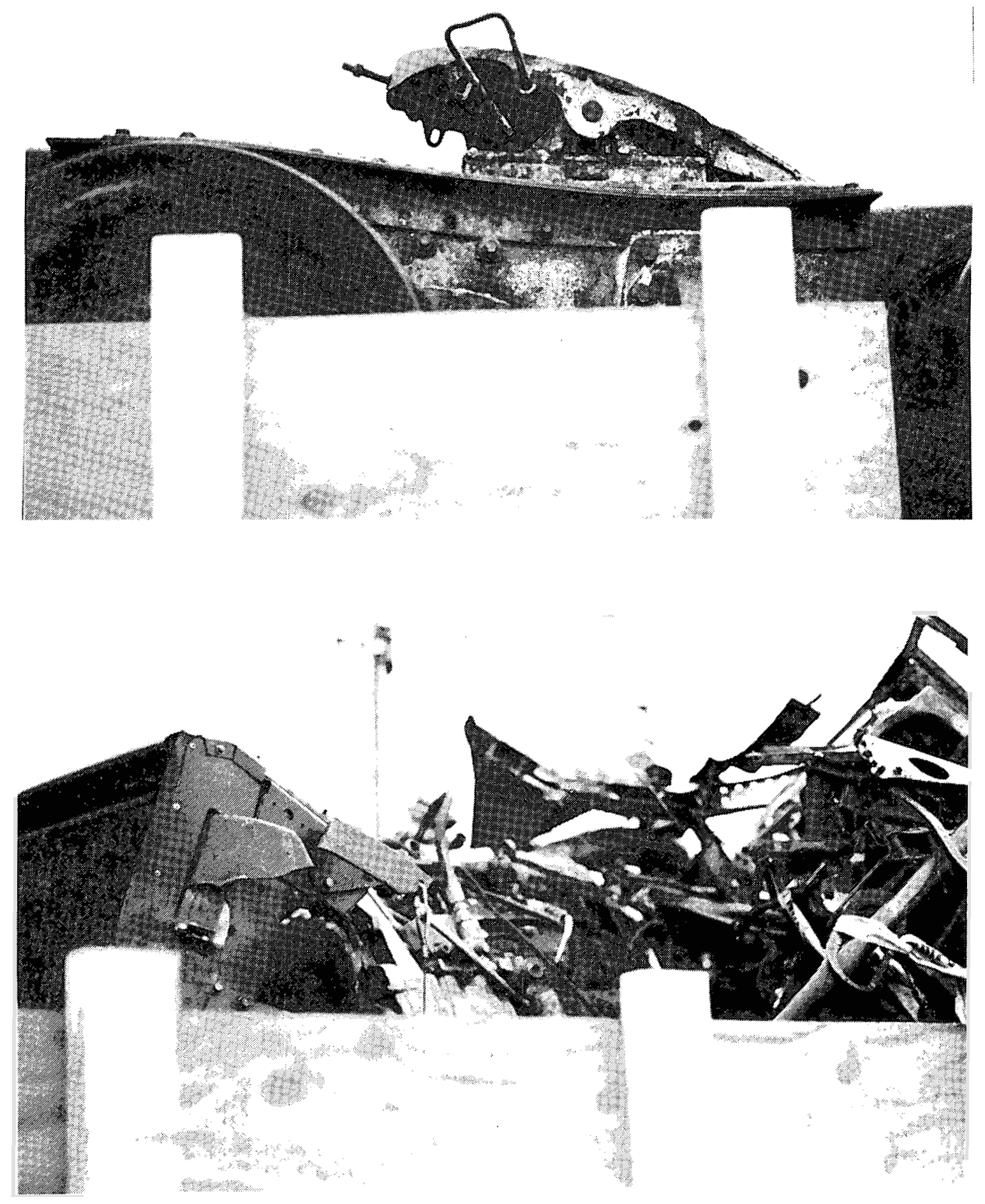

Figure 4.8 Photographs of Damaged Tractor Frame and Trailer Attachment 

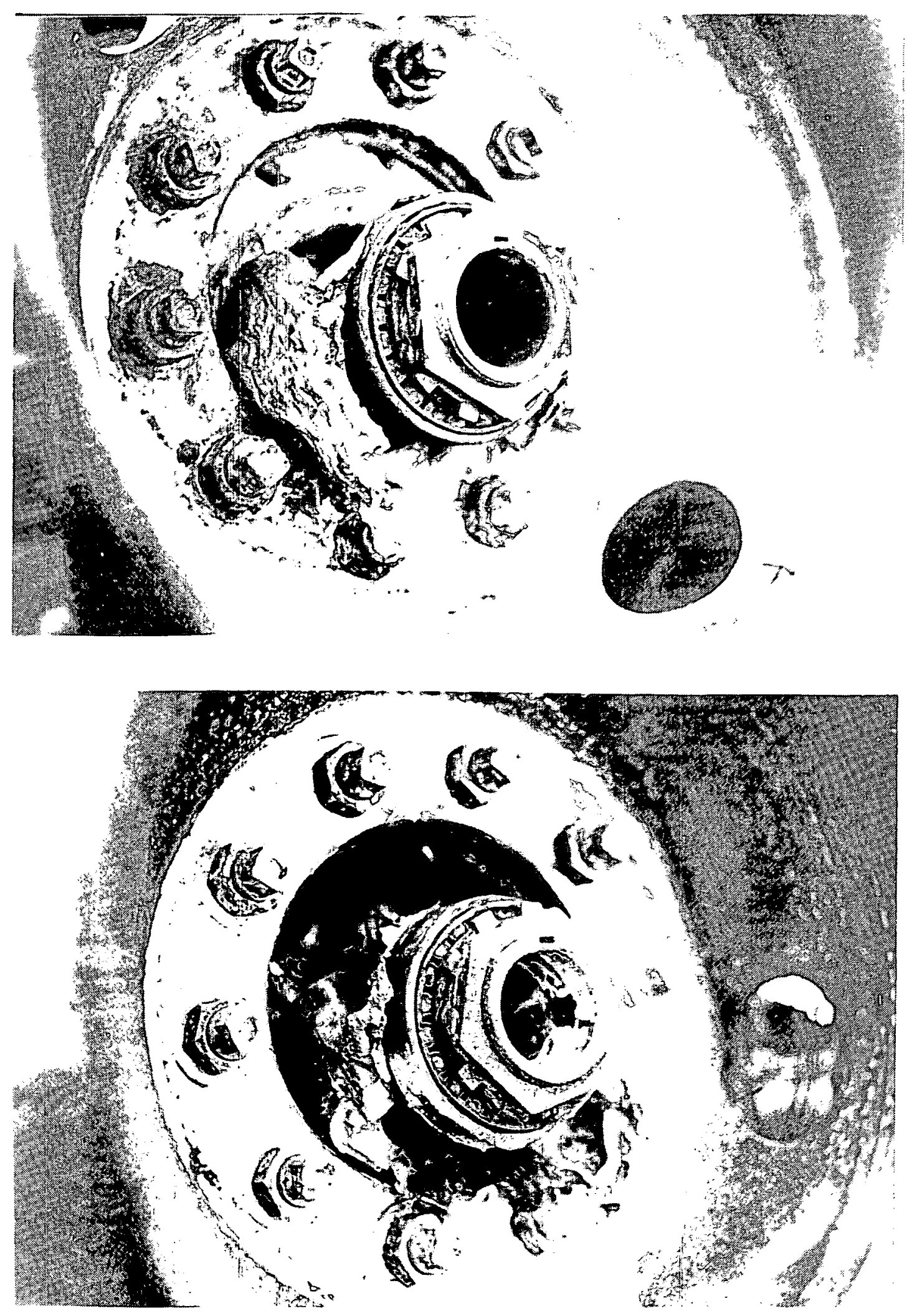

Figure 4.9 Photographs of Damaged Tractor Wheels 
- The gasket that seals the top to the bottom of the container was consumed during the fire.

- The breather plug was missing on most containers.

- The exterior yellow paint on the inner container was scorched on all containers and on many containers the primer paint was visible or scorched.

- The bolts securing the lid to the bottom of the container were bent on all containers.

- The bolts securing the lid to the bottom of the container were very ductile when the containers were opened.

Photographs of damaged inner containers are presented in Figures 4.10 and 4.11. The distortion of the lid on all containers cannot be classified as resulting from impact or thermal damage. The missing breather plugs and the gaps resulting from the loss of the gaskets is easily seen in these photographs.

\subsubsection{Damage to Fuel Assemblies}

The damage to the fuel assemblies can be classified as mechanical and thermal. Mechanically, the fuel assemblies appear to have deformed to accommodate the shape of the inner containers. The fuel assemblies appear to have contributed very little to the stiffness of the inner containers until the deformation of the inner container caused what can be termed large deformations in the fuel assembly. Removing those fuel rods that appeared to have been exposed to low to moderate temperatures from the fuel assemblies caused the fuel rods to return to essentially straight rods. When these fuel rods were in the spacers as part of the fuel assembly, the assembly was deformed by over an in. away from straight. However, those fuel rods that appeared to have been exposed to higher temperatures retained a large portion of the deformation that was present while the fuel rod was a part of the fuel assembly.

Four different states of thermal damage to the fuel rods were observed. These states are characterized as follows:

- The clad was blackened with localized deposits of tightly adhering residue from melting or burning of plastic inserts between fuel rods.

- The clad was blackened with ash like deposits loosely adhering over large portions of the surface of the cladding.

- The clad had developed a whitish color with a roughened surface.

- The clad expanded such that adjacent fuel rods were touching and the clad approached a square cross section with longitudinal cracks.

It was not uncommon to find two or three different states of damage on the same fuel rod. Where the clad had expanded, the expansion occurred over a 6 in. length in one case, and in another case, the expansion occurred over a length of about twenty in. The remainder of the fuel rods with the expansions appeared to fall into the second category of damage with a transition zone that could be characterized as the third type of damage. Typically, the fuel rods that ballooned were at the portion of the fuel assembly that was at the bottom of the inner container. Based upon the fact that most containers appear to have been inverted when they fell from the trailer, the ballooning appeared to have occurred in the fuel rods that were at the top of the fuel assembly. 


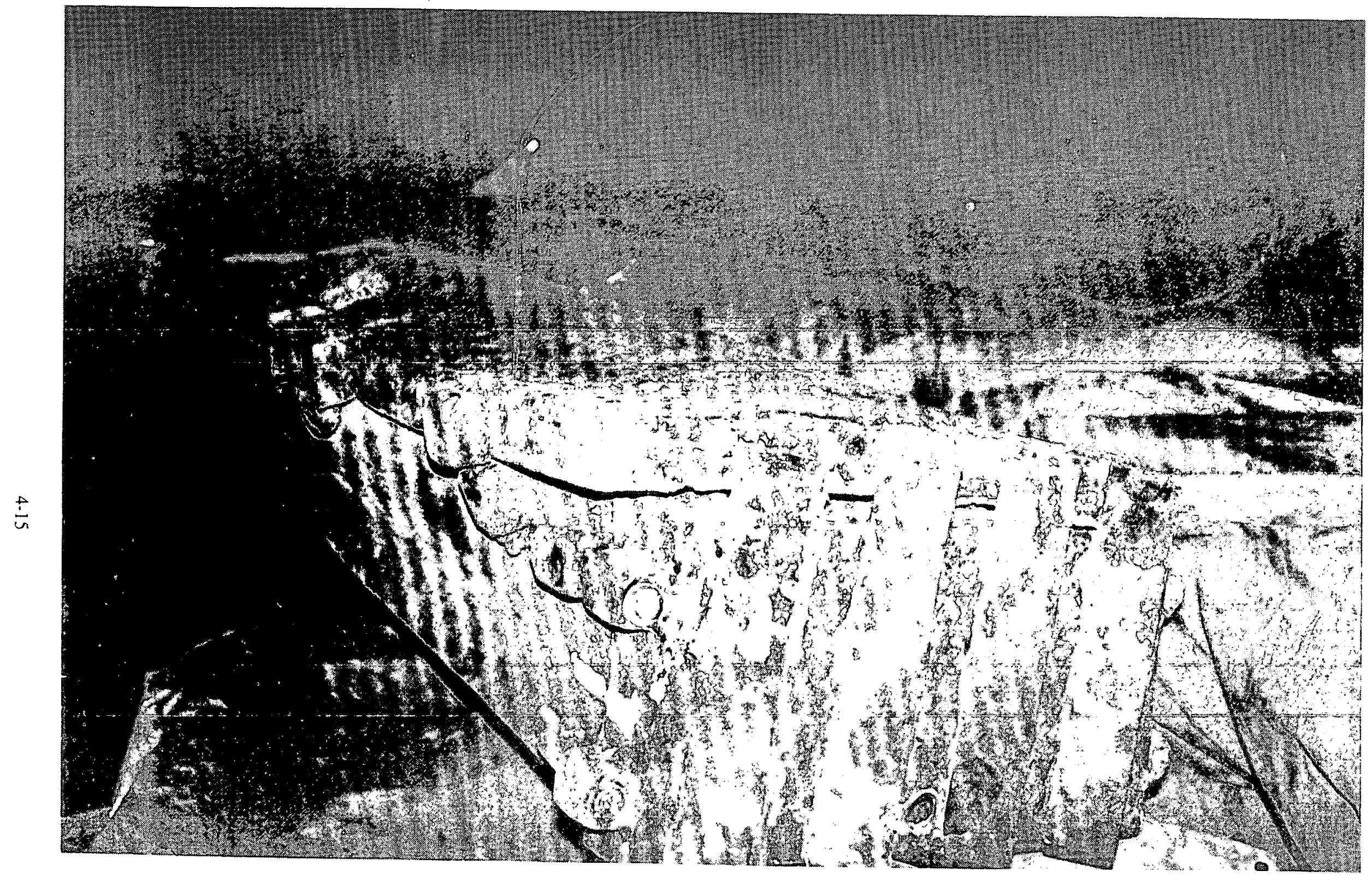

Figure 4.10 Photograph of Damaged Inner Container 


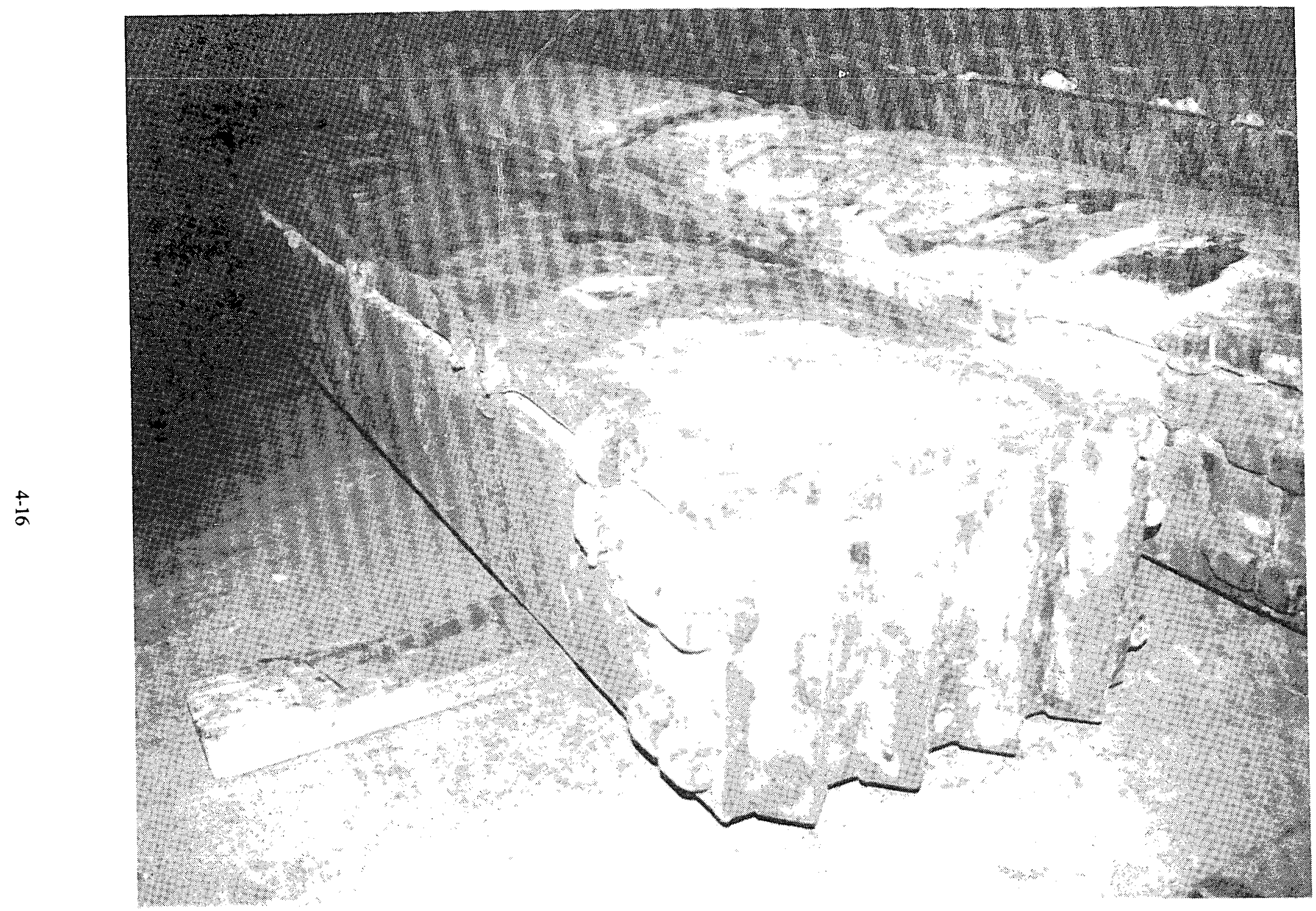

Figure 4.11 Photograph of Damaged Inner Container 


\section{Evaluation of Accident: Effect on Containers}

The damage to the containers can be roughly correlated with the location of the container during the accident. Consequently, the identification of the location of the containers that was discussed in Section 4.1 was very important to the analyses presented here. The containers have been grouped into three categories that represent the spectrum of damage to the containers. These categories are:

1. A single container which was severely deformed with the lid separated from the lower portion of the container resulting in a gap about $6 \mathrm{ft}$ long and several in. wide (one fuel assembly was clearly visible through the gap).

2. Four containers which remained on the trailer during the impacts and entire fire resulting in the steel inner container being heated to the point where it could deform to the configuration of its environment (principally the front of the trailer).

3. Seven containers which fell off the trailer at various times during the fire and endured various thermal environments.

The hypothesis that is central to the relation between container location and damage is that all containers remained on the trailer during the impact portions of the accident.

\subsection{Mechanical Analyses}

The consequences of the accident on the containers can be divided into mechanical and thermal because the truck impacted four times and endured a fire that lasted about three hours. The mechanical analyses of the tie-downs, kinematics of the truck and containers, and impact loading on the containers are evaluated in the following sections.

\subsubsection{Tie-down Analysis}

The driver of the truck believed that the containers remained on the trailer throughout the impact portions of the accident because the tarpaulins and tie-downs appeared intact and undamaged when the tractor-trailer came to rest. Video tape records of the fire on the rear of the trailer appear to support this observation. Based on these observations, it is possible to develop an estimate of the upper bound of the transverse inertial loads that were applied to the containers while the truck was rebounding from the various impacts with the guardrails and barriers.

The tie-downs described in Section 3.3 are nylon straps fastened to the two sides of the trailer and passing over the containers. It is impossible to obtain samples of the nylon straps used on the truck involved in the accident because they melted and/or were burned during the fire. However, the data presented in Figure 5.1 (Grayson, 1984) is representative of the type of nylon that was used for straps of this type. Contacts with vendors of nylon straps for truck tie-downs have confirmed key elements in this figure so it can be used to represent the tensile properties of nylon straps for this analysis. GE requires that McGill Carriers have records of pull tests of each nylon strap that shows that the breaking strength is greater than $13,000 \mathrm{lb}$. When new, nylon straps typically have a breaking strength near $20,000 \mathrm{lb}$ which provides an adequate margin to assure that the effects of age, wind damage, ultraviolet damage and other effects will not reduce the breaking strength below the required value. 


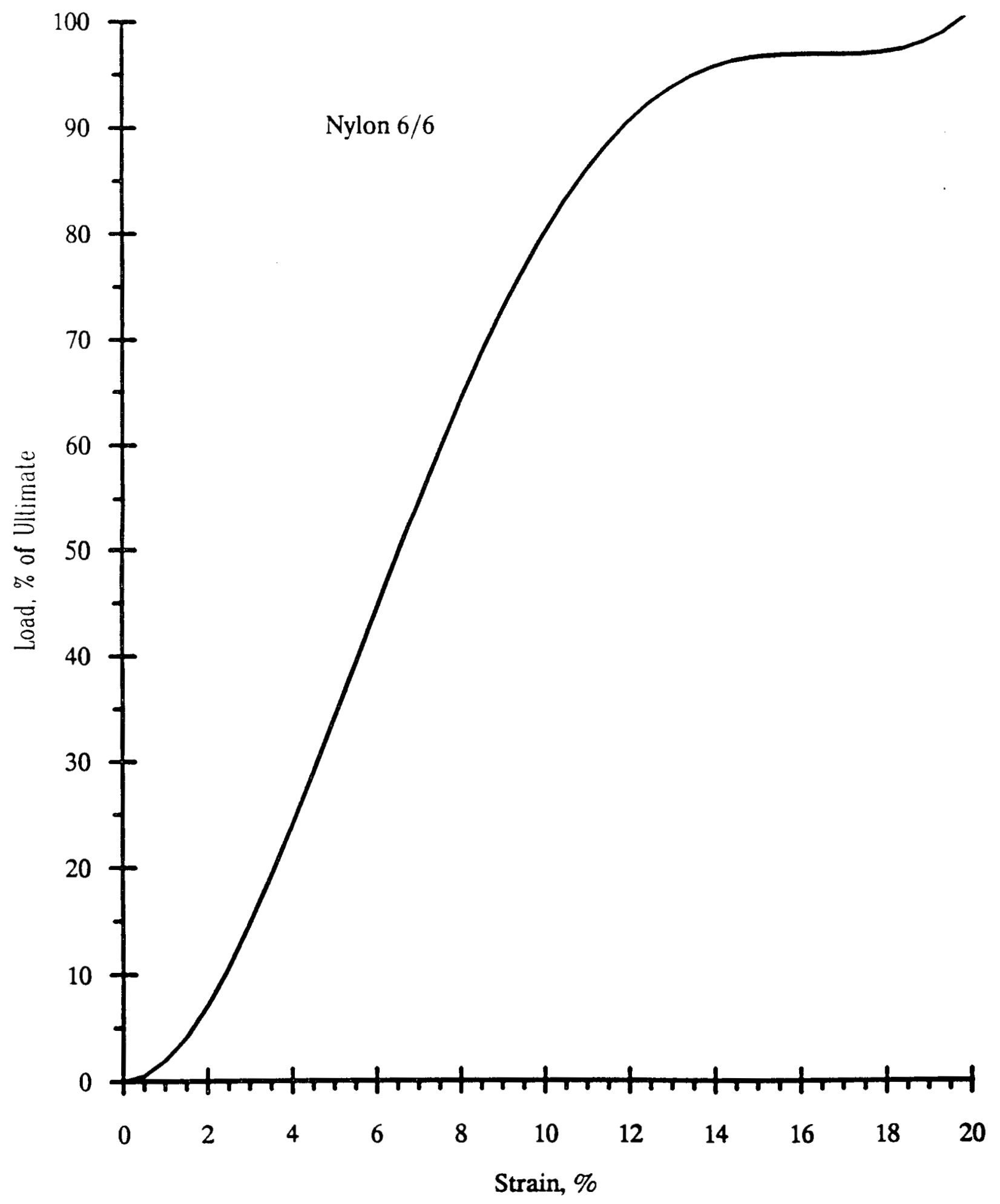

Figure 5.1 Load-Strain Curve for Nylon Straps 


\subsubsection{Pre-tension}

In addition to the variability of the material properties, the initial tension in the nylon strap at the time of the accident is unknown due to the lack of repeatability in the application of the pre-tension and the lack of knowledge about the variation in the initial tension during the trip. The initial tension was applied when the ambient temperature was above $50^{\circ} \mathrm{F}$ (during the day). At the time of the accident, the temperature was $20^{\circ} \mathrm{F}$. This change in temperature of the strap could have loosened or tightened the nylon strap. However, the following analysis will assume that some pretension remained.

An estimate of the pre-tension can be developed based upon the geometry of the ratchet (see Figure 3.7). A steel bar is inserted into the hole in the end of the shaft that protrudes from the far side (in Figure 3.7) of the ratchet. Typically, the steel bar is 24-to-30 in. long and, when this load was secured, the diameter of the roll of nylon strap remaining on the ratchet was between 2 and 3 in.

The geometry of the pre-tensioning is shown in the sketch to the right.

In this sketch:

$\mathrm{T}$ is the tension in the nylon strap in $\mathrm{lb}$.

$F$ is the force exerted by the truck driver as tension is applied in lb.

$\mathrm{L}$ is the length of the bar in in.

$r$ is the radius of the roll of nylon strap on the ratchet in in.

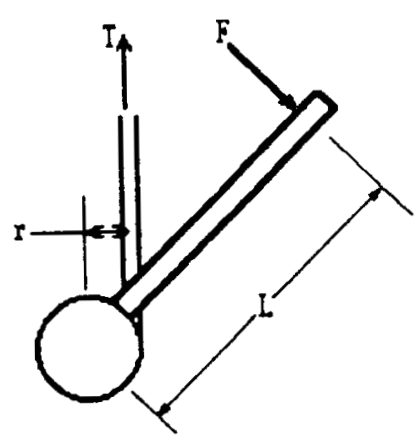

To estimate an upper bound on the force applied to the end of the bar, the bar is treated as a beam with a point load applied at one end while the other end is fixed (i.e., a cantilever beam) as shown in the following sketch:

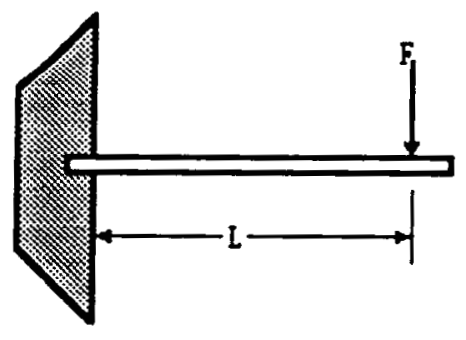

The maximum moment and maximum displacement occur at the end of the beam and are FL and $\frac{-\mathrm{FL}^{3}}{3 \mathrm{EI}}$, respectively. I is the moment of inertial about the centroid of the beam. The stress at the outside of the beam is given by $\sigma=\frac{\mathrm{Mc}}{\mathrm{I}}$, where $\mathrm{c}$ is the distance from the center of the beam to the outer fiber of the beam. For a solid cylindrical bar, the moment of inertia is $\frac{\pi}{4} R^{4}$ and the distance from the centroid to the outer fiber is $\mathbf{R}$. Therefore, the maximum stress in the bar is:

$$
\sigma=\frac{4 F L}{\pi R^{3}}
$$

Assuming that the truck driver would stop applying force when the stress reached or slightly exceeded the yield strength $\left(\sigma=\sigma_{y}\right)$ and the bar was visibly bending, gives the following 
expression as an estimate of the force that would be applied to the end of the bar:

$$
F=\frac{\sigma_{y} \pi R^{3}}{4 L} .
$$

Introducing numerical values and assuming the yield strength of the steel to be 33,000 psi gives bounds to the force applied to the end of the bar that range from about $5 \mathrm{lb}$, if the bar diameter is $0.4 \mathrm{in}$. and the length is $36 \mathrm{in}$., to $162 \mathrm{lb}$, if the bar diameter is $1 \mathrm{in}$. and the length is $20 \mathrm{in}$. These values are within the strength capability of a normal adult.

Balancing the moments on the ratchet gives the following expression for the pre-tension in the nylon strap:

$$
\mathrm{T}=\frac{\mathrm{FL}}{\mathrm{T}}
$$

After introducing the expression for the upper bound on the force, this expression becomes:

$$
T=\frac{\sigma_{y} \pi R^{3}}{4 r} .
$$

A plot of the pre-tension as a function of the radius of the bar, $R$, and the radius of the roll of nylon strap on the ratchet, $\mathrm{r}$, is presented in Figure 5.2. The maximum value of pre-tension is independent of the properties of the nylon strap and is less than $3,500 \mathrm{lb}$ for all realistic values of the size of the bar and the amount of nylon strap that remains on the ratchet. Consequently, all additional analyses that utilize the pre-tension of the nylon strap will treat 3,500 $\mathrm{lb}$ as the upper bound of the pre-tension.

\subsubsection{Frictionless Contact Between Strap and Tarpaulin}

The frictional resistance to motion between the nylon strap and the rubberized surface of the tarpaulin is difficult to predict. Rather than attempting to estimate the friction coefficient for these surfaces, the following analysis will be performed assuming no frictional resistance to motion of the tarpaulin under the nylon strap. This approach will underestimate the maximum transverse and longitudinal accelerations that are possible without breaking the nylon strap. Also, the friction coefficient should be small so assuming a value of zero is simultaneously a bound and a realistic value.

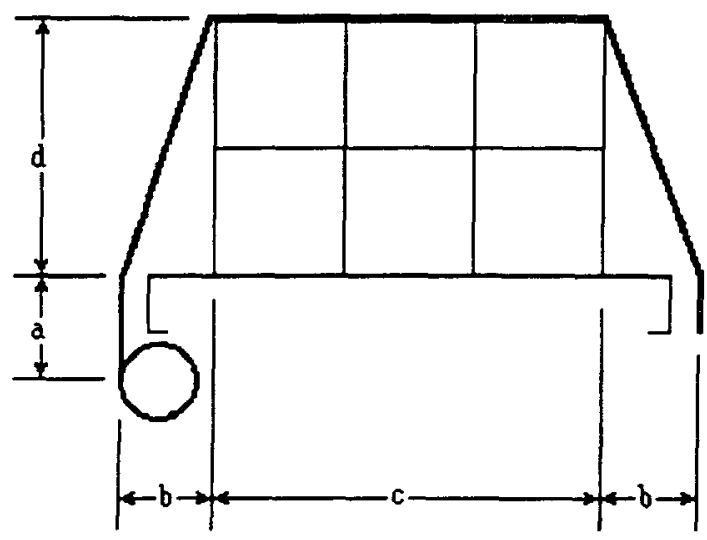

The sketch to the left represents a cross section of the trailer prior to transport (the containers are centered on the trailer) which focuses upon the geometry of the nylon strap. This sketch is not to scale to emphasize the regions where the nylon straps are attached to the trailer. The nylon tie-down is shown in bold in this sketch.

The length of the nylon strap (not including material still rolled up on the ratchet) can be calculated from the following equation:

$$
L=a+c+2 \sqrt{b^{2}+d^{2}},
$$




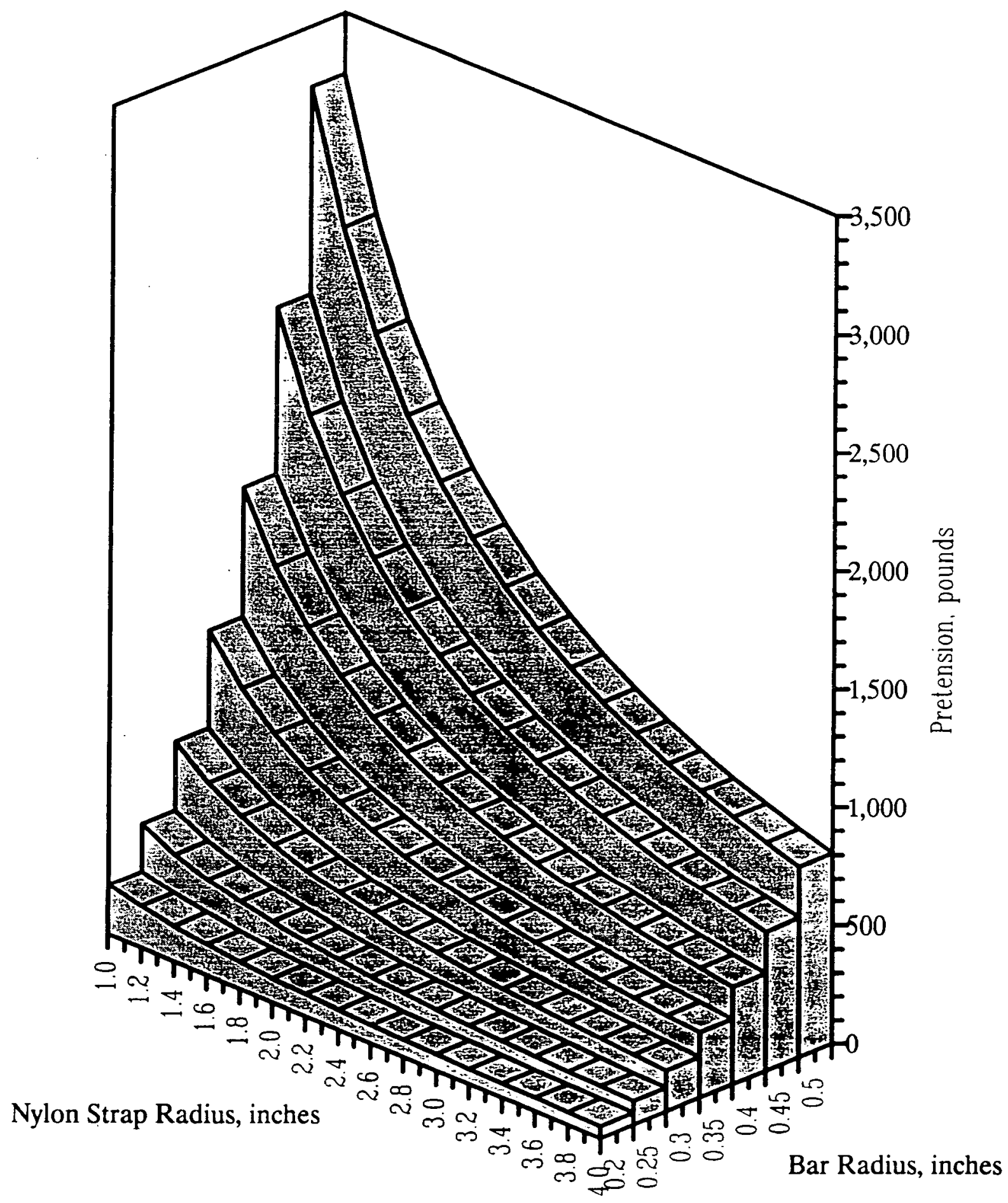

Figure 5.2 Pre-tension of Nylon Strap 
where:

$$
\begin{array}{ll}
\mathrm{a}=13 \text { in., } & \mathrm{c}=89.625 \text { in., and } \\
\mathrm{b}=4.1875 \text { in., } & \mathrm{d}=62 \text { in. }
\end{array}
$$

The initial length of the nylon strap is $226.9 \mathrm{in.}$

The photographs and video tapes of the rear of the trailer during the fire portion of this accident indicate that the containers shifted toward the left (driver's) side of the trailer during the impact portion of the accident. The displacement of the containers will induce a strain in the nylon straps that are holding the containers in place on the trailer.

If the containers move as a single unit, the geometry of the nylon straps would be as shown in the following sketch.

In this sketch, $\mathrm{x}$ is the displacement of the containers relative to their original positions.

The strain in the nylon strap for this case is given by:

$$
\begin{aligned}
& \varepsilon=\frac{a+c-L}{L}+ \\
& \frac{\sqrt{(b-x)^{2}+d^{2}+\sqrt{(b+x)^{2}+d^{2}}}}{L}
\end{aligned}
$$

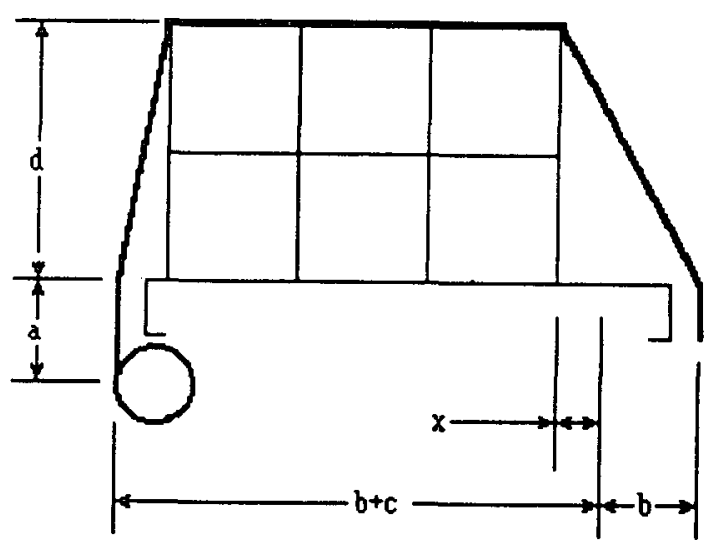

where:

$\varepsilon$ is the strain in the nylon strap.

If the containers continue moving as a unit such that the outer edge of the containers is outside the trailer, the geometry of the nylon straps changes to the configuration shown in the following sketch.

The strain in the nylon strap for this case is given by:

$$
\begin{aligned}
& \varepsilon=\frac{d+c-L}{L}+ \\
& \frac{\sqrt{(x-b)^{2}+a^{2}}+\sqrt{(b+x)^{2}+d^{2}}}{L} .
\end{aligned}
$$

The strain induced in the nylon strap is plotted as a function of the displacement of the containers in Figure 5.3. The strain can be converted to

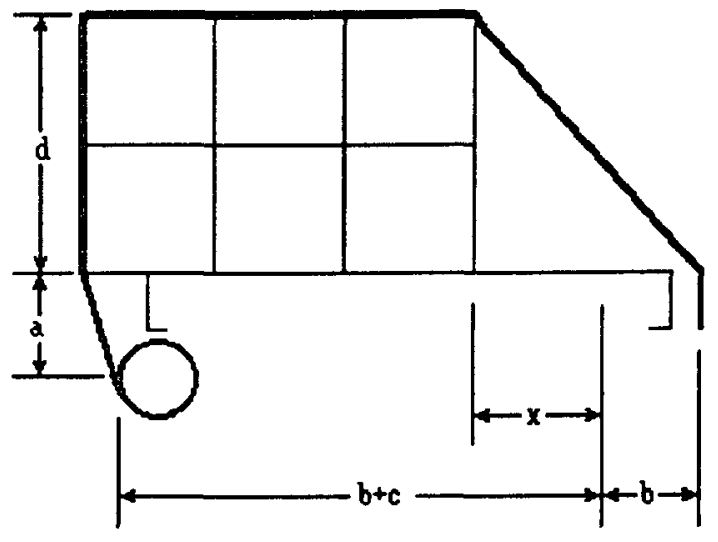
tension by referring to Figure 5.1 , and the tension in the nylon strap is plotted in Figure 5.4 as a function of the displacement of the containers for several values of the pre-tension. Figure 5.4 assumes that the ultimate strength $(100 \%$ load in Figure 5.1$)$ is $13,000 \mathrm{lb}$. Since the containers remained on the trailer during the impact portion of the containers, it can be concluded that the 


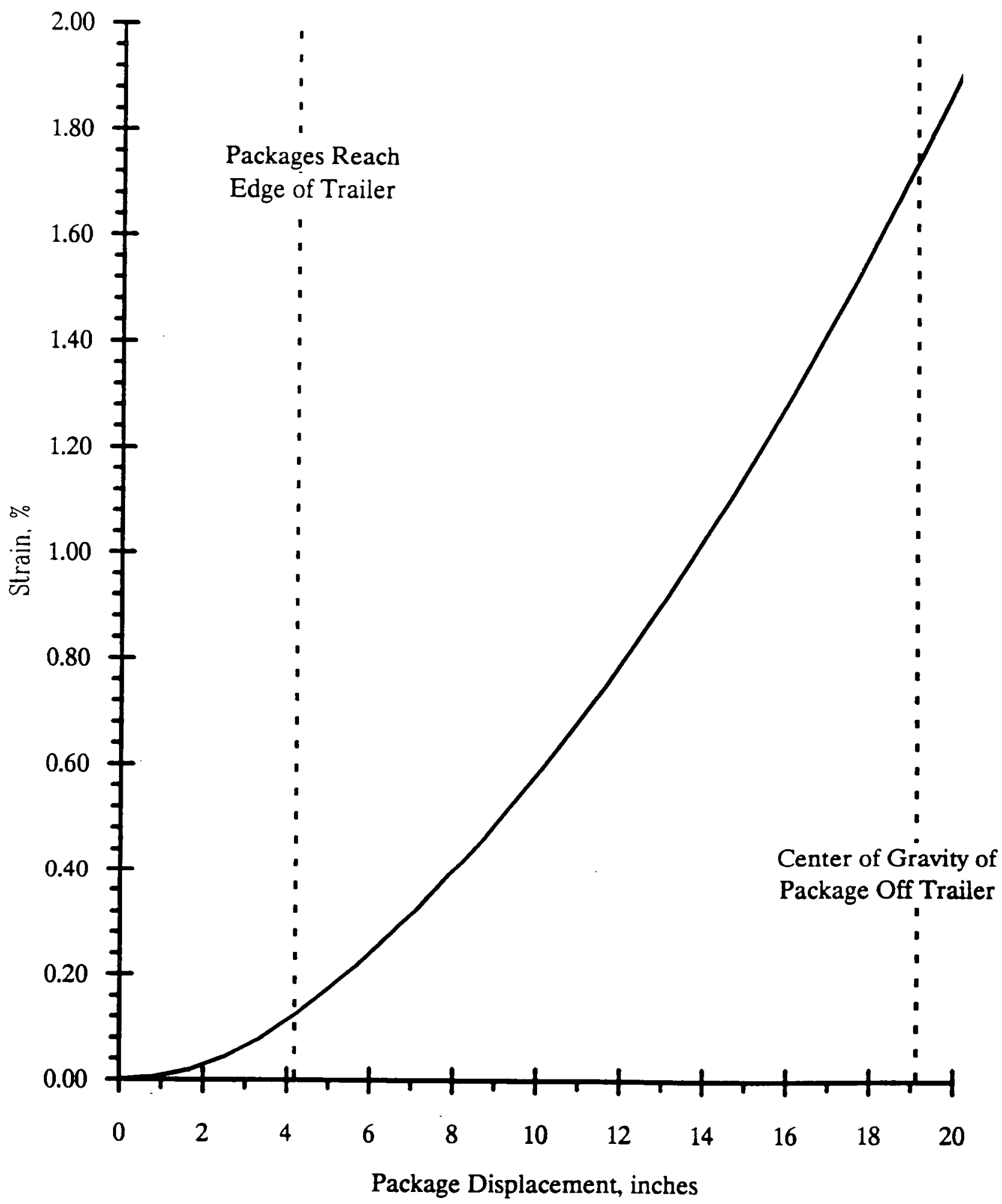

Figure 5.3 Strain in Tie-down Assuming No Friction Under Tie-down 


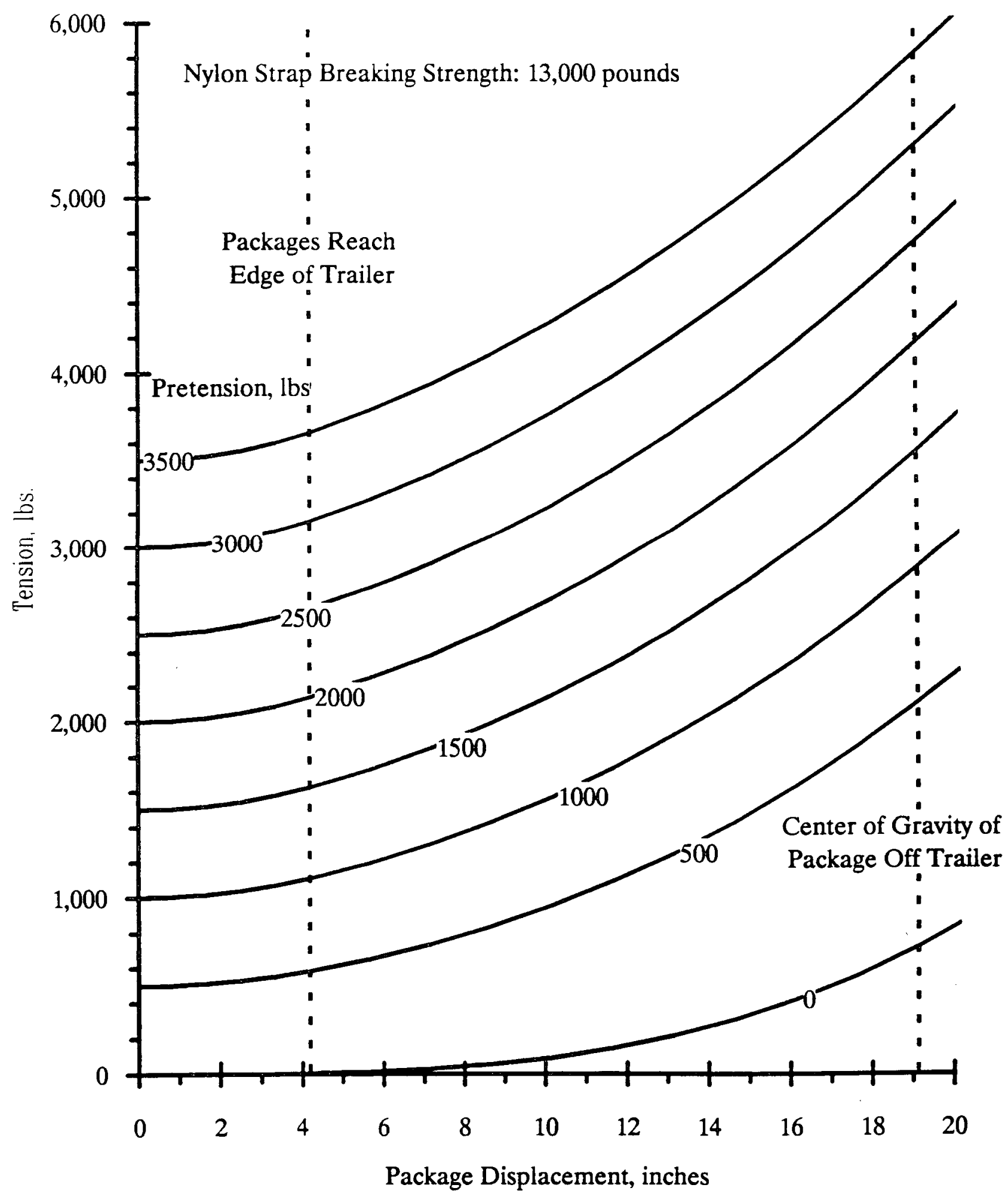

Figure 5.4 Tension in Tie-down Assuming No Friction Under Tie-Down 
center-of-gravity of any of the containers was never outside the perimeter of the trailer. Thus, the maximum displacement of the containers is less than one half of the width of a container. Allowing one in. for the width of the railing that surrounds the trailer to provide an attachment for the tie downs, the distance between the edge of a container and the edge of the trailer when the containers are centered is:

$$
\mathrm{b}=\frac{96-3 \times 29.875}{2}+1=4.1875 \mathrm{in}
$$

and the displacement of the containers when the center-of-gravity of a container is just at the edge of the trailer is:

$$
x=\frac{29.875}{2}+4.1875=19.125 \text { in }
$$

Assuming the containers moved to the point where the center-of-gravity of the outer container was at the edge of the trailer, the maximum tensile load in the nylon straps would be less than 6,000 lb which is well below the breaking strength of the nylon straps.
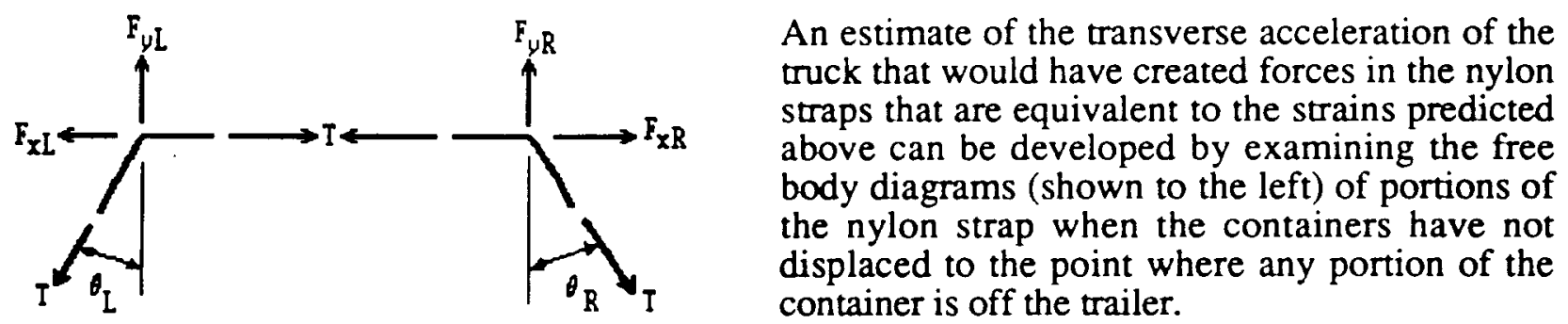

The forces acting on the nylon strap must be in equilibrium, resulting in the following equations for the forces acting on the left and right sides of the nylon strap:

$$
\begin{array}{cc}
\Sigma F_{x L}=T-F_{x L}-T \sin \theta_{L}=0, & \Sigma F_{x R}=-T+F_{x R}+T \sin \theta_{R}=0, \\
\Sigma F_{y L}=F_{y L}-T \cos \theta_{L}=0, & \Sigma F_{y R}=-F_{y R}-T \cos \theta_{R}=0 .
\end{array}
$$

Solving for the forces acting on the nylon strap gives:

$$
\begin{array}{cc}
\mathrm{F}_{\mathrm{XL}}=\mathrm{T}\left(1-\sin \theta_{\mathrm{L}}\right), & \mathrm{F}_{\mathrm{XR}}=\mathrm{T}\left(1-\sin \theta_{\mathrm{R}}\right), \\
\mathrm{F}_{\mathrm{yL}}=\mathrm{T} \cos \theta_{\mathrm{L}}, & \mathrm{F}_{\mathrm{yR}}=\mathrm{T} \cos \theta_{\mathrm{R}} .
\end{array}
$$

These forces are equal and opposite to the forces acting on the group of containers as indicated in the following free body diagram of the containers. This free body diagram also indicates the friction force that will exist to resist motion between the containers and the bed of the trailer.

Writing the equations of motion for the containers results in the following equations:

$$
\begin{aligned}
& \Sigma F_{x}=F_{x L}-F_{x R}+F_{f}=W \frac{a_{t}}{g_{c}}, \\
& \Sigma F_{y}=-F_{y L}-F_{y R}-W+N=0 .
\end{aligned}
$$

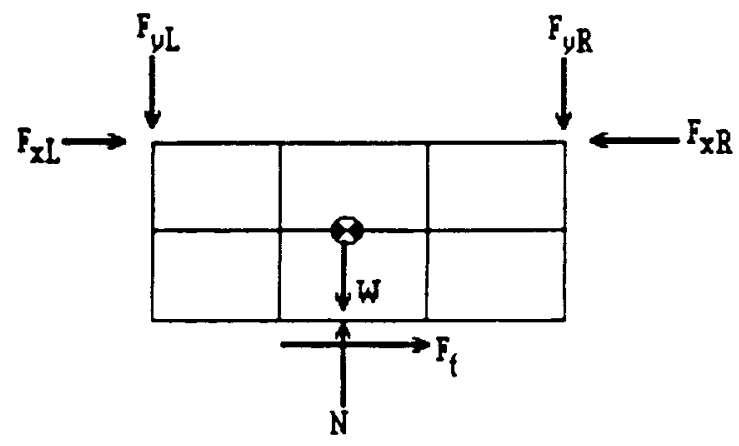


Solving the equation for the vertical direction for the normal force gives:

$$
\mathrm{N}=\mathrm{W}+\mathrm{T}\left(\cos \theta_{\mathrm{L}}+\mathrm{T} \cos \theta_{\mathrm{R}}\right)
$$

Introducing the definition of the friction force $F_{f}, \mu N$, permits solving for the maximum acceleration that can be tolerated. Any larger transverse acceleration of the trailer will cause the friction to change to dynamic friction which is smaller than the static friction assumed here, and the containers will move rapidly toward the side of the truck.

$$
\frac{a_{t}}{g_{c}}=\mu+\frac{T}{W}\left[\sin \theta_{R}-\sin \theta_{L}+\mu\left(\cos \theta_{L}+T \cos \theta_{R}\right)\right] .
$$

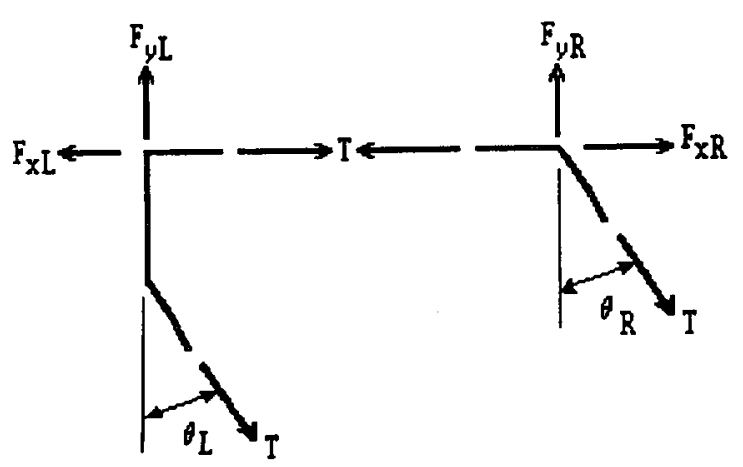

$$
\begin{gathered}
\Sigma F_{x L}=-F_{x L 1}-F_{x L 2}+T+T \sin \theta_{L}=0 \\
\Sigma F_{y L}=F_{y L 1}-F_{y L 2}-T \cos \theta_{L}=0 \\
F_{x L 1}+F_{x L 2}=T\left(1+\sin \theta_{L}\right) \\
F_{x L 1}-F_{x L 2}=T \cos \theta_{L}
\end{gathered}
$$

If the displacement of the containers is such that one stack of containers is partially off the trailer, the free body diagrams of portions of the nylon strap are different from those presented above and are as shown in the free body diagram to the left.

The forces acting on the nylon strap must be in equilibrium, resulting in the following equations for the forces acting on the left and right sides of the nylon strap:

$$
\begin{gathered}
\Sigma \mathrm{F}_{\mathrm{XR}}=-\mathrm{T}+\mathrm{F}_{\mathrm{XR}}+\mathrm{T} \sin \theta_{\mathrm{R}}=0, \\
\Sigma \mathrm{F}_{\mathrm{yR}}=\mathrm{F}_{\mathrm{yR}}-\mathrm{T} \cos \theta_{\mathrm{R}}=0 . \\
\mathrm{F}_{\mathrm{xR}}=\mathrm{T}\left(1-\sin \theta_{\mathrm{R}}\right), \\
\mathrm{F}_{\mathrm{yR}}=\mathrm{T} \cos \theta_{\mathrm{R}} .
\end{gathered}
$$

These forces are equal and opposite to the forces acting on the group of containers as indicated in the following free body diagram of the containers. This free body diagram also indicates the friction force that will exist to resist motion between the containers and the bed of the trailer.

Writing the equations of motion for the containers results in the following equations:

$$
\begin{aligned}
& \Sigma F_{x}=F_{x L 1}+F_{x L 2}-F_{x R}+F_{f}=W \frac{a_{t}}{g_{c}}, \\
& \Sigma F_{y}=F_{y L 2}+F_{y L 1}-F_{y R}-W+N=0 .
\end{aligned}
$$

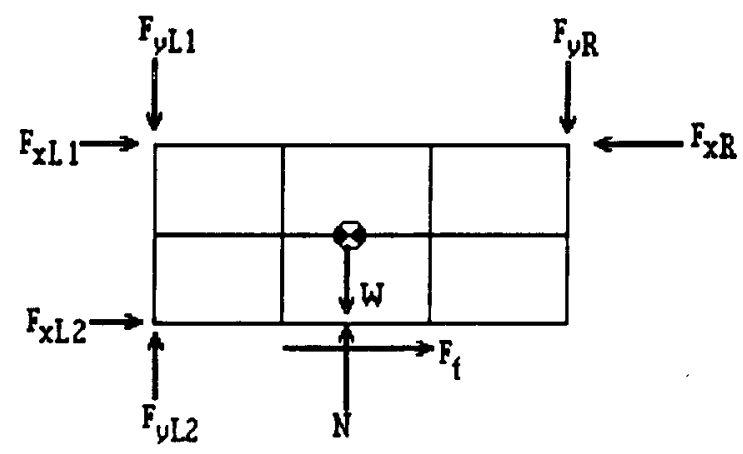




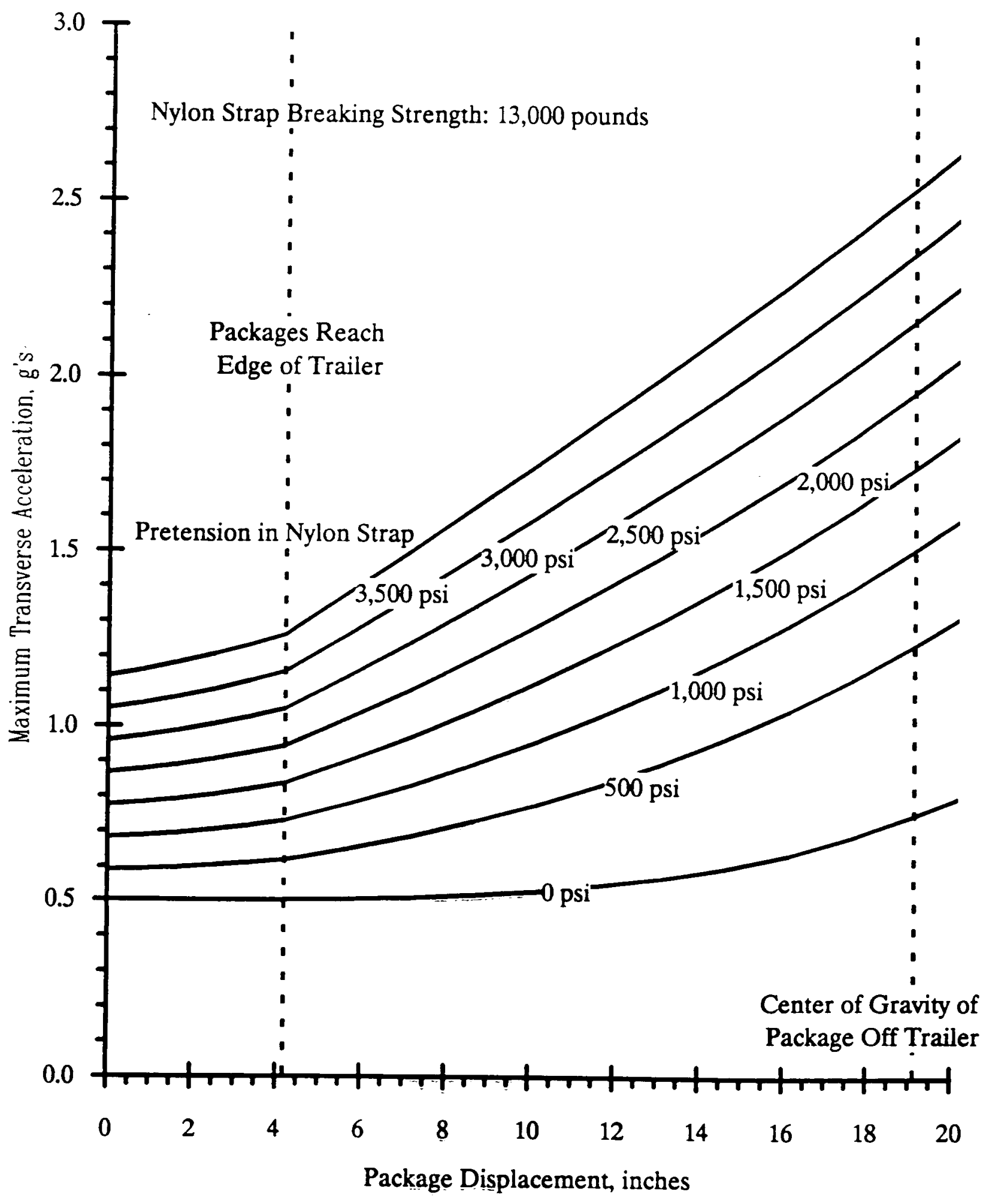

Figure 5.5 Maximum Possible Transverse Acceleration 
Proceeding as in the previous evaluation of the maximum transverse acceleration gives:

$$
\begin{gathered}
N=W+T \cos \theta_{L}+T \cos \theta_{R} \text { and } F_{f}=\mu N, \text { and } \\
\frac{a_{t}}{g_{c}}=\mu+\frac{T}{W}\left[\sin \theta_{L}+\sin \theta_{R}+\mu\left(\cos \theta_{L}+\cos \theta_{R}\right)\right] .
\end{gathered}
$$

The maximum possible acceleration that corresponds to various displacements of the containers is plotted in Figure 5.5 for several different values of the pre-tension of the nylon straps. During the impact portion of the accident, the trailer was swinging toward both sides, and it is possible that the containers slid to one side of the trailer and then, at a later time, slid to the other side. Consequently, the fact that the containers appear to extend about 4 in. (displacement of about 8 in.) off the left side of the trailer will be ignored, and it will be assumed that the maximum displacement of the containers was slightly less than the displacement that would have caused the center of gravity of any of the containers to be outside the trailer. This results in the conclusion that the transverse acceleration was no larger than about $1.5 \mathrm{~g}$. This is a small peak transverse acceleration which implies that the trailer did not swing far enough to either side to strike the concrete barrier at the outside of the roadway or the guardrail dividing the north and south bound lanes.

A similar approach can be employed to determine the maximum longitudinal deceleration that can be tolerated by the containers without exceeding static friction so the containers will experience only small displacements. The expression for the maximum longitudinal acceleration is:

$$
\frac{\mathrm{a}_{1}}{\mathrm{~g}_{\mathrm{c}}}=\mu\left[1+\frac{\mathrm{T}}{\mathrm{W}}\left(\sin \theta_{\mathrm{L}}-\sin \theta_{\mathrm{R}}\right)\right] \text {. }
$$

The expression for the maximum longitudinal deceleration does not change if the containers are displaced such that a portion of the containers is off the trailer.

The maximum longitudinal accelerations are plotted in Figure 5.6 as a function of the displacement of the containers and the pre-tension in the nylon straps. The maximum longitudinal deceleration must have been less than one $\mathrm{g}$ based on the observation that the containers did not slide forward by a large amount during the impact portions of the accident. The final resting positions of the containers after the conclusion of the fire appear to be 6 to 12 in. forward of the initial position on the trailer. However, this amount of motion is sufficiently small that it cannot represent gross sliding of the payload. The most likely explanation of the final position of the containers being forward of their initial position is motion during the fall off the trailer which could have included a sliding component which would have moved the containers forward.

It should be noted that this analysis indicates that if any container is to slide forward during the deceleration, it will be the center container in the top row. This container does not receive any of the downward forces due to the tie downs and it does not have another container resting on its top so it has the least frictional forces restricting its motion. The only frictional forces acting on the center container in the top row are the forces that arise from the clamping forces $F_{x L}$ and $F_{x R}$ which tend to hold the containers together in a single unit. If the center container in the top row were to move by about $6 \mathrm{ft}$, it would impact on the expanded metal barrier at the rear of the tractor. However, this barrier was free of any impact damage so it must be concluded that if there was any forward motion of the containers, it was not sufficient to allow the containers to reach this barrier. 


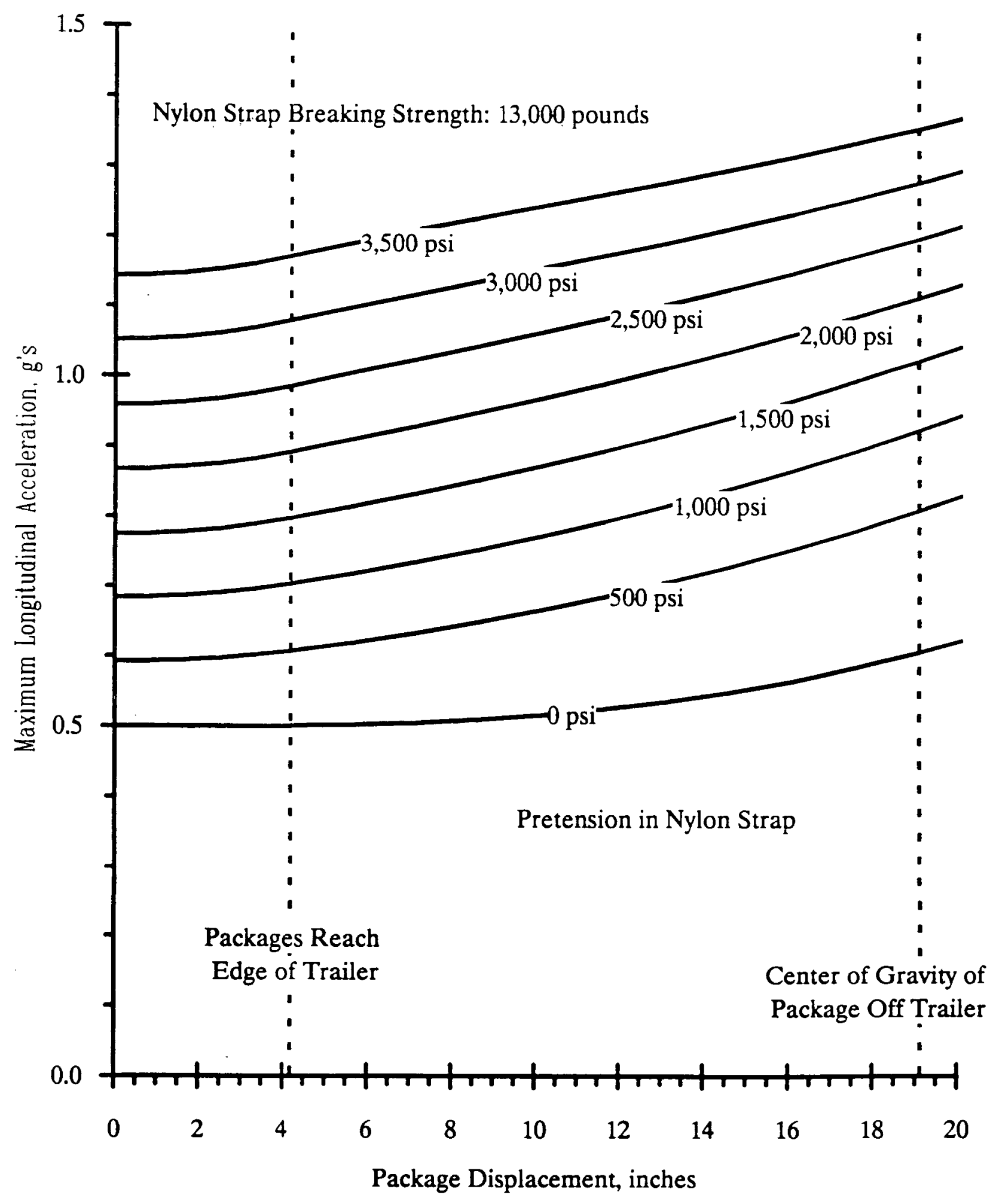

Figure 5.6 Maximum Possible Longitudinal Acceleration 


\subsubsection{Trailer Dynamics}

The analysis of the tie-downs developed an estimate of the maximum transverse and longitudinal accelerations that the trailer could have experienced while the containers remained on the trailer. The values indicated that the trailer did not impact the concrete barrier or the guardrail. A second approach to assuring that the trailer did not impact on the concrete barrier or guardrail can be developed by examining the dynamics of the trailer as it attempted to follow the tractor through the three impacts and three different trajectories during the impact portion of the accident. The photographs of the damage to the guardrail and concrete barrier (Figures 2.2 and 2.3) do not show any indication of impact of the trailer on the guardrail or concrete barrier. The importance of knowing that all of the containers were on the trailer prior to the start of the fire, and the containers fell off the trailer only during the fire, is sufficient to justify a second analysis.

\subsubsection{Analysis of Load Distribution of Tractor and Trailer}

The first portion of the analysis of the dynamics of the trailer is the calculation of the forces acting at each wheel on the truck. This calculation is based upon the dimensions of the tractor and trailer that are presented in Tables 2.2 and 2.3 .

The locations of the center-of-gravity of the tractor and trailer are based upon the equipment present at the time of construction of the tractor and trailer. Modifications could have been made to both the tractor and trailer during use which must be left as an uncertainty in this analysis due to the difficulty of characterizing these modifications. The payload was centered on the trailer and the miscellaneous items such as tarpaulins, tie-downs, etc. have been assumed to also be centered on the trailer because the majority of these items are associated with the payload.

The deceleration can be determined by assuming that the truck, when traveling at $55 \mathrm{mph}$, would have required $200 \mathrm{ft}$ to come to a halt on comparable pavement if the truck had stopped in a straight line. If it is also assumed that the tractor and trailer behaved as a single body, the equation of motion is:

$$
v^{2}=v_{0}^{2}+2 a s
$$

where:

$\mathrm{v}$ is the instantaneous velocity after decelerating while traveling a distance $\mathrm{s}$,

$v_{0}$ is the initial velocity ( $55 \mathrm{mph}$ ),

$\mathrm{s}$ is the distance traveled while decelerating (200 ft), and

$a$ is the constant acceleration that was applied during deceleration.

Solving for the acceleration and introducing numerical values gives:

$$
a=\frac{v^{2}-v^{2}}{2 s}=\frac{0^{2}-80.67^{2}}{2200}=-16.27 \frac{\mathrm{ft}}{\mathrm{sec}^{2}} \text {, }
$$

The coefficient of friction between the tires and the roadway is equal to $\frac{a}{g_{c}}$ because the retarding forces arise only from friction. 


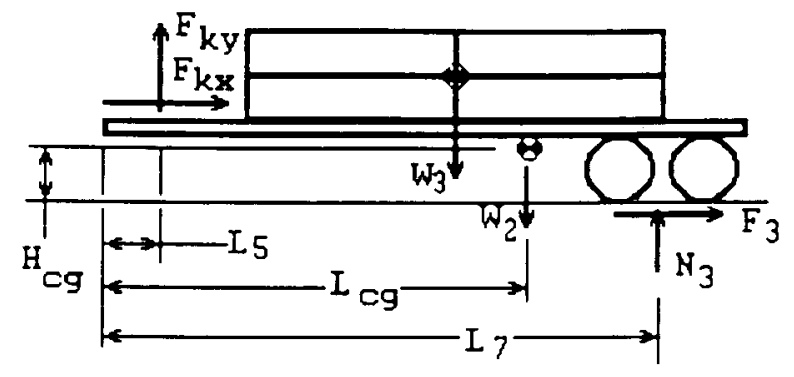

$$
\mu=\frac{\mathrm{a}}{\mathrm{g}_{\mathrm{c}}}=\frac{16.27}{32.147}=0.506
$$

The forces acting on the tractor and trailer can be determined by examining the tractor and trailer separately. The frictional forces acting at the interface between the tires and roadway represent the retarding force that is causing the truck to decelerate. The free body diagram of the trailer and payload including the forces acting at the kingpin is shown at left.

In this diagram:

$F_{3}$ is the friction force acting on the wheels of the trailer.

$F_{k x}$ and $F_{k y}$ are the forces acting on the kingpin connecting the tractor and trailer.

$\mathrm{N}_{3}$ is the force of the wheels of the trailer acting on the roadway.

$\mathrm{W}_{2}$ is the weight of the trailer.

$\mathrm{W}_{3}$ is the weight of the payload.

The weights and appropriate dimensions are presented in Tables 2.2 and 2.3. Equations that represent equilibrium of vertical and horizontal forces and moments can be solved to determine the forces which are:

$$
\begin{array}{rlrl}
\mathrm{F}_{\mathrm{ky}} & =21,000 \mathrm{lb}, & \mathrm{F}_{\mathrm{kx}} & =10,600 \mathrm{lb}, \\
\mathrm{N}_{3} & =25,500 \mathrm{lb}, & \mathrm{F}_{3}=12,900 \mathrm{lb} .
\end{array}
$$

The forces acting on the tractor are represented in the freebody diagram of the tractor.

In this diagram:

$\mathrm{W}_{1}$ is the weight of the tractor.

$F_{1}$ is the frictional force acting on the front wheels of the tractor.

$F_{2}$ is the frictional force acting on the rear wheels of the tractor.

$\mathrm{N}_{1}$ is the normal force acting on the front wheels of the tractor.

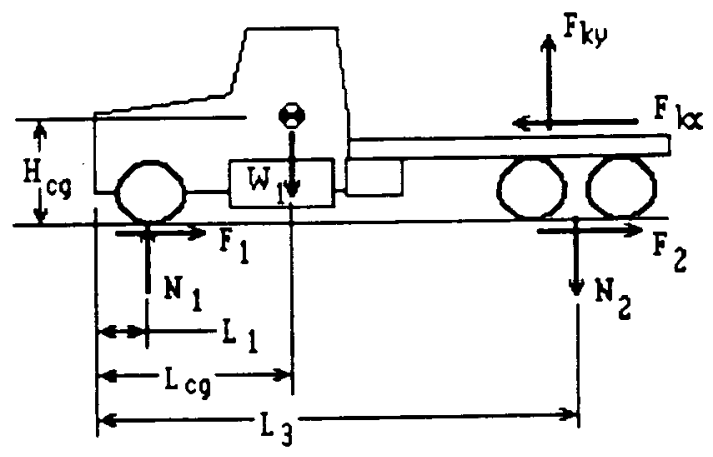

$\mathrm{N}_{2}$ is the normal force acting on the rear wheels of the tractor.

Solving the equations for vertical, horizontal and rotational equilibrium gives:

$$
\begin{array}{ll}
\mathrm{N}_{1}=21,000 \mathrm{lb}, & \mathrm{F}_{1}=10,600 \mathrm{lb}, \\
\mathrm{N}_{2}=25,500 \mathrm{lb}, & \mathrm{F}_{2}=12,900 \mathrm{lb} .
\end{array}
$$

This analysis corresponds to rolling friction between the wheels and the roadway which implies that static friction is acting at the point of contact between the tires and the roadway. If the wheels 
stop rotating due to the effects of the brakes, the tires will begin to slide and the coefficient of friction could be reduced by $50 \%$. Under these conditions the acceleration and stopping distance will be:

$$
\begin{aligned}
& \mathrm{a}=0.5 \times 16.27=8.13 \mathrm{ft} / \mathrm{sec}^{2}, \text { and } \\
& \mathrm{s}=\frac{\mathrm{V}^{2}-\mathrm{v}_{0}^{2}}{2 \mathrm{a}}=\frac{0^{2}-80.67^{2}}{28.13}=400 \mathrm{ft}
\end{aligned}
$$

This stopping distance is longer than the distance between the initial impact and the final resting position of the truck so it must be concluded that the brakes did not lock and the tires continued to rotate as the brakes absorbed energy. This is consistent with the absence of readily visible skid marks on the roadway.

During the final portion of the travel of the truck, the wheels and front axle of the tractor were separated from the tractor. This reduced the weight of the tractor by about $1,200 \mathrm{lb}$ and moved the center-of-gravity toward the rear by about $6.3 \mathrm{in}$. When the front wheels no longer support the tractor, it tilts forward until the tractor frame contacts the trailer frame near the kingpin. From this point to the conclusion of the impact portion of the accident, the tractor and trailer behaved as a single unit and the front of the tractor remained above the roadway. With the tractor and trailer behaving as a single unit, the forces acting on the tires are:

$$
\begin{array}{ll}
\mathrm{N}_{2}=43,400 \mathrm{lb}, & \mathrm{F}_{2}=21,900 \mathrm{lb}, \\
\mathrm{N}_{3}=20,900 \mathrm{lb}, & \mathrm{F}_{3}=10,600 \mathrm{lb} .
\end{array}
$$

These forces represent a substantial increase in the load applied to the tractor rear wheels $\left(\mathrm{N}_{2}\right)$. However, this load is not sufficient to damage the tractor rear axle which is rated to carry $40,000 \mathrm{lb}$. The load applied to the rear tractor wheels could have overloaded the tires creating the smoldering that was observed when the tractor and trailer came to rest.

\subsubsection{Kinetic Analysis of Trailer Motion During Accident}

During the initial portions of the travel after impacting with the car, the trailer will be subject to the forces that are indicated on the following free body diagram.

In this diagram:

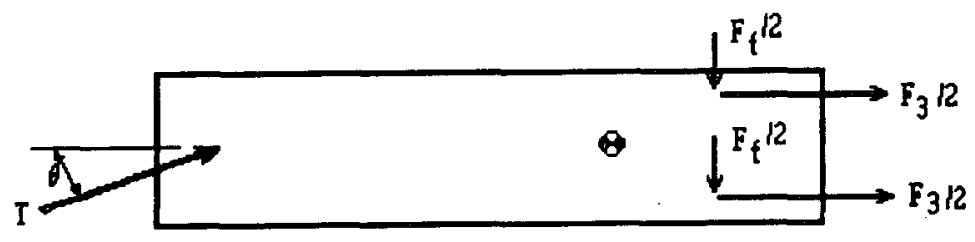

$\mathrm{F}_{3}$ is the longitudinal force due to braking.

$F_{f}$ is the transverse force due to friction at the wheels.

$T$ is the force applied at the kingpin.

$\theta$ is the angle between the force at the kingpin and the longitudinal axis of the trailer.

The retarding force that is applied at the kingpin is the result of friction of the tires of the tractor. The force at the kingpin has been assumed to follow a path that is formed by three straight lines as shown in Figure 5.7. Assuming the kingpin follows straight lines will maximize the rotation of the trailer at the points where the tractor impacts on the guardrail or barrier. 


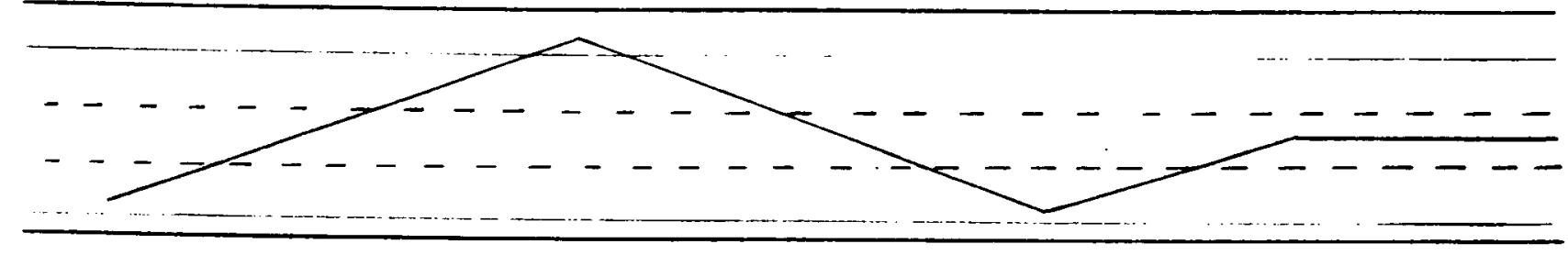

- Direction of Travel m

Assumed Motion of Force on Trailer at Kingpin

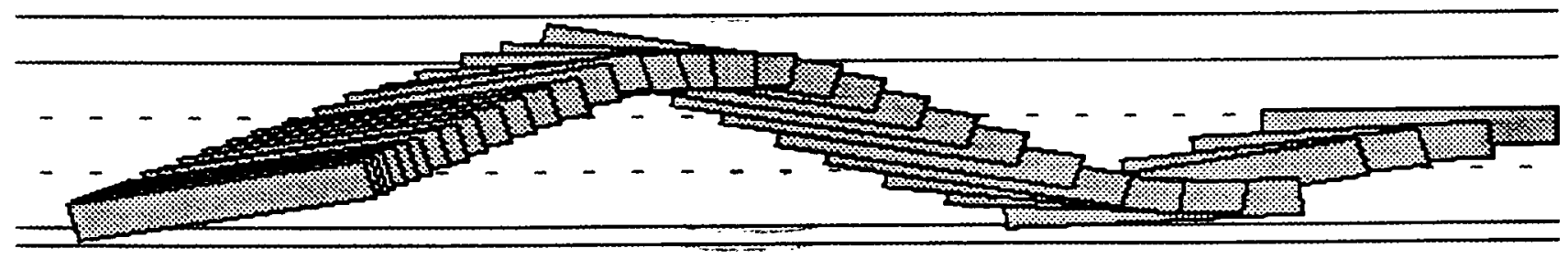

- Direction of Travel

Motion of Trailer

Trailer Rotation During Impact Portion of Accident

$\begin{array}{lccccc}\text { Time } & \text { Angle* } & \text { Time } & \text { Angle* } & \text { Time } & \text { Angle* } \\ 0.00 & 0.0 & 1.41 & -39.3 & 2.82 & 24.2 \\ 0.18 & 8.2 & 1.59 & -46.5 & 3.00 & 31.9 \\ 0.35 & 16.3 & 1.76 & -47.2 & 3.17 & 39.3 \\ 0.53 & 23.6 & 1.94 & -47.2 & 3.35 & 46.5 \\ 0.71 & -8.2 & 2.12 & -47.2 & 3.53 & 47.2 \\ 0.88 & -16.2 & 2.29 & -47.2 & 3.70 & 47.2 \\ 1.06 & -24.2 & 2.47 & 8.2 & 3.88 & 47.2 \\ 1.23 & -31.9 & 2.65 & 16.2 & & \end{array}$

*Angle relative to centerline of roadway

Figure 5.7 Trailer Dynamics During Impact Portion of Accident 
The transverse forces at the wheels represent the friction forces that act on the wheels to prevent sliding of the trailer in the transverse direction. The initial evaluation of the forces acting on the trailer will be based upon assumed equilibrium in the transverse direction which defines the friction force as:

$$
\mathrm{F}_{\mathrm{f}}=\mathrm{T} \sin \theta .
$$

As long as the transverse force at the wheels of the trailer is less than the frictional force at the wheels, there will be no transverse component of acceleration and the trailer wheels will follow behind the tractor. For the purposes of this analysis the friction coefficient for transverse motion of the wheels is assumed to be 0.4 which is slightly less than the value used to represent rolling friction. Using the normal force at the rear wheels which was determined in the previous section, this is equivalent to limiting the friction force to slightly more than $10,000 \mathrm{lb}$.

If the transverse friction force, $F_{f}$, exceeds $8,000 \mathrm{lb}$, a third equation of motion must also be included which is:

$$
\Sigma F_{y}=T \sin \theta-F_{f} m a_{y}
$$

where:

$a_{y}$ is the transverse acceleration of the center-of-gravity.

The equations of motion of the trailer are:

$$
\begin{gathered}
\Sigma F_{\mathrm{x}}=-\mathrm{T} \cos \theta \mathrm{F}_{3} \frac{\mathrm{W}}{\mathrm{g}_{\mathrm{c}}} \mathrm{a}_{\mathrm{x}} \text {, and } \\
\Sigma \mathrm{M}_{\mathrm{cg}}=\mathrm{T} \sin \theta\left(\mathrm{L}_{\mathrm{cg}}-\mathrm{L}_{5}\right)+\mathrm{F}_{\mathrm{f}}\left(\mathrm{L}_{7}-\mathrm{L}_{\mathrm{cg}}\right)+\left(\frac{\mathrm{F}_{3}}{2}\right)\left(\mathrm{w}_{\mathrm{w}}-0\right)-\left(\frac{\mathrm{F}_{3}}{2}\right)\left(\mathrm{w}_{\mathrm{w}}-0\right)=\mathrm{I}_{\mathrm{cg}} \alpha,
\end{gathered}
$$

where:

$\mathrm{F}_{\mathrm{x}}$ are the forces parallel to the longitudinal axis of the trailer.

$\mathrm{T}$ is the force applied to the kingpin by the motion of the tractor.

$\theta$ is the angle between the force applied to the kingpin and the longitudinal axis of the trailer.

$F_{3}$ are the friction forces acting at the rear wheels that are parallel to the longitudinal axis of the trailer.

$F_{f}$ are the friction forces acting at the rear wheels that are perpendicular to the longitudinal axis of the trailer.

$\mathrm{W}$ is the weight of the trailer.

$\mathrm{g}_{\mathrm{c}}$ is the gravitational constant.

$a_{x}$ is the longitudinal acceleration of the center-of-gravity.

$\mathrm{I}_{\mathrm{cg}}$ is the moment of inertia about the center-of-gravity of the trailer.

$\alpha$ is the angular acceleration of the trailer.

$w_{w}$ is the distance from the center of the trailer to the center of the wheels.

The L's are defined in Table 2.3 
The moment of inertia of the trailer has been determined from repeated application of the expression:

$$
I=\frac{W}{12}\left(a^{2}+b^{2}\right)+W d^{2},
$$

where:

$I$ is the moment of inertia about the axis that is distance $d$ away from the center-of-gravity.

$\mathrm{W}$ is the mass of the body in $\mathrm{lb}$.

$\mathrm{a}$ is the width of the body perpendicular to the axis of rotation.

$b$ is the length of the body perpendicular to the axis of rotation.

$\mathrm{d}$ is the distance between the center-of-gravity of the body and the axis of rotation.

The center-of-gravity of the trailer and payload is on the centerline of the trailer and 302 in. behind the front of the trailer. The values of the weights and dimensions for the trailer are as follows:

$\begin{array}{lcccc}\text { Component } & \text { Weight (lb) } & \text { a (in.) } & \text { b (in.) } & \text { d (in.) } \\ \text { Trailer Bed } & 11,700 & 96 & 576 & 14 \\ \text { Trailer Wheels } & 3,300 & 96 & 48 & 178 \\ \text { Containers } & 31,500 & 90 & 414 & 14\end{array}$

The moment of inertia of the combined trailer and payload is $92.3 \times 10^{9} \mathrm{lb}-\mathrm{ft}^{2}$.

Using the values determined in the previous section for the forces acting on the various components of the tractor and trailer the equations of motion for the trailer are:

$$
\begin{gathered}
\mathrm{a}_{\mathrm{x}}=-10.82 \cos \theta-13.17 \frac{\mathrm{ft}}{\mathrm{sec}^{2}}, \\
\mathrm{a}_{\mathrm{y}}=0 \frac{\mathrm{ft}}{\sec ^{2}}, \\
\text { and } \alpha_{\mathrm{cg}}=2.5 \times 10^{-5} \sin \theta+0.55 \times 10^{-6} \frac{\mathrm{radians}}{\mathrm{sec}^{2}} .
\end{gathered}
$$

Solving the equations for the translation and rotation of the center-of-gravity results in the motions of the trailer that are depicted in Figure 5.7. The direction of the force at the kingpin between the tractor and trailer was assumed to follow the path that is shown in the initial portion of Figure 5.7. The direction of this force has been assumed to abruptly change direction when the tractor impacted the barrier or guardrail to maximize the likelihood that the trailer would swing to the point where the trailer impacted on either the guardrail or barrier.

The predicted motion of the trailer supports the conclusion that the trailer did not swing into the guardrail or concrete barrier when the tractor impacted the guardrail or outer barrier. The photographic evidence that indicate no impacts other than the front of the tractor which is consistent with the results of this analysis. 


\subsubsection{Container Impact Analysis}

One of the major elements in the assessment of the performance of the containers during this accident is the evaluation of the magnitude of the forces acting on the containers during any impacts that might have occurred. The previous analyses of the tie downs and trailer dynamics indicated that the containers were subjected to impact forces in the one-to two-g range. However, the containers were subjected to much higher impact forces when they fell off the trailer. The video tapes of the fire portion of the accident give a clear indication that the containers that were loaded on the rear of the trailer fell off the trailer during the fire which provides a clear upper bound on the container energy when it impacted on the roadway.

There are four possible combinations of conditions that could exist when a container fell off the trailer, which are:

- The wooden outer container was intact at the point of impact so the honeycomb and Ethafoam were capable of absorbing energy.

- The wooden outer container was consumed by the fire prior to the impact so the energy must be dissipated by crushing the inner container.

- The wooden outer container was partially consumed by the fire so the container slid off the trailer, landing on one end followed by a pivoting type of fall to a horizontal position.

The first two possibilities will be evaluated to provide bounds upon the impact forces that could have been experienced by the containers as they fell from the trailer during the fire.

The most severe impact was for the container that was in the top layer of containers on the left side (driver's side) of the trailer. The video tapes of the fire show this container and the one below it fell off the trailer as a unit and did not separate until the containers were approximately horizontal and the containers had rotated $90^{\circ}$. During the remainder of the fall, both containers rotated an additional $90^{\circ}$ such that the total rotation was $180^{\circ}$ and both containers landed on their tops. The top container landed several $\mathrm{ft}$ from the trailer while the bottom container came to rest leaning against the tire on that side of the trailer. The separation between the containers was not enough to allow another container to reach the roadway when it fell off the trailer. The final container was suspended about one $\mathrm{ft}$ above the roadway until the wooden outer containers burned away and then the final container slowly dropped onto the roadway.

The top container fell through a distance of $85 \mathrm{in.}$ ( $31 \mathrm{in.}$ from the top of the bottom container to the trailer bed and 54 in. from the trailer bed to the roadway) which resulted in an impact velocity of:

$$
\mathrm{V}=\sqrt{2 \mathrm{gh}}
$$

where:

$\mathrm{V}$ is the impact velocity in in. per sec.

$\mathrm{g}$ is the acceleration due to gravity in in/ $\mathrm{sec}^{2}$.

$h$ is the height of the free fall in in.

Introducing numerical values gives:

$$
V=\sqrt{232.168512}=256.1 \mathrm{in} . / \mathrm{sec} .
$$


and the kinetic energy at the time of impact was:

$$
E=\frac{W V^{2}}{2}=W h
$$

where:

$E$ is the kinetic energy of the container at the point of impact.

$\mathrm{W}$ is the weight of the impacting object.

If the honeycomb is intact at the time of impact, the kinetic energy of the container is absorbed by crushing of the honeycomb within the wooden outer container. The relationship between the kinetic energy of the container and the work required to crush the honeycomb is:

$$
W h=\int_{0}^{X} F d x=A_{i} \int_{0}^{X} \sigma_{c} d x
$$

where:

$F$ is the force required to crush the honeycomb in $l b$.

$A_{i}$ is the area of the top of the inner container.

$\sigma_{c}$ is the crush strength of the honeycomb.

$\mathrm{X}$ is the crush depth in in.

A typical crush strength vs crush depth curve for honeycomb has an initial peak which is usually bypassed by precrushing the honeycomb to a depth beyond the peak crush strength. After the initial peak, the crush strength is essentially independent of crush depth until the honeycomb approaches solid (about $70 \%$ of the original thickness). The integral in the above expression can be evaluated analytically and the expression becomes:

$$
\mathrm{Wh}=\sigma_{\mathrm{c}} \mathrm{A}_{\mathrm{i}} \mathrm{X}
$$

Solving for the crush depth gives:

$$
X=\frac{W h}{\sigma_{c} A_{l}}
$$

Introducing numerical values:

$$
\begin{array}{rlrl}
W_{f} & =610 \mathrm{lb} \text { for a fuel assembly, } & & \sigma_{c}=110 \mathrm{psi}, \\
W_{i p} & =610 \mathrm{lb} \text { for the inner container, } & A_{i}=179.5 \cdot 18.125 \text { square in., and } \\
h & =85 \text { in. free fall height. } &
\end{array}
$$

The crush depth is:

$$
X=\frac{(2610+610) 85}{110(179.518 .125)}=0.435 \text { in }
$$


Since this is small compared to the dimension where the honeycomb changes from an open structure to a solid mass, the assumption that the crush strength was independent of crush depth is appropriate. At this point it is also possible to assess the impact force on the inner container during this impact. The impact force is the product of the crush stress and the impact area which is:

$$
\mathrm{F}=110(179.518 .125)=357,900 \mathrm{lb} \text { or } 195 \mathrm{~g},
$$

or expressed in terms of the weight of the container:

$$
F=\frac{357900}{(2610+610)}=195 \mathrm{~g} .
$$

This analysis did not include the Ethafoam which would also absorb energy as it is compressed. The Ethafoam would compress before the honeycomb begins to crush until the force required to compress the Ethafoam equaled the force required to crush the honeycomb. After this point, the honeycomb will crush and the Ethafoam will remain partially compressed. The result of this sharing of the energy absorption is overprediction of the crush depth of the honeycomb; however, the force required to crush the honeycomb will not change so the maximum deceleration of the inner container will remain as predicted above.

If the honeycomb has combusted and is not available to absorb energy, the energy absorption mechanism will be crushing and/or buckling of the steel of the inner container. Under these conditions, the energy absorption is expressed as:

$$
W h=\int_{0}^{X} \sigma A d x
$$

where:

$\sigma$ is the crush strength of the steel.

$X$ is the total crush distance.

$A$ is the cross section area of the members that are crushing.

If the steel remains in the elastic range, the stress is proportional to the strain or:

$$
\sigma=\mathrm{E} \frac{\mathrm{x}}{\mathrm{L}} \text {. }
$$

This can be combined with the integral for the energy absorbed

$$
W h=\frac{A E}{L} \int_{0}^{X} x d x .
$$

This integral can be integrated analytically resulting in the expression:

$$
W h=\left.\frac{A E}{L} \frac{x^{2}}{2}\right|_{x} ^{0} .
$$


Solving for the crush depth gives:

$$
X=\sqrt{\frac{2 W h L}{A E}} .
$$

The side of the lid is the member that must absorb the energy because the remainder of the container (bottom, fuel assemblies, etc.) represent the masses that have the energy that must be absorbed. Introducing numerical values for the carbon steel inner container impacting on its lid so the sides of the lid compress:

$$
\begin{array}{rlrl}
W & =1,830 \mathrm{lb}, & \mathrm{L} & =2 \mathrm{in} ., \\
\mathrm{h} & =85 \mathrm{in} ., & \mathrm{E}=30 \times 10^{6} \mathrm{psi}, \text { and } \\
\mathrm{A} & =2(179.5+18.125) & 0.059=23.320 \text { square in. }
\end{array}
$$

The resulting value for the compression, $\mathrm{X}$, is 0.0298 in. At this compression the strain is $1.48 \%$ and the stress is 447,000 psi. This stress is well beyond yielding for this material $\left(\sigma_{y}=33,000\right.$ psi) so the integrand must be revised to reflect the discontinuity in the stress-strain curve at the yield strength as follows.

$$
\mathrm{Wh}=\int_{0}^{\text {yield }} \sigma_{\mathrm{e}} \mathrm{Adx}+\int_{\text {yield }}^{\mathrm{X}} \sigma_{\mathrm{e}} \mathrm{A} d \mathrm{x}
$$

For the purposes of this approximation, the carbon steel will be assumed to behave as an elastic, perfectly plastic material where the stress cannot exceed the yield strength. Under this condition, the maximum force acting on the inner container will be:

$$
\mathrm{F}=\sigma_{\mathrm{y}} \mathrm{A}=33,000 \quad 23.230=770,000 \mathrm{lb} \text { or } 420 \mathrm{~g} .
$$

It is also possible that the steel plates in the inner container will buckle rather than crush. The force required to buckle a plate with edge loads is given by (Timoshenko, 1961).

where:

$$
\sigma_{b}=\frac{\pi^{2} E t^{2}}{12 b^{2}\left(1-v^{2}\right)}\left[\frac{b}{a}+\frac{a}{b}\right]^{2},
$$

$\sigma_{\mathrm{b}}$ is the stress that causes the plate to buckle rather than crush.

$E$ is the modulus of elasticity.

$v$ is Poisson's ratio.

$a$ is the height of the plate.

$b$ is the length of the plate between supports.

$t$ is the thickness of the plate.

Introducing numerical values for the carbon steel sides of the lid gives:

$$
\begin{array}{lr}
\mathrm{a}=2 \mathrm{in.}, & \mathrm{t}=0.059 \mathrm{in} . \\
\mathrm{E}=30 \times 10^{6} \mathrm{psi}, & v=0.3, \text { and } \\
\mathrm{b}=28.50 \mathrm{in} . & \sigma_{\mathrm{b}}=23,800 \mathrm{psi} .
\end{array}
$$


The force that is exerted on the container is the stress times the area which includes the side and end plates.

$$
\mathrm{F}=\sigma_{\mathrm{b}} \mathrm{A}=23,80023.320=556,000 \mathrm{lb} \text { or } 304 \mathrm{~g}
$$

This analysis is very conservative because it has been assumed that all of the weight of the inner container is acting on the side of the lid which is the component that will fail due to buckling. In reality, the angles that brace the sides and top of the inner container will transfer a large fraction of the impact forces directly from the fuel assembly to the impact surface (top of the inner container) without requiring the side of the lid to support all of the force. Consequently, impact loads much larger than $304 \mathrm{~g}$ will be required to cause the side of the lid of the inner container to fail by buckling.

In summary, the analyses presented here have indicate that an impact on the lid of the inner container would crush the Ethafoam and honeycomb $(195 \mathrm{~g})$ if these components had not been damaged by the fire. However, if the Ethafoam and honeycomb were consumed by the fire, the side of the lid of the inner container would fail by buckling at a load in excess of $304 \mathrm{~g}$.

\subsubsection{Evaluation of Container Resting on Guardrail}

The most severely damaged inner container was observed to have one end resting on the guardrail and the other end resting on the roadway. In addition, another container was partially resting on the end which was on the guardrail. Marks on the most severely damaged container indicated that it was in contact with a burning tire for some period of time at the location of the maximum deformation. The location of maximum deformation was about one third of the length of the container from one end and can be characterized as distortion from a rectangle into a parallelogram with a transverse crease in one corner of the container.

The analyses that follow attempt to demonstrate that the deformation is consistent with the static loads that were applied to this container following its fall from the trailer and no damage should be attributed to any impact between the truck and the guardrail at the conclusion of the impact portion of the accident. The container is treated as a beam that is initially resting on the roadway at one end and resting on or leaning against the top of a tire about one third of the length of the container from the guardrail. When the containers fell from the trailer, the second container probably was resting on the edge of the damaged container but not resting on the guardrail. Probably, the second container did not contact the guardrail until the first container deformed, giving the missimpression that both containers were resting on the guardrail during the entire fire. Top and side views of these two containers are as shown below both before and after the bottom container deformed.
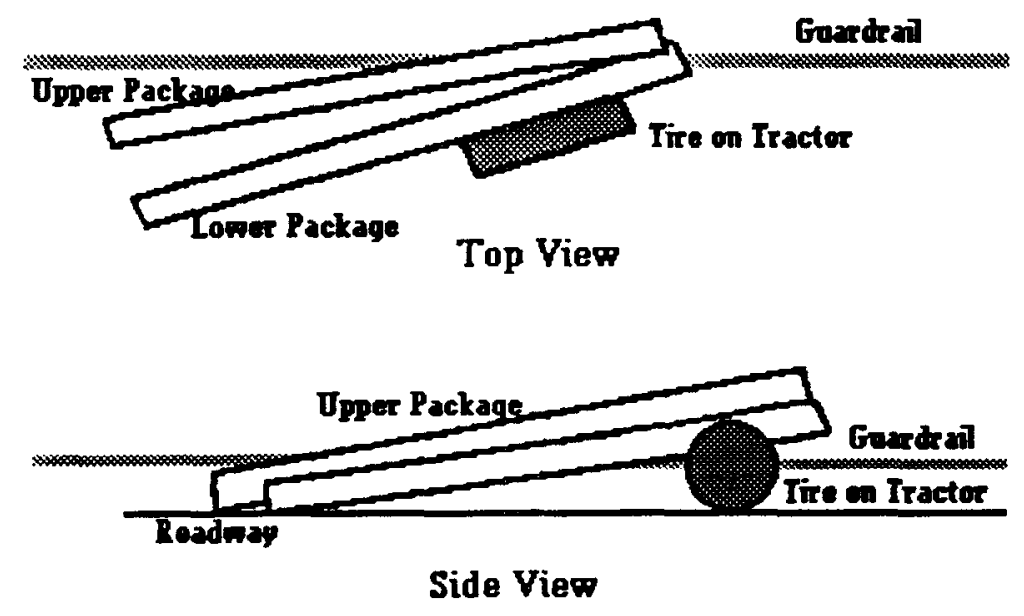

The free-body diagram for the upper and lower containers are:

where:

$F_{1}$ is the reaction force where the upper container rests on the roadway,

$F_{2}$ is the reaction force where the upper container rests on the lower container, 
$F_{3}$ is the reaction force where the lower container rests on the lower container,

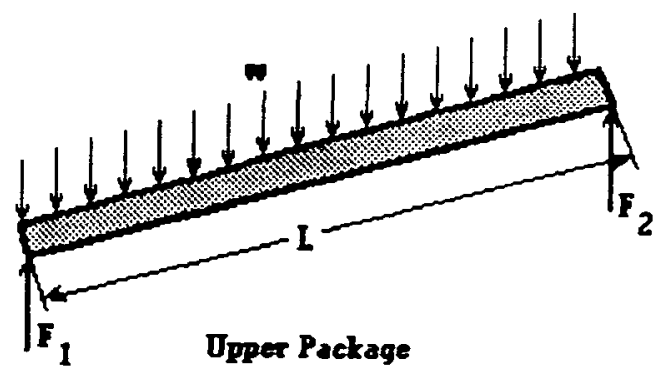

$F_{4}$ is the reaction force where the lower container rests on the tire of the tractor,

$w$ is the weight per unit length of a single container,

$\mathrm{L}$ is the length of a single container, and

$a$ is the distance between the end of the lower container and the tire.

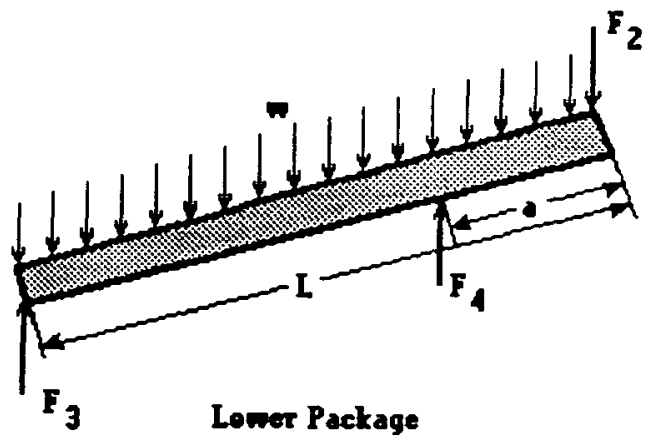

The reaction forces, $F_{1}, F_{2}, F_{3}$, and $F_{4}$ can be determined from equations that represent equality of vertical forces and quality of moments about the lower ends of the two containers. The resulting expressions for the reaction forces are:

$$
\begin{aligned}
& F_{1}=\frac{w L}{2}, F_{2}=\frac{w L}{2}, \\
& F_{3}=3 \frac{w L}{2}-\frac{w L^{2}}{(L-a)}, \quad F_{4}=\frac{w L^{2}}{(L-a)} .
\end{aligned}
$$

The force of the roadway on the end of the lower container becomes zero when the distance between the tire and the end of the container becomes L/3. If the distance between the point of support on the tire and the end of the container exceeds $L / 3$ the lower container will be lifted off the roadway. Under these conditions, the equilibrium equations can no longer be satisfied and the container would not be in equilibrium. Consequently, the point of support on the tire (a) is limited to $1 / 3$ of the length of the container.

The shear force at any position along the beam is determined from equality of forces perpendicular to the beam with the beam truncated at any length (Roark, 1975). The expressions for the shear
forces are:

$$
\begin{gathered}
\mathrm{Q}=\left(\frac{w \mathrm{~L}}{2}-w \mathrm{x}\right) \cos \theta \text { if } \mathrm{x}<\mathrm{L} \text { in the package, } \\
\mathrm{Q}=\left(\frac{3 w \mathrm{~L}}{2}-\frac{w \mathrm{~L}^{2}}{(\mathrm{~L}-\mathrm{a})}-w \mathrm{x}\right) \cos \theta \text { if } \mathrm{x}<\mathrm{L}-\mathrm{a} \text { in the lower package, } \\
\mathrm{Q}=\left(\frac{3 w \mathrm{~L}}{2}-\mathrm{wx}\right) \cos \theta \text { if } \mathrm{L}-\mathrm{a}<\mathrm{x}<\mathrm{L} \text { in the lower package. }
\end{gathered}
$$


The moment at any position along the beam is determined from equilibrium of moments with the beam truncated at any length. The expressions for the moments are:

$$
\begin{gathered}
M=\left(\frac{w \times L}{2}-\frac{w x^{2}}{2}\right) \cos \theta \text { if } x<L \text { in the upper package. } \\
M=\left(3 \frac{w \times L}{2}-\frac{w \times L^{2}}{(L-a)}-\frac{w x^{2}}{2}\right) \cos \theta \text { if } x<L-a \text { in the lower package, } \\
M=\left(3 \frac{w \times L}{2}-w^{2}-\frac{w x^{2}}{2}\right) \cos \theta \text { if } L-a<x<L \text { in the lower package. }
\end{gathered}
$$

The shear forces and moments are plotted as a function of position along the beam in Figure 5.8. The maximum moment occurs at $\mathrm{x}=(\mathrm{L}-\mathrm{a})$ and is:

$$
\mathrm{M}_{\max }=\left(3 \frac{\mathrm{w}(\mathrm{L}-\mathrm{a}) \mathrm{L}}{2}-\mathrm{wL}^{2}-\frac{\mathrm{w}(\mathrm{L}-\mathrm{a})^{2}}{2}\right) \cos \theta \text {. }
$$

The maximum shear stress and maximum moment for both containers are plotted in Figure 5.9 as a function of the distance between the end of the upper container and the point where it is supported on the tire.

The stress in the inner container is the product of the moment, distance between the centroid and the moment of inertia as:

$$
\sigma=\frac{\mathrm{Mc}}{\mathrm{I}}
$$

When the lower container is assumed to rest on the tire at a location $50 \mathrm{in}$. from the end of the container, the maximum moment is $58,000 \mathrm{in}-\mathrm{lb}$, the moment of inertia of the inner container about an axis that passes through a corner of the cross section of the container at an angle of $45^{\circ}$ to the sides of the container is $1488 \mathrm{in}^{4}$ and the distance from this axis to the extreme fiber of the container is $21 \mathrm{in}$. These values give a maximum stress of $818 \mathrm{psi}$.

The container which suffered the extreme damage was located adjacent to a burning tire which had a flame temperature near $1800^{\circ} \mathrm{F}$ with flame characteristics that should have produced a high flame emissivity. Consequently, after 0.5 hour exposure to the burning tires, the metal temperature in this container should have been close to $1800^{\circ} \mathrm{F}$. The temperature dependence of the yield strength and ultimate strength of carbon steel are presented in Figure 5.10 as a function of temperature. Properties have been extracted from Appendix I of Section III of the ASME Boiler and Pressure Vessel Code and from the Mil Handbook to provide the strength of carbon steel up to $1200^{\circ} \mathrm{F}$. However, above $1200^{\circ} \mathrm{F}$ there is very little tabulated data. The ultimate strength of armco iron has been reported for temperatures exceeding $1200^{\circ} \mathrm{F}$ and has been used to extrapolate the data from the MIL-HDBK to temperatures approaching $1800^{\circ} \mathrm{F}$. At temperatures between $1700^{\circ} \mathrm{F}$ and $1800^{\circ} \mathrm{F}$, the yield strength of carbon steel approaches 800 psi. Consequently, the inner container which was resting on the tire would fail in bending when the tire was involved in the fire and producing flame temperatures in the vicinity of $1800^{\circ} \mathrm{F}$. 


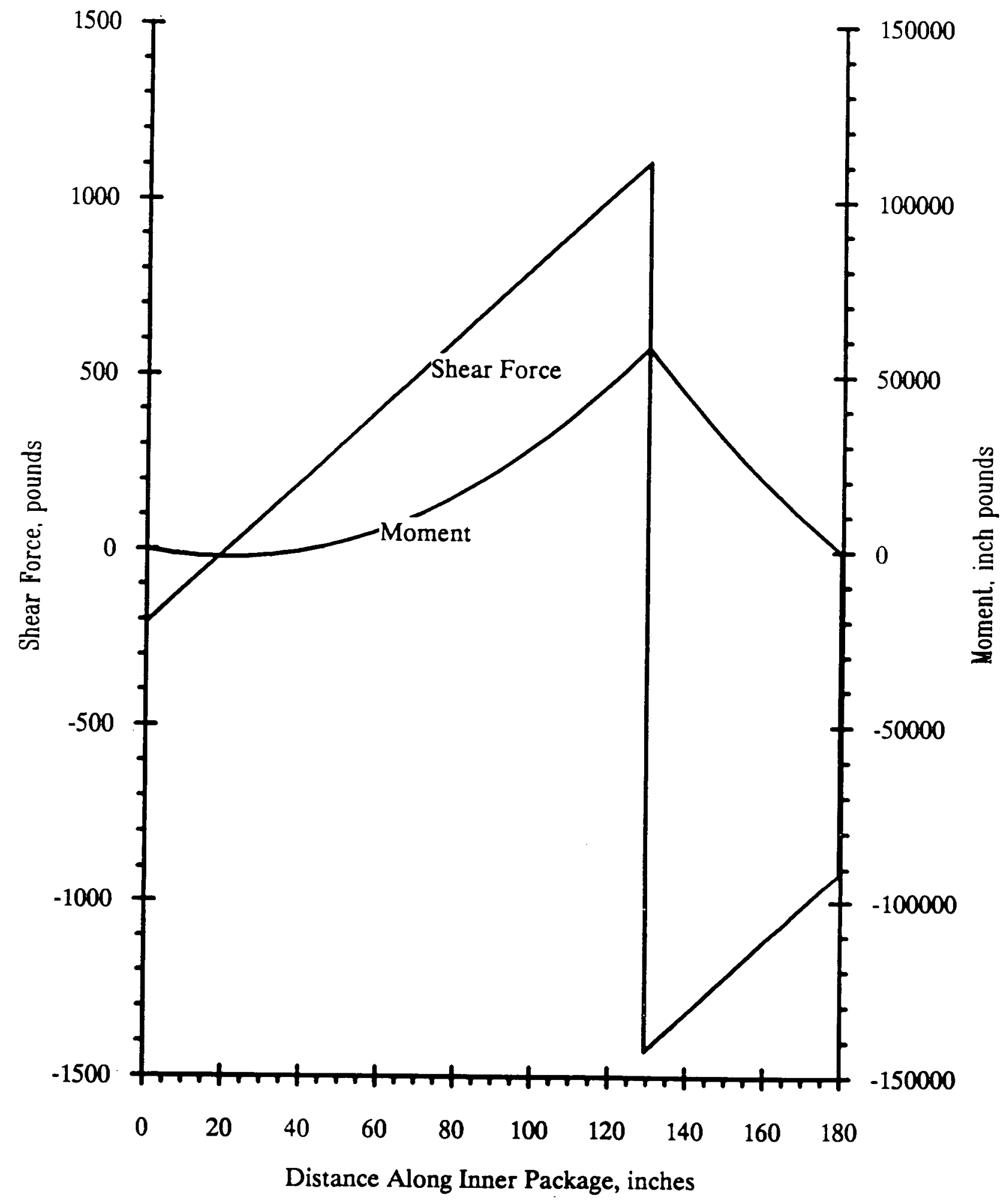

Figure 5.8 Shear Force and Moment Distribution in Beam Model of Container Supported by Guardrail 


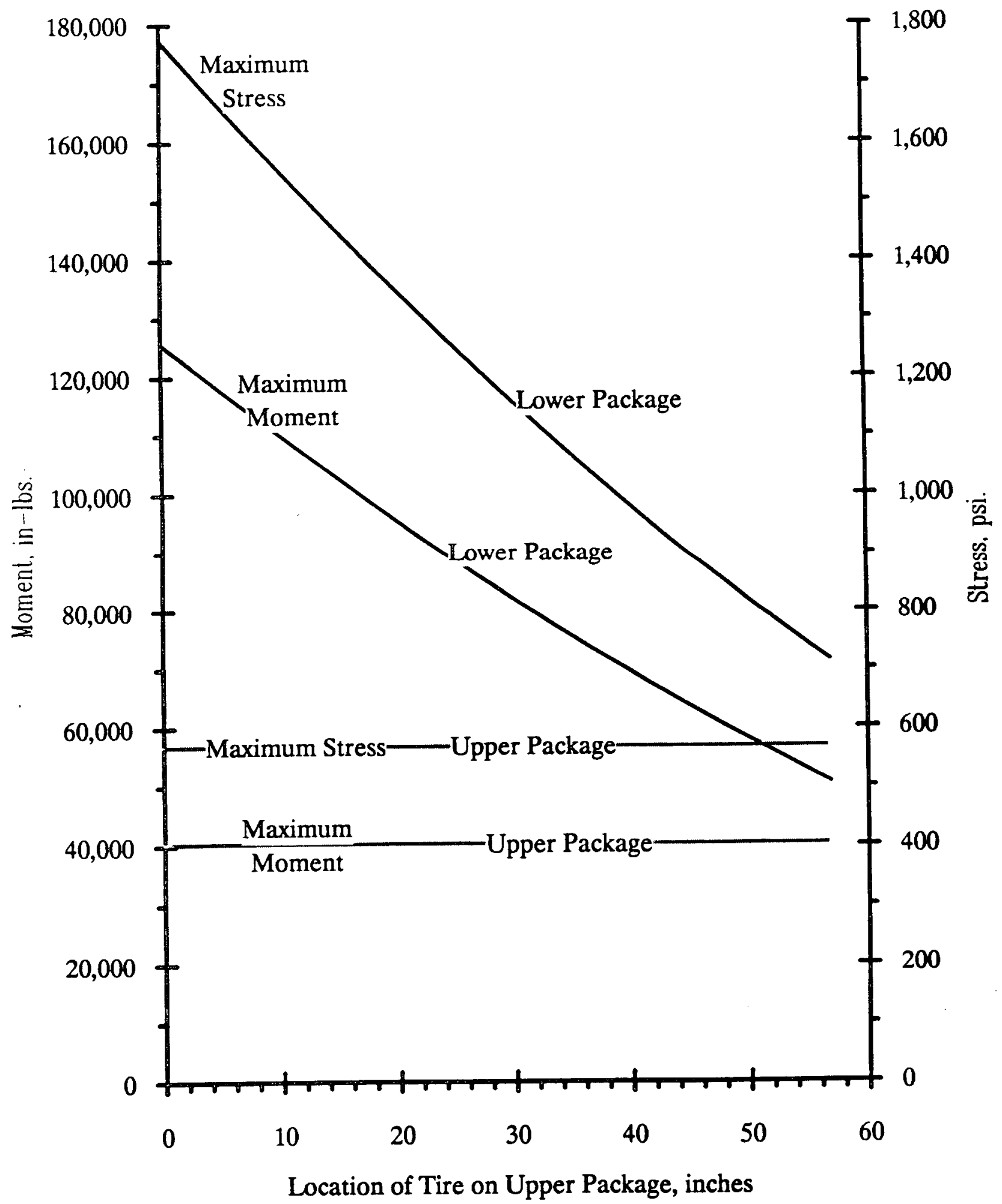

Figure 5.9 Maximum Shear Force and Moment in Beam Model of Container Supported by Guardrail 


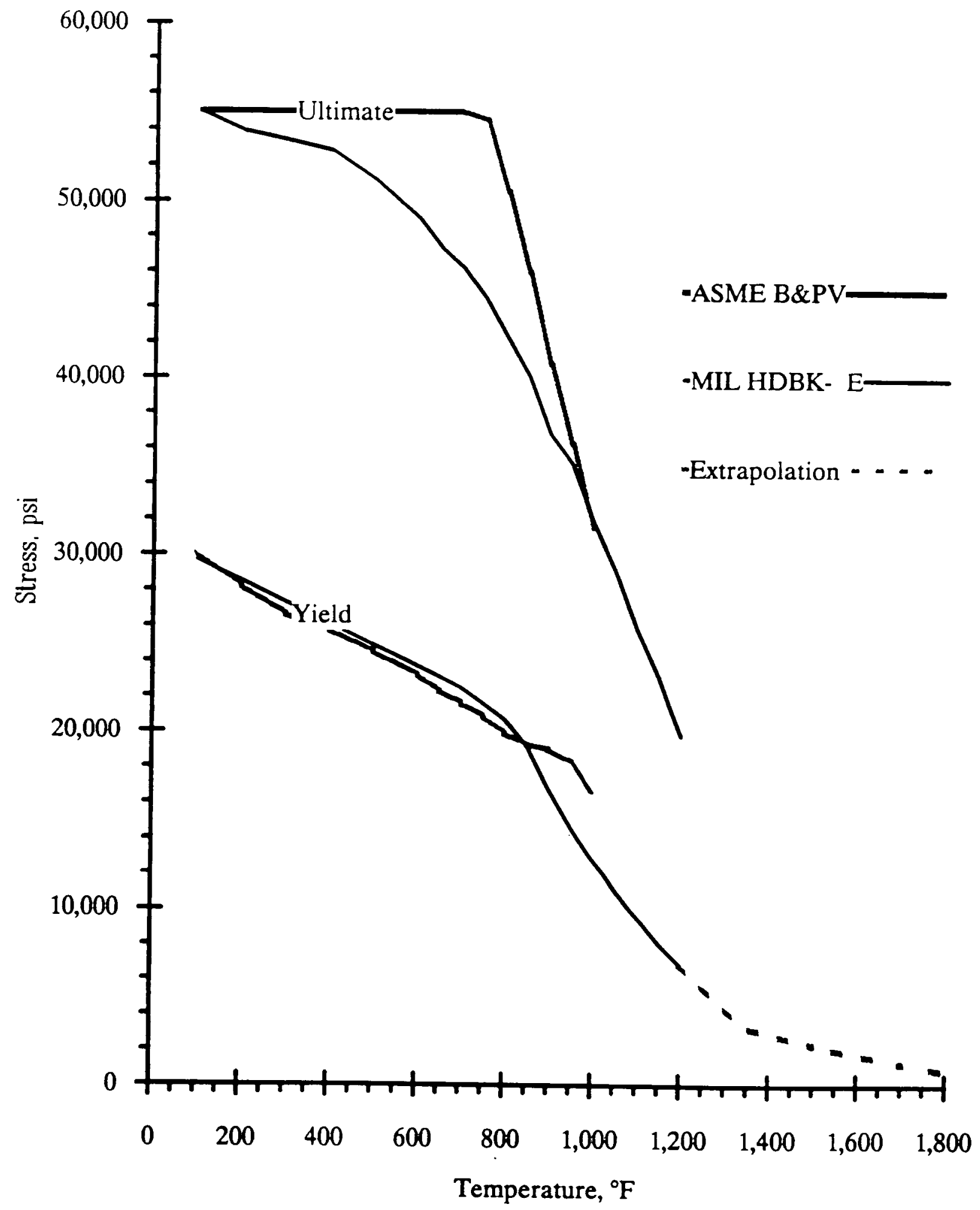

Figure 5.10 Temperature Dependence of Strength of Steel 
The maximum moment in the upper container of the two that were adjacent to the burning tire was 40,000 in.-Ib when the tire supports the lower container at $50 \mathrm{in}$. from the end of the lower container. The maximum moment in the upper container is presented in Figure 5.9 for comparison to the maximum moment in the lower container.

The maximum moment in the upper container is less than the maximum moment in the lower container and results in a maximum stress in the inner container of $570 \mathrm{psi}$. Both the maximum moment and maximum stress are independent of the location of the support of the lower container on the tire.

The stress in the upper container does not exceed the yield strength of the carbon steel because the temperature of the upper container is substantially cooler than the lower container because the upper container is over 18 in. away from the burning tire. This separation will reduce the heat transfer from the burning tire to the upper container which will limit the temperature of the upper container to less than $1800^{\circ} \mathrm{F}$ which, in turn, will result in a yield strength that is larger than 1,000 psi. Consequently, the upper container should not suffer a bending type of failure as was the case with the lower container.

The results of this analysis confirm the hypothesis that the container that suffered the most severe deformation was resting on the tire at the time that the tire ignited and the temperature of the flames originating from the tire were close to $1800^{\circ} \mathrm{F}$. In addition, this analysis indicates that the deformation to the most severely damaged container uccurred during the fire and not during an impact.

\subsubsection{Kinematic Analysis of the Containers as They Fall}

Prior to the start of the accident, all of the containers were on the trailer, protected by a tarpaulin and secured in place by nylon straps. At the conclusion of the fire four containers remained on the trailer and eight containers were lying on the roadway, five between the trailer and the guardrail and three on the other side of the trailer. One of the major issues to be addressed in this study is the mechanism that permitted the containers to leave the trailer and fall to the roadway. The video tapes of the rear of the trailer clearly show all of the rear end of the containers as they fall. However, the opacity of the flames prevents any visual record of the motion of either the front containers or the motion of the front of the rear containers. Consequently, the following kinematic analysis is presented to characterize the motion that the containers must have endured as they moved from their initial position to their positions at the conclusion of the fire.

\subsubsection{Fall From Trailer to Roadway}

The video tapes of the rear of the trailer indicate that the primary mechanism for a container falling from the trailer to the roadway was the reduction in strength of the front of the container resting on the trailer. This allowed the upper container to tip toward the front of the trailer and toward the outside of the trailer. When the center-of-gravity of the upper container reached a point where sliding was possible, the upper container would slide outward and forward until the front end of the container reached the roadway. At this point, the container would fall until it was entirely on the roadway. This sequence of events is summarized in Figure 5.11. The choice of the rear container on the left side of the trailer to illustrate the motion of a container as it fell from the trailer was arbitrary to enhance clarity of the sketches. In fact, this particular container did not fall from the trailer in the manner described in this figure as will be discussed below.

The kinematics described in Figure 5.11 is consistent with the observation that the final resting position of a majority of the containers was closer to the front of the truck than the initial position 


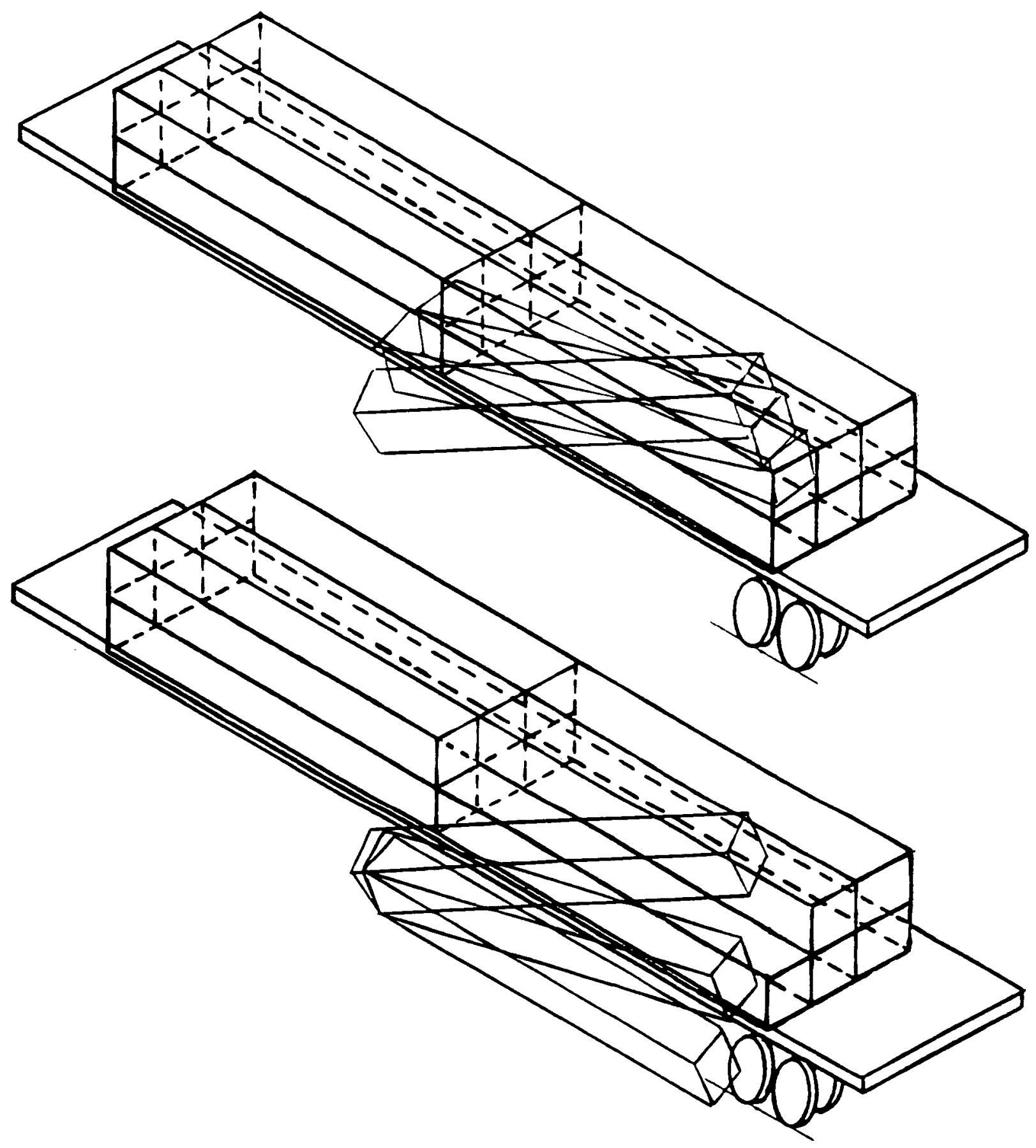

Figure 5.11 Motion of Container Falling off Trailer During Fire 
of the container. As the container is tipping off the container beneath, it will begin to slide down the inclined plain that is formed by the deformed end of the lower container. Since the fire progressed from the front of the truck to the rear, the front end of the containers will be deformed first, causing any container motion to be toward the front of the truck.

The kinematics described in Figure 5.11 does not address the motion of the two containers at the left rear of the trailer. These two containers fell as a coupled pair, until they had rotated about 90 degrees and both containers were about at the height of the trailer. At this point the containers separated and the container that was originally on top moved further away from the trailer and the container that was originally on the bottom fell and rested against the tire of the trailer.

\subsubsection{Fall of Inner Container within Outer Container}

Several of the inner containers were resting at an angle of $45^{\circ}$ at the conclusion of the fire. This included one of the containers that remained on the trailer which apparently experienced no fall. The explanation that best fits the available evidence suggests that the inner container experienced a fall while it was inside the outer container.

The configuration of the inner and outer containers before the fire is shown in Figure 3.3. It is possible for the plywood to burn through along one side and the paper honeycomb on that side of the container would be consumed by the flames. Additionally, if part of the paper honeycomb in the bottom of the container were to be consumed by flames, it would be possible for the inner container to roll, or fall, onto a corner as shown in Figure 5.12. The mechanics of combustion are sufficiently complex that it is impossible to predict the occurrence of conditions that would cause this type of damage within the outer container so this must be left as a hypothesis.

The same mechanics would apply if the outer container had rotated such that it was resting on its lid. In both cases, this is a very gentle impact because the Ethafoam will provide cushioning for the 3 to 6 in. fall. Even if the Ethafoam has been consumed by the fire, the fall has very little energy because it is a rotational fall and the distance is very small.

\subsection{Estimate of Thermal Container Environment}

The dominant element of this accident was the fire that lasted for about three hours and consumed almost all of the combustible materials on the truck. The fire affected the packages with the fuel assemblies for about two hours and had locally very high temperatures. Consequently, it is important to both assess the consequences of the fire on the packaging and its contents and to attempt to define the characteristics of the fire.

\subsubsection{Estimate of Fire Temperatures}

Intense heating was evident around the rear wheels (also front support of the trailer) of the tractor. The fire department estimated the flame temperature to be about $1500^{\circ} \mathrm{F}$ but the fact that one of the leaf springs at the rear of the tractor had annealed to the point where its curvature was reversed suggests a flame temperature closer to $2000^{\circ} \mathrm{F}$. Almost all aluminum parts (melting temperature $1100^{\circ} \mathrm{F}$ to $1300^{\circ} \mathrm{F}$ ) in this portion of the tractor melted and there were some suggestions that steel components (melting temperature above $2000^{\circ} \mathrm{F}$ ) were beginning to melt.

Fire started in the engine, progressed to entire tractor, then to trailer and containers. At this point the entire tractor, trailer, and contents were fully engulfed by the fire. As the fuels began to be depleted, the fire on the tractor extinguished, the fire on the containers on the roadway extinguished, the fire on the trailer extinguished, the fire on the containers on the trailer extinguished, and the fire of the tires on the trailer extinguished. 


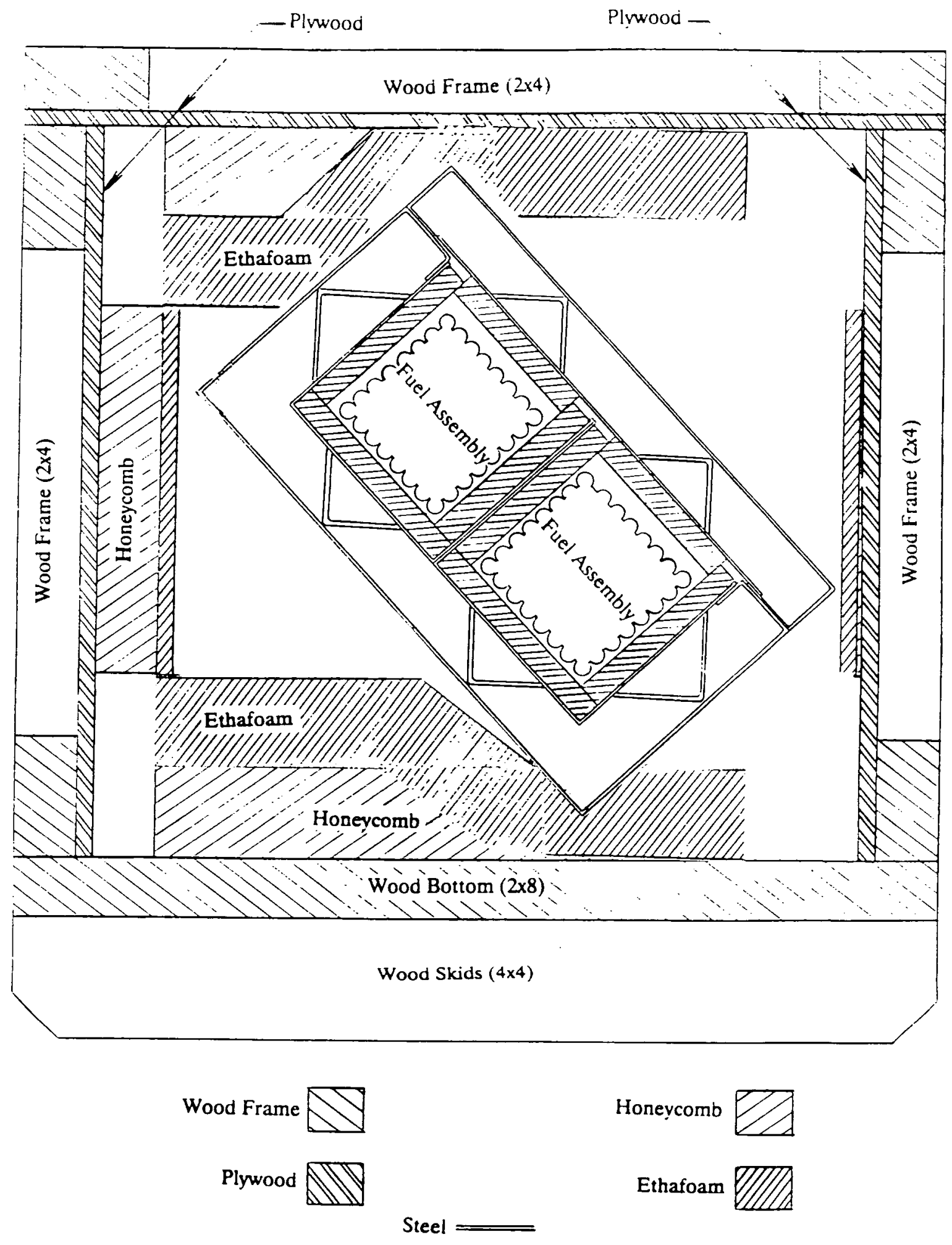

Figure 5.12 Possible Rotation of Inner Container Within Outer Container 
The ignition temperatures and flame temperatures for combustion of many of the materials involved in the fire portion of this accident are presented in Table 5.1. The flame temperatures represent the combustion of that material in an open fire (with no wind) such that the oxygen reaching the source of combustion is governed only by natural circulation in the presence of the fire. The fire following the accident could have had much larger air velocities due to the size and intensity of the fire. If this were so, the flame temperatures could have been several hundred degrees hotter than indicated in Table 5.1 due to the increased availability of oxygen. Conversely, the flame temperature at the very center of the fire could have been lower than the values indicated in Table 5.1 due to the starvation of oxygen that naturally occurs at the center of a large fire when the oxygen is preferentially consumed by combustion at the periphery of the fire.

One of the significant materials that was involved in the combustion of the tractor is aluminum which is not included in Table 5.1. The skin of the cab was fabricated from aluminum which will melt if its temperature is in the range from $1100^{\circ} \mathrm{F}$ to $1300^{\circ} \mathrm{F}$. However, if the temperature is in the vicinity of $5000^{\circ} \mathrm{F}$ the aluminum vaporizes. The most likely scenario lies between these extremes and involves the aluminum reacting with oxygen to form aluminum oxide $\left(\mathrm{Al}_{2} \mathrm{O}_{3}\right)$ which will be a powder and either settle to the roadway or be swept away in the smoke plume. This reaction occurs at all temperatures including room temperature so a flame temperature is not definable. However, it is certain that the presence of thin sections of aluminum contributed to the intense temperatures in the flames originating in the cab portion of the tractor.

A sketch of tractor and trailer with locations of various flame temperatures is presented in Figure 5.13. This sketch is based upon the damage to the tractor, trailer and wind direction during the fire.

Table 5.1 Ignition Temperatures and Flame Temperatures for Flammable Materials in Tractor-Trailer and Containers

\begin{tabular}{lcc}
\hline & Ignition Temperature & Flame Temperature \\
\hline Material & ${ }^{\circ} \mathrm{F}$ & ${ }^{\circ} \mathrm{F}$ \\
Wood & $>600$ & 1290 to 1475 \\
Plywood & 730 & 1290 to 1475 \\
Paper & $\sim 500$ & - \\
Plastic & 1160 & 1290 to 1475 \\
Ethafoam & 730 & - \\
Rubber & $>500$ & 1740 to 1830 \\
Nylon & 850 & - \\
Epoxy Paint & 400 to 480 & - \\
Diesel Fuel & 490 to 545 & 1740 to 1830 \\
Asphalt & $\sim 900$ & 1560 to 1650 \\
\hline
\end{tabular}

The fuel for the flames that surrounded the containers was primarily wood from the outer containers and the wood in the bed of the trailer. The flame temperature for a wood fire is about $1300^{\circ} \mathrm{F}$. However, some of the containers were adjacent to tires as they burned and experienced flame temperatures over $1800^{\circ} \mathrm{F}$. 


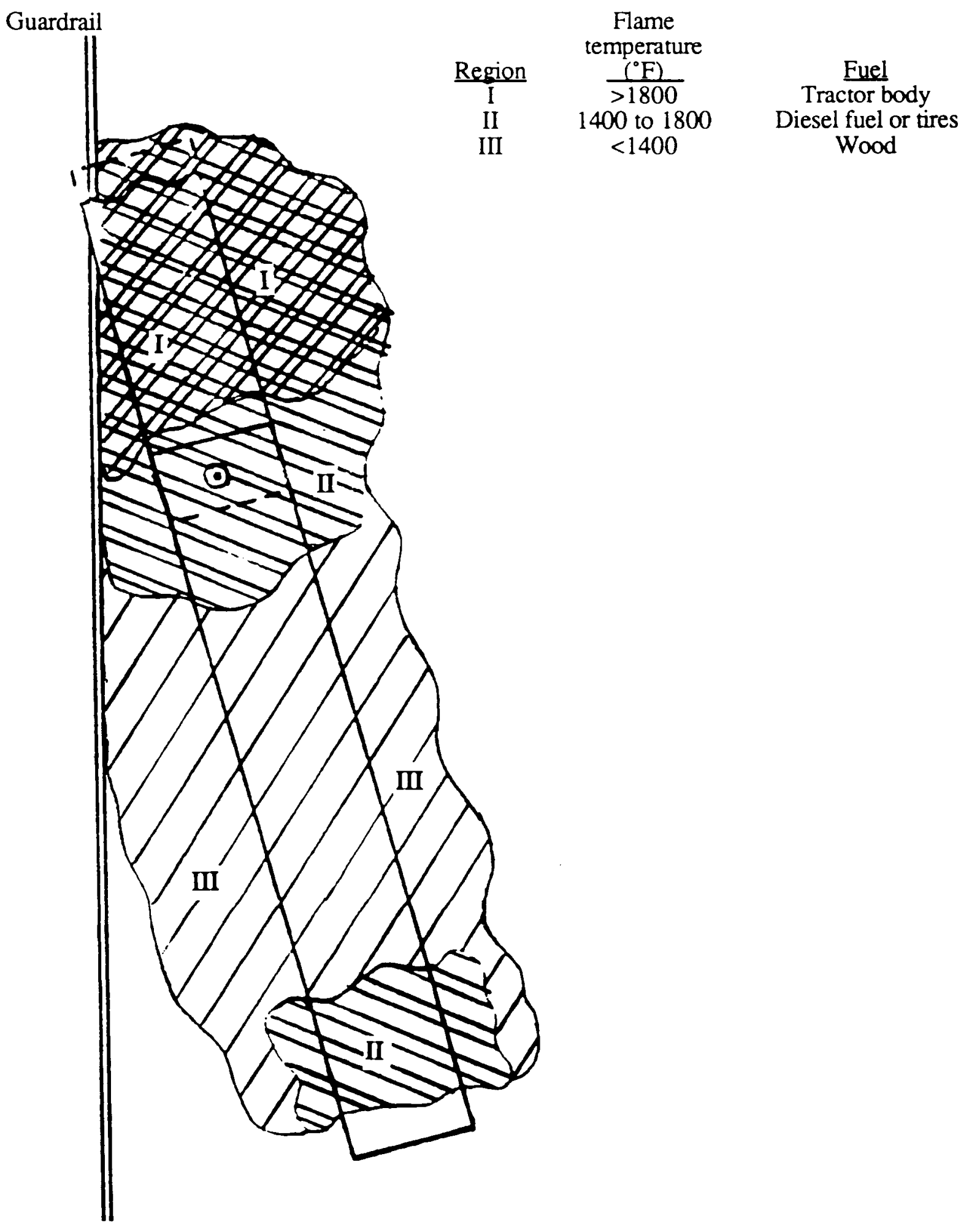

Figure 5.13 Flame Temperature Distribution During Fire 


\subsubsection{Evaluation of Transient Heat Conduction in Outer Container}

The video tapes of the rear of the trailer indicate that the outer containers were essentially intact when they fell from the trailer which would imply that the honeycomb remained capable of absorbing energy when the container impacted on the roadway. Combustion of the outer container was evident after the containers were lying on the roadway. The following analysis is an attempt to verify the viability of the honeycomb by demonstrating that the plywood acts as an insulator to protect the honeycomb until long after the containers fell from the trailer. The analyses of the impact presented previously, indicate that the honeycomb limits the impact forces to $195 \mathrm{~g}$ while absence of the honeycomb would require buckling of the side of the lid of the container to be the primary mechanism for impact energy absorption and the impact forces would be about $300 \mathrm{~g}$.

To study the transfer of heat within the outer container, a one-dimensional, transient analysis of plywood outer container was prepared with a radiant energy source outside container and adiabatic surface at the inside of the plywood. The objective of this calculations is to determine if plywood or paper honeycomb reaches ignition temperature first. If plywood reaches its ignition temperature first, then the honeycomb will be assured to be in place when the containers fall off truck because it appears that the plywood has not reached its ignition temperature when the containers fall off the truck.

The one dimensional heat conduction equation to be solved is (Holman, 1976):

$$
k \frac{d^{2} T}{d x^{2}}=\rho c_{p} \frac{d T}{d t} .
$$

The boundary conditions for the solution of this equation are a combination of convection and radiation heat transfer to the flames at the outside of the container and an adiabatic surface at the inside of the container. An adiabatic surface was chosen to represent the interface between the plywood and the paper honeycomb at the inner surface of the plywood. The principal thermal effect of the honeycomb is to prevent convection in the air that is trapped inside the honeycomb. Thus, the honeycomb becomes a very good insulator because the thermal conductivity of stationary air is very low when compared to the thermal conductivity of the plywood. An additional simplification that has been adopted is to assume that the properties of the plywood do not change with temperature. In general this would be a poor approximation; however, the object of this analysis is to determine the time of ignition of the plywood and the paper in the honeycomb. Since the ignition temperatures of these materials are about $730^{\circ} \mathrm{F}$ and $500^{\circ} \mathrm{F}$, the temperature increase of the plywood during the period of interest is relatively small and the properties will not change by a large amount.

Convection heat transfer at the surface of the plywood is represented by the Colburn correlation for forced convection (Incropera, 1985) which is:

$$
\mathrm{Nu}=0.023 \operatorname{Re}^{0.8} \operatorname{Pr}^{0.4},
$$

where:

$\mathrm{Nu}$ is the Nusselt number $\frac{\mathrm{hL}}{\mathrm{k}}$,

$\mathrm{Re}$ is the Reynolds number $\frac{\mathrm{VL}}{\mathrm{V}}$,

Pr is the Prandtl number $\frac{c_{p} \mu}{k}$, 
$V$ is the velocity of the flames.

$L$ is the height of the surface.

$h$ is the average surface heat transfer coefficient.

$\mathrm{k}$ is the thermal conductivity of air at the film temperature.

$c_{p}$ is the specific heat of air at the film temperature.

$v$ is the viscosity of air at the film temperature.

Experimental measurement of flame velocities in large pool type fires report flame velocities in the region of $20 \mathrm{ft} / \mathrm{sec}$ (Gregory, 1980) so this value will be used here. All of the properties in the above correlation are to be evaluated at the film temperature which is defined as the average of the surface temperature and the flame temperature.

The radiant heat transfer at the outer surface of the plywood is expressed as:

$$
\mathrm{q}^{\prime \prime}=\mathrm{F} \sigma\left(\mathrm{T}_{\mathrm{f}}^{4}-\mathrm{T}_{\mathrm{s}}^{4}\right)
$$

where:

$F$ incorporates the view factor and emissivities and is defined as:

$$
F=\frac{1}{\left(\frac{1}{\mathrm{~A}_{1} \mathrm{~F}_{12}}+\frac{1}{\mathrm{~A}_{1}}\left[\frac{1}{\varepsilon_{1}}-1\right]+\frac{1}{\mathrm{~A}_{2}}\left[\frac{1}{\varepsilon_{2}}-1\right]\right)} .
$$

$\sigma$ is the Stefan-Boltzman constant.

$\mathrm{T}_{\mathrm{f}}$ is the absolute flame temperature.

$\mathrm{T}_{\mathrm{s}}$ is the absolute plywood surface temperature.

$\varepsilon_{1}$ is the surface emissivity of the plywood outer surface of the container.

$\varepsilon_{2}$ is the emissivity of the flames.

$\mathrm{F}_{12}$ is the view factor between the plywood and the flames.

$A_{1}$ is the surface area of the plywood.

$A_{2}$ is the surface are of the flames.

For this analysis, the flames are assumed to totally surround the plywood surface so the view factor becomes unity.

Using finite difference calculation technique where the time step was selected such that the surface temperature did not increase by more than $15^{\circ} \mathrm{F}$ in any time step, resulted in the histories of the surface temperatures of the plywood that are presented in Figure 5.14. The plywood surface was predicted to reach its ignition temperature $\left(730^{\circ} \mathrm{F}\right)$ about $0.08 \mathrm{~min}$ after the fire reached the surface of the plywood. At this time heat had conducted only a small fraction of the thickness into the plywood and the inner surface temperature was still $20^{\circ} \mathrm{F}$. Consequently, the plywood will ignite prior to the paper honeycomb that is inside the container.

The combustion of wood or other cellulosic material is a complex process. The difficulty with analytically solving the problem is that the chemistry of wood and wood products is dependent on many variables including type of wood, moisture content, etc. The heating of wood causes 


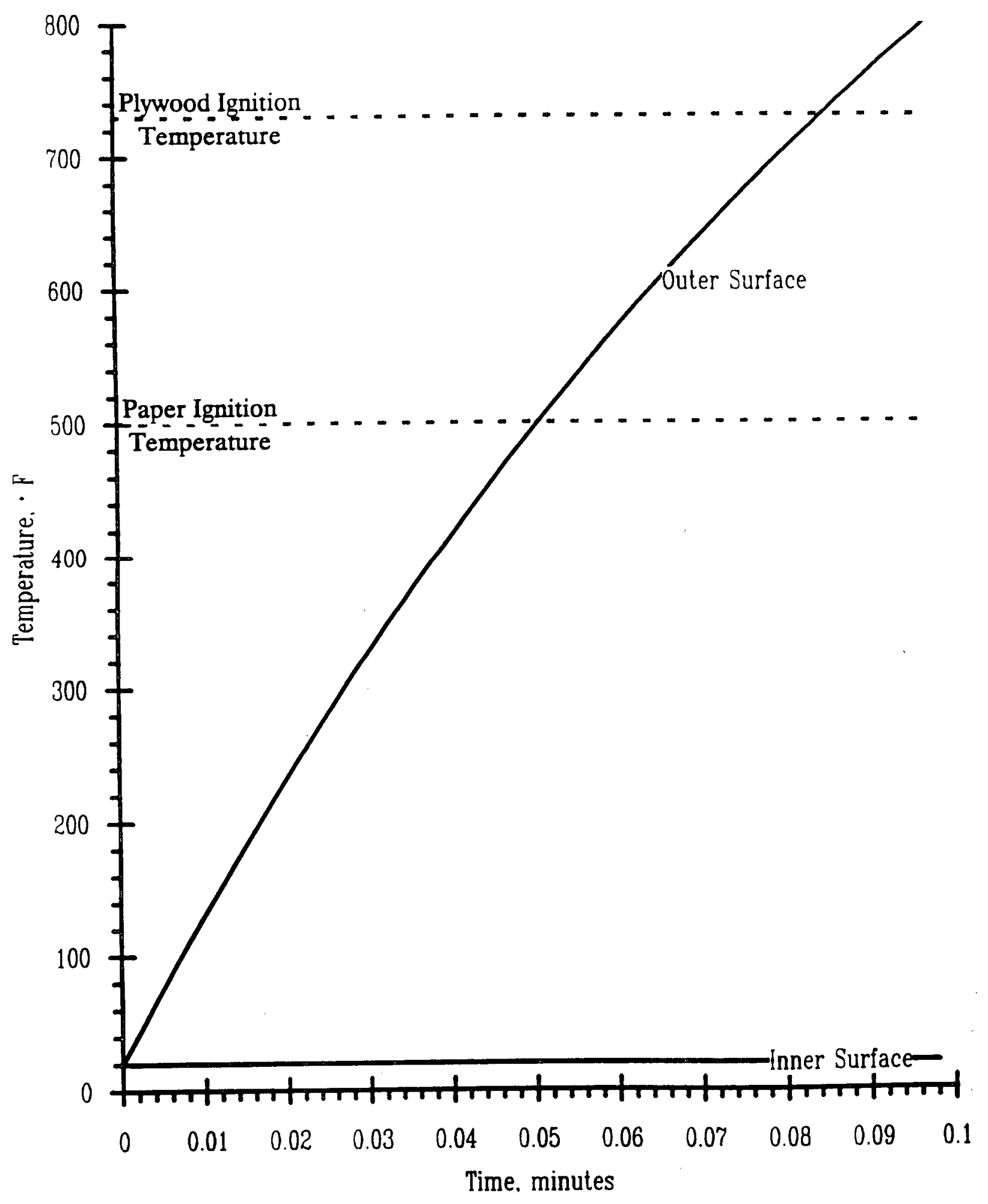

Figure 5.14 Plywood Temperature History When Exposed to Fire 
pyrolysis with the gaseous products (including combustible organic gases and non-combustible water vapor) migrating along the pore system of the wood. The gases flow both toward the hot surface from which the heat flows and also toward the unburned wood in the interior of the container. The volatiles that flow into the unburned region of the wood transfer their heat to the wood by convection and conduction, and recondense transferring their latent heat to the unburned wood. The gases that flow toward the heated surface through the relatively porous charcoal are heated by the charcoal until they encounter enough oxygen to sustain combustion near the hot surface of the charcoal. These physical processes defy analytical modeling so an approximation of the detailed behavior was necessary.

To obtain an estimate of the duration of the fire prior to the ignition of the honeycomb, an approximation for the effects of combustion of the plywood was required. It was assumed that the temperature of the plywood would remain at $800^{\circ} \mathrm{F}$ anywhere the plywood had reached its ignition temperature. This approximates the condition that the combustion of the plywood generates gases that transport energy both into the plywood and out of the plywood through the charred wood that remains (Meyers, 1987). It is expected that most of the energy will be transported away from the wood by the gases that are leaving the site of combustion and leaving the charred region.

The temperature histories for the outer and inner surfaces of the plywood are presented in Figure 5.15 and temperature profiles through the plywood are presented in Figure 5.16 at selected times during the transient. Based upon this representation of the combustion process, the paper honeycomb ignites about $11 \mathrm{~min}$ after the flames initially impact upon the surface of the plywood. There are no records of the times that the containers fell from the trailer; however, the video tapes of the rear of the trailer indicate that the containers fell from the trailer while the outer containers were largely intact which was probable before the honeycomb had reached its ignition temperature.

To approximate the median fire conditions, the analyses presented here have been based upon a regulatory fire, i.e. flame temperature of $1475^{\circ} \mathrm{F}$, flame emissivity of 0.9 , surface emissivity of 0.8 , and fully engulfing flames. Bounding the flame conditions to represent the fire in the vicinity of a burning tire would increase the flame temperature and reducing the flame temperature to represent the fire caused by combustion of wood in either the trailer bed or other outer containers will change the time required for ignition of the materials to occur. The variation of the flames is addressed in Table 5.2.

\section{Table 5.2 Time Required For Ignition of Plywood and Paper Honeycomb}

\begin{tabular}{ccccc}
\hline $\begin{array}{l}\text { Flame } \\
\text { Temperature }\end{array}$ & $\begin{array}{c}\text { Flame } \\
\text { Emissivity }\end{array}$ & $\begin{array}{c}\text { Container } \\
\text { Emissivity }\end{array}$ & \multicolumn{2}{c}{ Time in min for } \\
\hline 1832 & 0.9 & 0.8 & $0.04 \mathrm{~min}$. & $12.2 \mathrm{~min}$. \\
1472 & 0.9 & 0.8 & $0.08 \mathrm{~min}$. & $12.2 \mathrm{~min}$. \\
1292 & 0.2 & 0.8 & $0.32 \mathrm{~min}$. & $12.2 \mathrm{~min}$. \\
\hline
\end{tabular}

These variations in the flame representations would not alter the conclusion that the plywood will ignite and begin to combust before the ignition of the paper honeycomb. This analysis must be based upon the analysis of the portion outer container that is first exposed to flames. When the first point in the plywood burns through, the paper honeycomb would ignite and rapidly consume all of the honeycomb and Ethafoam inside the outer container. 


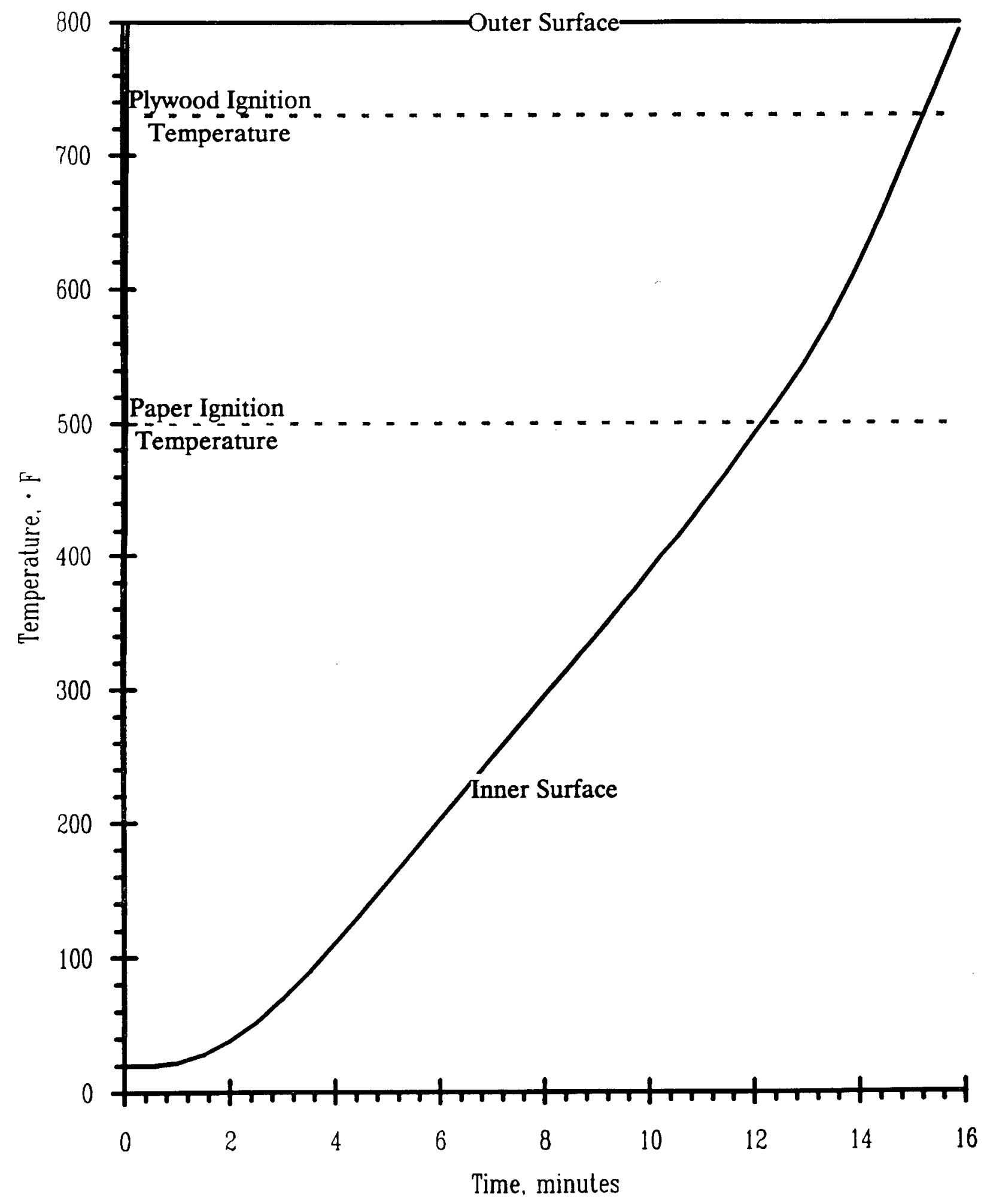

Figure 5.15 Extended Plywood Temperature History when Exposed to Fire 


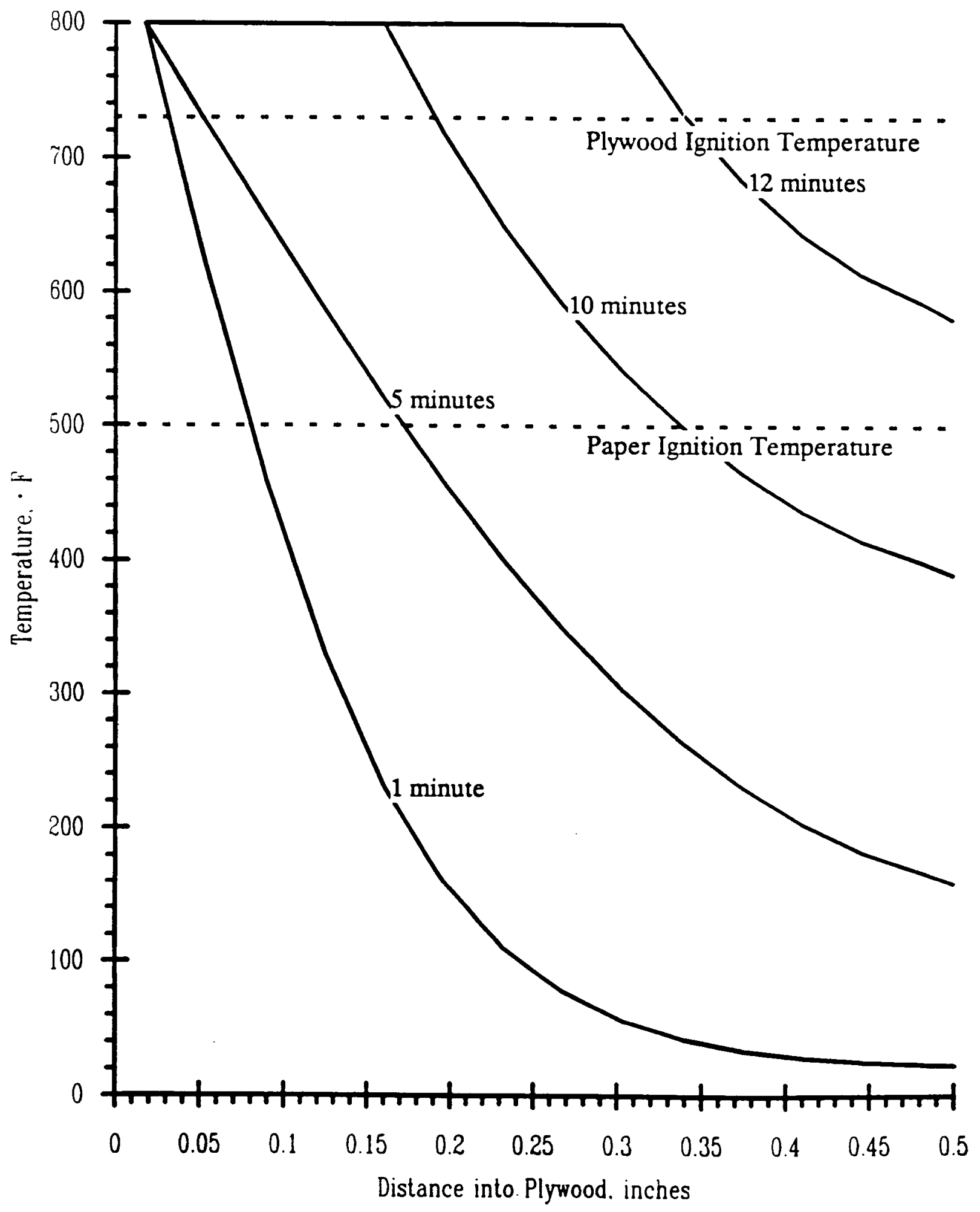

Figure 5.16 Plywood Temperature Distribution at Selected Times After Exposure to Fire 


\subsubsection{Evaluation of Transient Heat Conduction in Inner Container}

When comparing this fire to the fire evaluated during the container certification process, the duration of the fire and the temperature of the flames must be considered. Previous consideration of the materials involved in the fire indicate that the local flame temperatures exceeded $1475^{\circ} \mathrm{F}$ in come locations and was less than $1475^{\circ} \mathrm{F}$ in other locations. The duration of the fire is addressed in this section by evaluating the temperatures reached in the inner container after the outer container has been consumed. The transient analysis of the inner container demonstrated that the inner container temperature reached the temperature of the flames well before the end of the fire. Thus, the duration of the fire was a minor factor in comparing this fire to the fire considered for container certification because the maximum container temperatures would not be significantly changed by a fire that lasted more than fifteen min after the outer container had been consumed.

For this transient analysis, the outer container was assumed to have completely combusted and was not present. Consequently, the inner container was exposed directly to the flames. The model for this analysis assumed that the conductance through the metal walls was essentially infinite and the metal was considered as a uniform temperature body. The radiation, conduction and convection heat transfer in the air gaps was represented by correlations that have been developed to represent heat transfer in enclosures.

The temperature history of the outer wall, inner wall and surface of the fuel assembly are presented in Figure 5.17. This analysis conclusively demonstrates that the metal temperature rapidly approaches that temperature of the flames, and after less than fifteen min, the temperature of the entire container is essentially equal to the temperature of the flames. Consequently, the evaluations of the inner container as a structural component should be based upon material properties at the temperature of the flames in the location of the container under consideration.

\subsection{Fuel Rod Temperatures}

During the process of opening the inner containers and removing the fuel rods from the spacers and other fuel assembly hardware, four different states of damage were observed. These states are characterized as follows:

1. Clad was blackened with localized deposits of residue from melting or burning of plastic inserts between fuel rods.

2. Clad was blackened with ash like deposits essentially uniformly distributed over the surface of the cladding.

3. The clad had developed a whitish color with a roughened surface.

4. The clad had developed a whitish color with a roughened surface, and the clad had expanded such that adjacent fuel rods were touching and the clad approached a square cross section with longitudinal cracks.

It was not uncommon to find two or three different states of damage on the same fuel rod. Where the clad had expanded, the expansion occurred over a 6 in. length at the end of the fuel rods in one case and in another case the expansion occurred over a length of about twenty in. near the middle of the fuel rods. Typically the first two types of damage occurred in adjacent portions of a fuel assembly and, if ballooning of the clad did occur, there were other portions of the same fuel assembly that had surface characteristic of type 2 and type 3 . The objective of this section is to attempt to associate the fuel rod maximum temperature with the damage. 


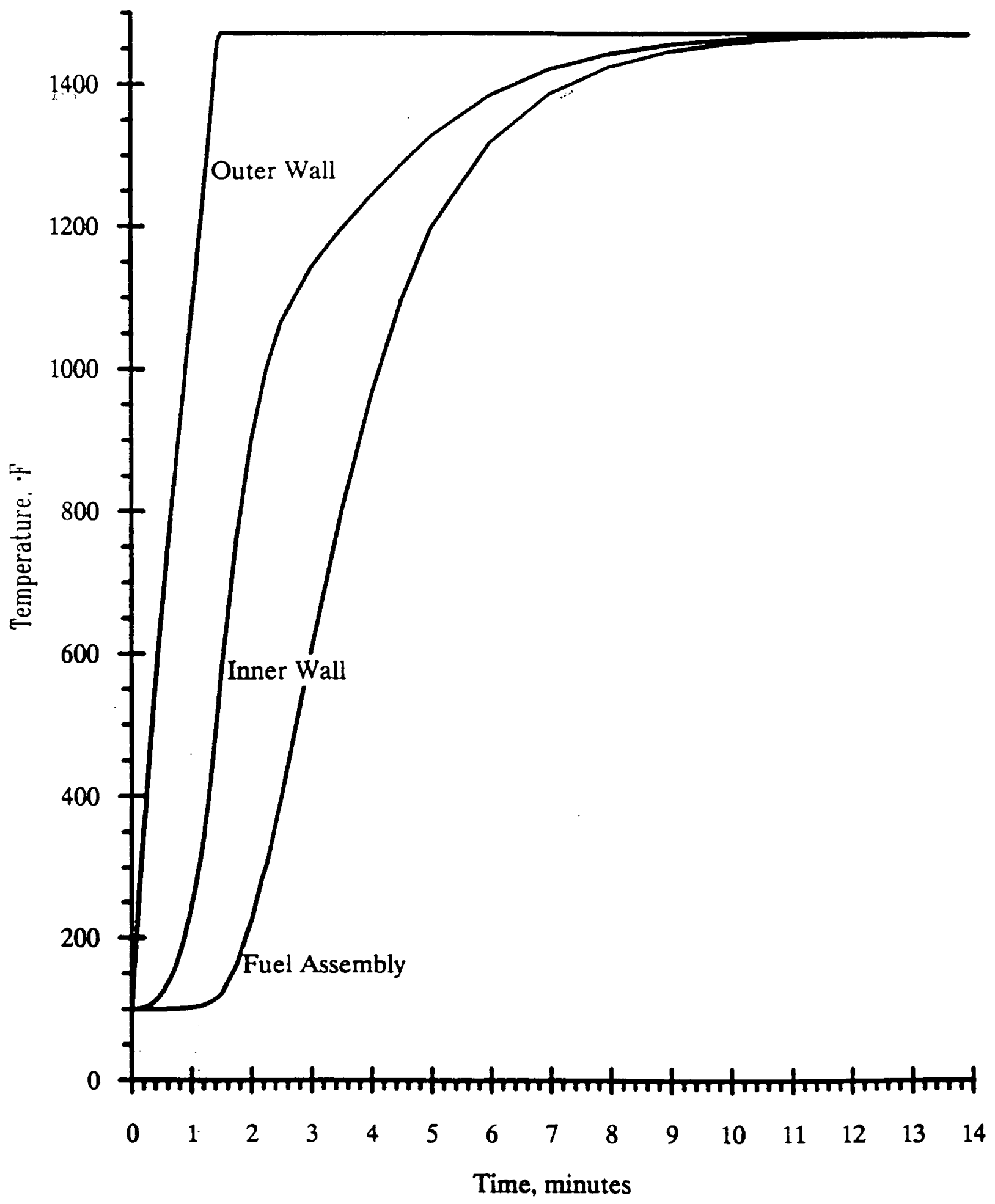

Figure 5.17 Temperature Histories in Inner Container After Direct Exposure to the Fire 
The first type of damage has been associated with incomplete combustion of the plastic inserts that are placed between the fuel rods to prevent flexing of the fuel rods during transport. The residue was rigidly attached to the fuel rods and required substantial shearing type forces to separate the residue from the fuel rods. The temperature of the clad was probably about $1160^{\circ} \mathrm{F}$ because the plastic was partially combusted and partially melted.

The second type of damage has been associated with complete combustion of the foam pads and plastic inserts that are placed between the fuel rods to prevent flexing of the fuel rods during transport. The residue was powdery and loosely adhering to the fuel rods. The clad temperature that was associated with this condition of the clad is about $1200^{\circ} \mathrm{F}$ because the temperature exceeded the ignition temperature of the plastic inserts.

The third type of damage has been associated with the formation of zirconium oxide due to elevated temperature of the clad. This implies that there was enough oxygen inside the container to react with the zirconium after essentially complete combustion of the plastic and foam components that were inside the container.

A substantial amount of research has been presented in the literature that addresses the formation of zirconium oxide on the surface of Zircalloy- 2 and Zircalloy- 4 clad fuel rods. However, this is not appropriate for this investigation because the research focused upon the formation of the oxide film in the presence of water where the zirconium had to compete with hydrogen for the available oxygen. Conditions during the fire were greatly different because the environment contained a substantial amount of free oxygen which was available to react with the zirconium when the temperature was elevated.

The fourth type of damage has been associated with the combination of reduction in strength of the clad and the increase in internal pressure in the fuel rod as the temperature increases. When the temperature reaches a specific value, the internal pressure will produce stresses that exceed the yield strength of the clad and the clad will begin to expand. As the temperature increases, this process will continue until the clad reaches its ultimate strength or the clad cracks, releasing the internal pressure. Since the elevated clad temperatures persisted for one hour or less, creep of the clad has been discounted as a mechanism for increase of the clad diameter.

Zircalloy has a hexagonal close packed structure in the temperature range between room temperature and $1500^{\circ} \mathrm{F}$ which is referred to as the $\alpha$ phase of Zircalloy. As the temperature increases from $1500^{\circ} \mathrm{F}$ to $1800^{\circ} \mathrm{F}$ the structure of Zircalloy changes and at temperatures above $1800^{\circ} \mathrm{F}$ the structure is entirely body centered cubic. A considerable amount of plastic deformation occurs in the temperature range between $1500^{\circ} \mathrm{F}$ and $1800^{\circ} \mathrm{F}$. The melting temperature of Zircalloy is $3317^{\circ} \mathrm{F}$. However, there were no fuel rods that appeared to approach melting.

The cladding stress as a function of temperature is presented in Figure 5.18 based upon the assumption that the clad could be treated as a thin wall pressure vessel. The initial pressure inside the fuel rod at the time of fabrication has been evaluated parametrically because this value has not been released by GE. Also, the temperature dependence of the yield strength and ultimate strength of Zircalloy-2 are presented in Figure 5.18. There is a discontinuity in the curves of yield and ultimate strength at $1500^{\circ} \mathrm{F}$ due to the transition between the $\alpha$ and $\beta$ phases of zirconium.

The intersection of the yield strength and clad stress curves indicates the temperature at which the clad will begin to yield and expand. Similarly, the intersection of the ultimate strength curve with the clad stress curves indicates the temperature that will cause the clad to fail. The intersections occur at temperatures ranging from $1250^{\circ} \mathrm{F}$ to $1600^{\circ} \mathrm{F}$. The value of $1250^{\circ} \mathrm{F}$ is considered to be 


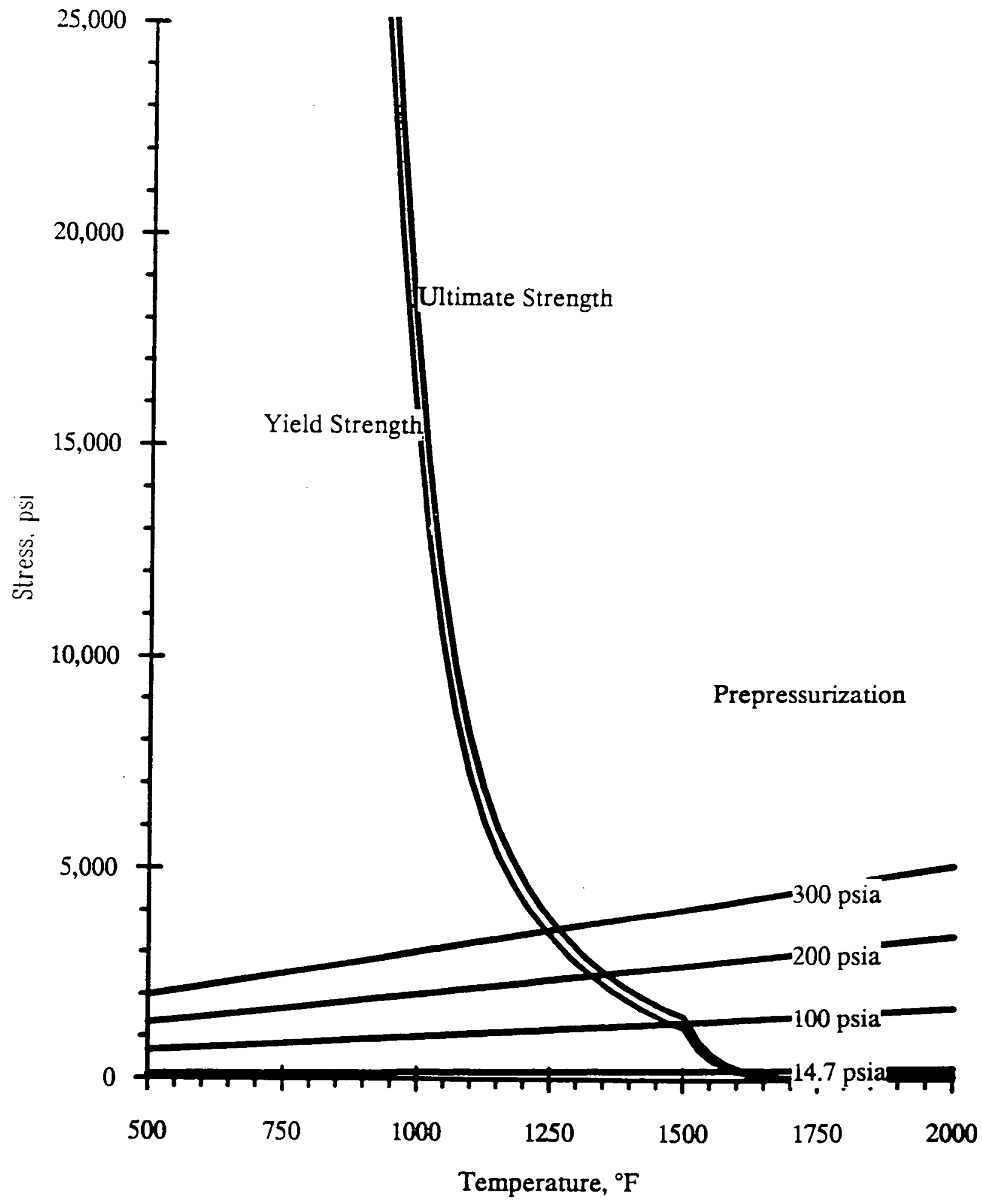

Figure 5.18 Stress in Clad at Elevated Temperatures 
somewhat low and $1600^{\circ} \mathrm{F}$ is considered more reasonable for the onset of clad ballooning. The temperature dependence of the ultimate strength and yield strength of unirradiated Zircalloy have been taken from MATPRO (Hagrman, 1981) which is applicable up to temperatures that take the Zirconium into the $\beta$ phase.

\subsection{Criticality Evaluation}

A criticality analysis is not considered necessary for this accident. During container certification, the containers were shown to meet the requirements of 10 CFR Part 71 for Fissile Class I containers. That is, both an unlimited number of undamaged containers and 250 damaged containers were shown to be subcritical in any arrangement and with optimum interspersed moderation.

The fuel assemblies were damaged; however, the geometry changes of the fuel assemblies consisted entirely of reducing the fuel assembly volume, thus reducing the amount of potential moderator that could enter the spaces between fuel rods. Since the fuel assemblies were designed to be under moderated, reducing the fuel assembly volume would reduce its reactivity.

Consequently, it must be concluded that there was no possibility of a criticality incident during this accident. No water was allowed near the containers at any time; however, this conclusion would remain valid even if the fire department had applied water to the containers in an attempt to extinguish the fire.

\subsection{Shielding Evaluation}

No analysis of the adequacy of the shielding is considered necessary for this accident because the contents of the containers were unirradiated, low enriched, uranium oxide fuel assemblies. The radiation dose was measured several times during and after the fire portion of this accident. No radiation levels above background were reported. 


\section{Conclusions}

An inquiry, assessment, and analysis were performed of a severe accident involving a passenger vehicle colliding with a tractor-trailer carrying 12 containers, each containing 2 unirradiated nuclear fuel assemblies. The accident occurred at 3:15 a.m. on Dec. 16, 1991, on I-91 as it passed through downtown Springfield, Massachusetts. During the collision the truck veered to the left to miss the car that was proceeding in the wrong direction and hit on the center guardrail and outer concrete barrier before coming to rest against the center guardrail.

The collisions suffered by the truck appear to have allowed the containers to remain intact on the trailer. However, eight containers fell from the trailer during the fire that started in the engine. The fire spread to the tractor and then to the trailer. The containers and the unirradiated nuclear fuel assemblies appear to have had very little damage due to falling from the trailer. The wooden outer containers appear to have been intact, at least partially, at the time of the impact of the containers on the roadway. The containers provided substantial protection due to the presence of honeycomb and foam in the outer containers. Based upon the analyses reported here, all of the significant mechanical damage to the containers occurred as a result of the fire that followed the collisions.

Local flame temperatures during the fire were about $1800^{\circ} \mathrm{F}$ in the vicinity of the tires and about $1300^{\circ} \mathrm{F}$ throughout the remainder of the portion of the fire that affected the containers and unirradiated nuclear fuel assemblies. Consequently, only portions of containers were exposed to temperatures greater than $1300^{\circ} \mathrm{F}$. The fire burned for over three hours; however, the containers and the unirradiated nuclear fuel assemblies were exposed to the fire for about two hours. The damage to the metal inner containers ranged from minimal to very severe based upon the location of the container and the intensity of the flames during the fire. The fuel assemblies inside the container were distorted to conform to the configuration of the metal inner container. In addition, some of the clad tubes had swollen due to the increase in pressure within the fuel rod as a result of the elevated temperatures during the accident. Analyses indicate that temperatures in excess of $1500^{\circ} \mathrm{F}$ are required to cause this type of damage. Some cracks were observed in the clad tubes at the location of swelling; however, no uranium dioxide fuel escaped from the clad tubes.

All of the fuel assemblies remained in their inner containers and were maintained in a safe geometry throughout the entire accident. A criticality accident was not possible during this accident. There were no serious injuries or fatalities, and the health and safety of the public and the personnel responding to the accident were never at risk. 


\section{References}

Grayson, Martin (1984). Encyclopedia of Textiles, Fibers and Nonwoven Fabrics, John Wiley \& Sons, New York, NY.

Gregory, J.J., R. Mata, and N.R. Keltner (1987). Thermal Measurements in a Series of Large Pool Fires, Sandia National Laboratories, Albuquerque, NM, SAND85-0196, TTC-0659, UC-71.

Hagrman, Donald L., Gregory A. Reymann, and Richard E. Mason (1981). MATPRO-Version 11 (Revision 2) A Handbook of Materials Properties for Use in the Analysis of Light Water Reactor Fuel Rod Behavior, NUREG/CR-0479, TREE-1280, Rev 2. EG\&G Idaho, Inc. Idaho Falls, ID.

Holman, J.P. (1976). Heat Transfer, McGraw-Hill Book Company, New York, NY.

Incropera, Frank P. and David P. DeWitt (1985). Fundamentals of Heat and Mass Transfer, $2^{\text {nd }}$ ed., John Wiley \& Sons, New York, NY.

McCaffrey, B.J. (1979). Purely Buoyant Diffusion Flames: Some Experimental Results, NBSIR 79-1910, National Bureau of Standards, Washington, DC.

Meyers, Glen E. (1987). Analytical Methods in Conduction Heat Transfer, Genium Publishing Corporation, Schenectady, NY.

Roark, Raymond J., and Warren C. Young (1975). Formulas for Stress and Strain, $5^{\text {th }}$ ed., McGraw-Hill Book Company, New York, NY.

Standard Safety Analysis Report (1975), BWR-6, General Electric Company.

Timoshenko, Stephen P. and James M. Gere (1961). Theory of Elastic Stability, $2^{\text {nd }}$ ed., Hill Book company, New York, NY. 
(See instructions on the reverse)

A Highway Accident Involving Unirradiated Nuclear Fuel in Springfield, Massachusetts, on December 16, 1991

R. W. Carlson, L. E. Fischer

Technical

7. PERIOD COVERED (Inc/usive Dares)

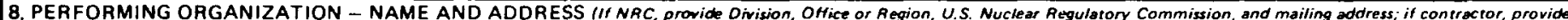
name ond mailing address

Lawrence Livermore National Laboratory

P.0. Box 808

Livermore, CA 94551

9. SPONSORING ORGANIZATION - NAME AND ADDRESS III NRC, ivpe "Same as above"; if contractor, provide NRC Oivision, Office or Region, U.S, Nuclear Regulatory Commission. and mailing address.)

Division of Safeguards and Transportation

Office of Nuclear Material Safety and Safeguards

U.S. Nuclear Regulatory Commission

Washington, DC 20555

10. SUPPLEMENTARY NOTES

11. ABSTRACT (200 words or kess)

In the early morning of Dec. 16, 1991, a severe accident occurred when a passenger vehicle traveling in the wrong direction collided with a tractor trailer carrying 24 unirradiated nuclear fuel assemblies in 12 containers on Interstate 1-91 in Springfield, Massachusetts. The purpose of this report is to document the mechanical circumstances of the severe accident, confirm the nature and quantity of the radioactive materials involved, and assess the physical environment to which the containers were exposed and the response of the containers and their contents.

The report consists of five major sections. The first section describes the circumstances and conditions of the accident and the finding of facts. The second describes the containers, the unirradiated nuclear fuel assemblies, and the tie down arrangement used for the trailer. The third describes the damage sustained during the accident to the tractor, trailer, containers, and the unirradiated nuclear fuel assemblies. The fourth evaluates the accident environment and its effects on the containers and their contents. The final section gives conclusions derived from the analysis and the fact finding investigation. During this severe accident, only minor injuries occurred, and at no time was the public health and safety at risk.

Springfield, MA

Transportation-incidents

Transportation-emergency response

fuel accident

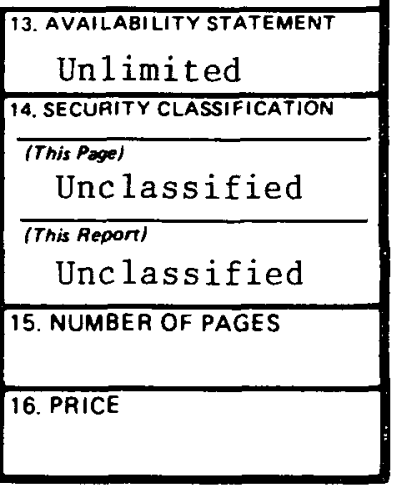


THIS DOCUMENT WAS PRINTED USING RECYCLED PAPER 